UNIVERSIDADE DE SÃO PAULO

FFCLRP - DEPARTAMENTO DE FÍSICA

PÓS-GRADUAÇÃO EM FÍSICA APLICADA À MEDICINA E BIOLOGIA

\title{
DOSIMETRIA 3D DE UM TRATAMENTO SIMULADO DE PRÓSTATA NA PRESENÇA DE PRÓTESES FEMORAIS METÁLICAS
}

ESTUDANTE

DIANA MARITZA CUEVAS ROJAS

Dissertação apresentada à Faculdade de Filosofia, Ciências e Letras da Universidade de São Paulo como parte das exigências para a obtenção do título de Mestre em Ciências. Área: Física Aplicada à Medicina e Biologia.

Ribeirão Preto - SP 
DIANA MARITZA CUEVAS ROJAS

\section{DOSIMETRIA 3D DE UM TRATAMENTO SIMULADO DE PRÓSTATA NA PRESENÇA DE PRÓTESES FEMORAIS METÁLICAS}

Dissertação apresentada à Faculdade de Filosofia, Ciências e Letras de Ribeirão Preto da Universidade de São Paulo, como parte das exigências para a obtenção do título de Mestre em Ciências. Área de concentração : Física aplicada à medicina e biologia Orientador: Oswaldo Baffa Filho

Ribeirão Preto - SP 
Autorizo a reprodução e divulgação total ou parcial deste trabalho, por qualquer meio convencional ou eletrônico para fins de estudo e pesquisa, desde que citada a fonte.

Cuevas Rojas, Diana Maritza
Dosimetria 3D de um tratamento simulado de próstata na presença de próteses femorais
metálicas (3D dosimetry of a simulated prostate treatment in the presence
femoral prostheses) / Diana Maritza Cuevas Rojas; orientador Oswaldo Baffa. Ri-
beirão Preto - SP, 2016. 110 f.:il.
Dissertação (Mestrado - Programa de Pós-graduação em Física aplicada à Medicina e
Biologia) - Faculdade de Filosofia, Ciências e Letras de Ribeirão Preto da Universidade
de São Paulo, 2016.
1. gel magic-f. 2. Dosimetria Termoluminescente. 3. Dosimetria ESR com Alanina 4.
Radioterapia convencional.


Para a pessoa mais importante da minha vida, minha mãe pela dedicação e amor sempre entregado. 
Nome: Cuevas Rojas, Diana Maritza

Título : Dosimetria 3D de um tratamento simulado de próstata na presença de próteses femorais metálicas.

Dissertação apresentada à Faculdade de Filosofia, Ciências e Letras da Universidade de São Paulo como parte das exigências para a obtenção do título de Mestre em Ciências. Área: Física Aplicada à Medicina e biologia.

Aprovado em : _ _ _ _ _

\section{Banca examinadora}

$\operatorname{Prof}(\mathrm{a}) \cdot \operatorname{Dr}(\mathrm{a})$. Instituição:

Julgamento : Assinatura:

Prof(a). Dr(a). : Instituição:

Julgamento : Assinatura:

Prof(a). Dr(a). : Instituição:

Julgamento : Assinatura: 


\section{Agradecimentos}

Agradeço imensamente ao meu orientador, Prof. Dr Oswaldo Baffa por toda a contribuição intelectual, profissional e pessoal durante meu mestrado e no processo da elaboração deste trabalho. Por me deixar ser parte do grupo BIOMAG do qual é responsável.

À professora Dr Juliana Pavoni, por facilitar a realização dessa pesquisa com o aceso aos equipamentos de medida e por todo o tempo investido no planejamento e na coorientação deste trabalho.

Ao técnico do laboratório Lourenço Rocha pela ajuda no acondicionamento de todos os materiais usados para o desenvolvimento neste projeto.

Ao Hospital Das Clinicas de Ribeirão Preto, especialmente a Alexandre e Euclides físicos médicos da unidade radioterapia. Também agradeço ao pessoal de ressonância magnética pela ajuda na aquisição das imagens.

À FAPESP, CNPq e CAPES pelo suporte financeiro.

A Erick, Matheus e Alejandro pelas ajudas durante meu trabalho.

A Freddy Jackson Poveda pela ajuda com meus documentos quando cheguei no brasil, por todo o apoio e tempo inicialmente entregado.

A todos meus amigos que de uma forma ou outra contribuíram na culminação deste passo importante na minha vida. 


\section{Resumo}

Cuevas, Diana. Dosimetria 3D de um tratamento simulado de próstata na presença de próteses femorais metálicas. 2016. 108 f. Dissertação (Mestrado - Programa de Pós-graduação em Física aplicada à Medicina e Biologia) - Faculdade de Filosofia, Ciências e Letras de Ribeirão Preto, Universidade de São Paulo, Ribeirão Preto - SP, 2016.

Historicamente a radioterapia é divida em radioterapia externa, braquiterapia e radioisotopoterapia sistemática. As diferenças entre as três está no posicionamento da fonte de radiação com respeito ao corpo humano. Na radioterapia externa a fonte fica a uma certa distância do paciente, já no caso da braquiterapia as fontes podem ser inseridas dentro de cavidades do corpo ou implantadas diretamente nos tecidos. Na radioisotopoterapia sistemática isotopos radiativos são administrados por via oral ou venosa. Dessas três a radioterapia externa é a mais usada pois, ela permite realizar planejamentos de radioterapia em três dimensões (3D), partindo inicialmente de uma tomografia computadorizada da região do tumor. O planejamento baseado na tomografia computadorizada permite que a distribuição da radiação nos tecidos seja feito com mais precisão evitando assim, que os tecidos sadios sejam afetados. Atualmente, se dispõe de três tipos de radioterapia externa : convencional, radioterapia conformada tridimensional e a radioterapia de intensidade modulada (IMRT). Nesse trabalho a radioterapia externa convencional, foi implementada e executada para um tratamento de próstata com implantes metálicos, usando 4 campos de irradiação (0, 90, 180, 270 graus) e uma dose total planejada de 70 Gy fracionada em 35 sessões, cada uma com 2 Gy.

Em qualquer tipo de tratamento que envolva a radiação ionizante é exigido um controle de qualidade para assim, determinar se a dose inicialmente planejada será entregue ou não ao tumor. Idealmente deveria ser implementado um controle de qualidade em três dimensões mas, até o momento não há um dosímetro 3D consolidado na rotina clinica. No entanto, o uso de géis poliméricos associados à técnica de leitura de dose com 
imagem de ressonância magnética (IRM) possibilita a dosimetria tridimensional. Nesse contexto, é aplicada a dosimetria 3D usando para isso, o gel magic com formaldeído (magic-f). Além da dosimetria 3D, foram realizadas medidas de dose absorvida por meio de dosimetria pontual, para tal fim são utilizados dosímetros termoluminescentes e de alanina. Na avaliação da distribuição de dose feita pelo planejamento e a medida com o gel é usado a análise gama $(3 \% / 3 \mathrm{~mm})$, neste caso, a distribuição de dose medida concorda com a distribuição de dose planejada TPS. A análise gama apresenta um porcentagem de aprovação do $93 \%$.

Os valores de dose absorvida na interface osso-metal determinados pelos dosímetros TL apresentam um aumento de 1,73 Gy na região do osso sacro e outros aumentos entre o 0,16 e 0,33 Gy foram encontrados em regiões como a cabeça do fêmur e quadril. Esses aumentos na dose foram só para duas sessões com doses entregadas ao fantom de 2 Gy. De igual maneira para os dosímetros de alanina se encontro um aumento na dose de 1,22 e 2,42 Gy na região do osso sacro. O planejamento feito nesse caso foi de 6 Gy. Os resultados evidentemente mostram como as inomogeneidades de um material com número atômico alto, gera perturbações sobre as distribuições de dose inicialmente planejadas.

Palavras - Chave : Radioterapia convencional, gel magic- $f$, dosimetria termoluminescente, dosimetria ESR com alanina. 


\section{Abstract}

Cuevas, Diana. 3D dosimetry of a simulated prostate treatment in the presence femoral prostheses. 2016. 108 f. Dissertation (M.Sc. - postgraduate program in Physics Applied to Medicine and Biology) - Faculty of Philosophy, Sciences and Letters, University of São Paulo, Ribeirão Preto - SP, 2016.

Historically, Radiotherapy is divided into external radiotherapy, brachytherapy and systemic radioisotopotherapy. The difference between the three lies in the position of the radiation source regarding the human body. In external radiotherapy the source is at a certain distances of patient, and in the case of brachytherapy, this source can be inserted into cavities of body or implanted directly in the tissues. In systemic radiotherapy radioisotopes are administered orally or intravenously. Of these three, external radiotherapy is the most used because it allows planning of radiotherapy in three dimensions (3D), starting from a CT scan of the tumor region. Computed tomography planning allows the distribution of radiation in the tissues to be more accurate thus avoiding, that healthy tissues are affected. Currently, there are three types external radiotherapy: conventional, three-dimensional conformal radiotherapy and intensity-modulated radiotherapy (IMRT). In our case, conventional external radiotherapy was implemented and executed for a prostate treatment with metal implants, using 4 irradiation fields $(0,90,180,270$ degrees $)$ and a total planned dose of 70 Gy fractioned in 35 sessions each with 2 Gy.

In any type of treatment involving ionizing radiation, quality control (QC) is required to determine if the dose initially planned is delivered or not to the tumor. Ideally, a quality control should be implemented in three dimensions but to date there is no consolidated 3D dosimeter system in the clinic routine. However, the used of polymeric gels associated with magnetic resonance image (IRM) allow three-tridimensional dosimetry. In this context, the 3D dosimetry is applied using the magic gel with formaldehyde (magic- $f$ ). In addition to 3D dosimetry, absorbed dose measurements were performed 
by means of a dose in a point, using thermoluminescent and alanine dosimeters. The comparison of dose distributions calculated by TPS and measured in the gel was made using by gamma analysis $(3 \% / 3 \mathrm{~mm})$, in this case, the distribution of dose measurement agrees with the distributions expected by TPS. The analysis shows a percentage of approval of $93 \%$.

The absorbed dose values at the bone-metal interface determined by the TL dosimeters, presented a $1.73 \mathrm{~Gy}$ increase in the region of the sacral bone, and another increases between 0,16 and 0,33 Gy were found in the regions as the head of the femur and the hip. These dose increases were only for two sessions with doses delivered to the phanton of 2 Gy. Similarly for alanine dosimeters were found increases in the dose of 1.22 and $2.42 \mathrm{~Gy}$ in the region of sacral bone. The planning done in this case was 6 Gy. The results evidently show how the inomogeneities of a material with a high atomic number generate disturbances over the initially planned dose distributions.

Key - words : Radiotherapy, Thermoluminescent dosimetry, ESR dosimetry with alanine. 


\section{Sumário}

$\begin{array}{ll}\text { Agradecimentos } & \text { I }\end{array}$

Lista de Figuras $\quad$ XV

$\begin{array}{ll}\text { Lista de Tabelas } & \text { XVII }\end{array}$

1 Introdução 1

2 Objetivos 4

3 Dosimetria Gel 5

3.1 Evolução da dosimetria gel . . . . . . . . . . . . . . . . . . 5

3.2 Propriedades físicas e químicas do gel magic $f \ldots \ldots \ldots$

3.3 Características dos dosímetros géis poliméricos f . . . . . . . 13

$3.3 .1 \quad$ Efeitos do oxigênio . . . . . . . . . . . . . . . . . . 13

3.3 .2 Efeitos da luz . . . . . . . . . . . . . . . . . . . . . 14

3.3 .3 Temperatura $\ldots \ldots \ldots \ldots \ldots \ldots$

3.3.4 Concentração dos monômeros . . . . . . . . . . . . 15

3.3.5 Envelhecimento do gel . . . . . . . . . . . . . . . 15

3.3 .6 Toxicidade . . . . . . . . . . . . . . . . . . . 16

3.4 Avaliação da dosimetria gel polimérica . . . . . . . . . . . . 16

3.4 .1 Imagens por ressonância magnética $\ldots \ldots \ldots$ 
3.4.1.1 Princípios básicos na imagem de ressonância magnética 17

3.4.1.2 Como determinar T2 . . . . . . . . . . . . 22

3.4.1.3 Possíveis erros na realização das seqüências de imagem 25

3.4.1.4 Falta de uniformidade nas imagens . . . . . . . . . . . 26

3.4.1.5 Distorções nas imagens . . . . . . . . . . . . . . . . 28

3.4.1.6 Erros na dose . . . . . . . . . . . . . . . 29

3.4.2 Tomografia ótica computadorizada . . . . . . . . . . . . . 30

3.4.3 Tomografia computadorizada com raios $\mathrm{x}$. . . . . . . . . . . 31

3.4.4 Ultrassom . . . . . . . . . . . . . . . . . . . . . . 32

4 Dosimetria Termoluminescente $\quad 34$

4.1 Introdução . . . . . . . . . . . . . . . . . . . . 34

4.2 Fundamentos teóricos . . . . . . . . . . . . . . . . . . 35

4.3 Materiais termoluminescentes . . . . . . . . . . . . . . . . . . 37

4.3 .1 Linearidade ..................... 37

4.3 .2 Sensibilidade .................... 37

4.3 .3 Estabilidade . . . . . . . . . . . . . . . 38

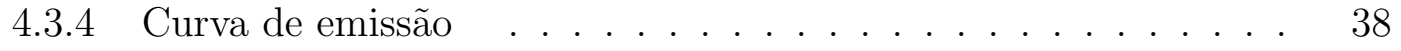

4.3.5 Reprodutibilidade .................. 38

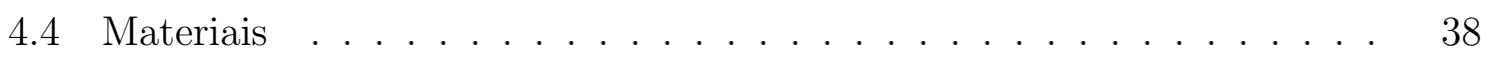

4.4.1 Fluoreto de lítio, LiF: Ti, mg . . . . . . . . . . 39

4.5 Equipamento de leitura dos dosimetros TL . . . . . . . . . . . . 39

5 Dosimetria por Ressonância Spin-Eletrônico de Alanina 41

5.1 Introdução . . . . . . . . . . . . . . . . . . . . . 41

5.2 Moléculas orgânicas . . . . . . . . . . . . . . . . 42

5.2.1 Alanina .......................... 43

5.2.2 Alanina-ESR ..................... 44 
5.3 Espectroscopia por ressonância de spin eletrônico (ESR) . . . . . . . . 45

5.3.1 Equipamento de leitura . . . . . . . . . . . . . . 47

6 Materiais e Métodos $\quad 49$

Parte I - Manufatura, acondicionamento, irradiação e aquisição das IRM $\begin{array}{ll}\text { obtidas com o gel magic- } f & 49\end{array}$

6.1 Manufatura do objeto simulador . . . . . . . . . . . . . 49

6.2 Manufatura dos dosímetros . . . . . . . . . . . . . . 52

6.2.1 Elaboração do gel . . . . . . . . . . . . . 52

6.2.2 Acondicionamento do gel . . . . . . . . . . . 53

6.2.2.1 Recipientes para verificação de dose 3D . . . . . . . 53

6.2.2.2 Tubos de ensaio usados para calibração . . . . . . . 54

6.3 Planejamento do tratamento e irradiação do gel magic- $f$. . . . . . . . 55

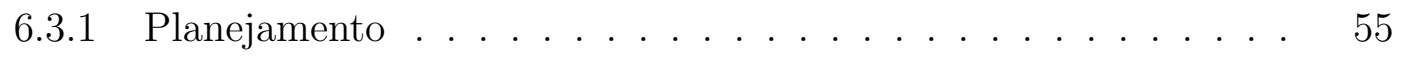

6.4 Irradiação do gel magic- $f$. . . . . . . . . . . . . . . . . . 57

6.4.1 Irradiação do objeto simulador . . . . . . . . . . . . . . . . 57

6.4.1.1 Irradiação dos tubos teste usados para calibração . . . 58

6.5 Aquisições das imagens de ressonância magnética . . . . . . . . . . . 58

6.6 Leitura das IRM . . . . . . . . . . . . . . . . . . . . . . . 60

6.6.1 Programa de relaxometria . . . . . . . . . . . . . 60

6.6.2 Análises das distribuições de dose . . . . . . . . . . . . . . 60

6.6.2.1 Comparação das imagens do TPS e adquiridas pela res-

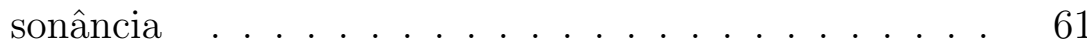

Parte II - Manufatura, tratamento térmico, irradiação e leitura da dose absorvida nos dosímetros de TL por aquecimento

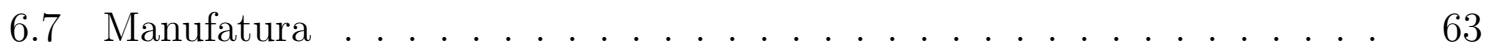

6.8 Tratamento térmico . . . . . . . . . . . . . . . . . . 64 
6.9 Irradiação . . . . . . . . . . . . . . . . . . . . . 65

6.9.1 Irradiação das pastilhas de calibração . . . . . . . . . . 65

6.9.2 Irradiação do objeto simulador com os TL . . . . . . . . . 66

6.10 Leitura . . . . . . . . . . . . . . . . . . . . . 68

Parte III - Manufatura, acondicionamento, irradiação e leitura da dose absorvida nos dosímetros de alanina por meio de espectroscopia ESR 71

6.11 Manufatura dos dosímetros de alanina . . . . . . . . . . . . . . . 71

6.12 Acondicionamento dos dosímetros de alanina . . . . . . . . . . . 72

6.13 Irradiação dos tubos de ensaio com alanina usados para calibração . 73

6.14 Irradiação do objeto simulador contendo os dosímetros de alanina . . . 73

6.15 Leitura da dose absorvida nos dosímetros por meio de espectroscopia ESR. 74

$\begin{array}{lll}7 & \text { Resultados e Discussões } & 76\end{array}$

$\begin{array}{ll}\text { Parte I - Resultados dosimetria gel magic- } f & 76\end{array}$

7.1 Curva de calibração do gel magic- $f \ldots \ldots \ldots \ldots$

7.2 Controle de qualidade tridimensional gel magic- $f \ldots \ldots$. . . . . 77

Parte II - Resultados de dosimetria termoluminescente 83

7.3 Curva de calibração do dosímetro TL . . . . . . . . . . . . . . 83

7.4 Avaliação do tratamento previamente planejado pelo TPS . . . . . . 86

Parte III - Resultados de dosimetria por ressonância spin-eletrônico de $\begin{array}{ll}\text { alanina } & 87\end{array}$

7.5 Curva de calibração . . . . . . . . . . . . . . . . . . . . . 88

7.6 Avaliação do tratamento previamente planejado pelo TPS para os dosímetros de alanina . . . . . . . . . . . . . . . . . . 90

7.7 Discussão . . . . . . . . . . . . . . . . . . . . . . . . . . . . 92

8 Conclusões $\quad 99$ 
Bibliografia 


\section{Lista de Figuras}

3.2.1 Fórmula estrutural do monômero presente no gel polimérico, neste caso gel magic- $f$ e o processo de iniciação da polimerização [1] . . . . . . . . . . . . . 12

3.2.2 Fórmula estrutural do crescimento da cadeia polimérica por meio do processo de propagação $[1] . \ldots \ldots \ldots$. . . . . . . . . . . . . . . 13

3.2.3 Fórmula estrutural do processo de terminação da polimerização [1]. . . . .

3.4.1 (a) Propriedades do spin. (b) Campo magnético dipolar pode ser associado com um campo magnético externo aplicado, permitindo que os prótons se alinhem como este campo externo. A figura foi retirada do Tofts, 2003 [2].

3.4.2 Na parte esquerda da imagem temos os possíveis estados onde pode existir o próton: estado de menor energia com tendência a seguir a direção do $B_{0}$ e um estado de maior energia que tende a estar em contra do campo $B_{0}$. O lado direito, mostra que a diferença de energia entre os dois estados aumenta à medida que a força do campo $B_{0}$ aumenta [2]. Figura retirada e modificada do Tofts, 2003 . . . . . . . . . . . . . . . . . . . .

3.4.3 Movimento de precessão do próton na direção do campo magnético externo $B_{0}$. Figura retirada do Tofts, $2003[2] \ldots \ldots$. . . . . . . . . . . .

3.4.4 Esquema da seqüência spin-eco repetida duas vezes com dois tempos de eco diferentes produz informação suficiente para fazer a reconstrução de um mapa de R2. a) Tempo entre o primeiro pulso curto com respeito ao pulso de $180^{\circ}$. b) Tempo entre o primeiro pulso longo com respeito ao pulso de $180^{\circ}$. Figura retirada do De Deene, 2008 [3] . . . . . . . . . . . . . . . . . 
3.4.5 Esquema da seqüência multi spin-eco. A primeira imagem mostra uma seqüência multi spin-eco produzindo vários ecos durante um mesmo tempo de repetição. Todos os ecos obtidos durante o mesmo tempo de repetição tem a mesma codificação de fase. Na segunda imagem se observa o decaimento do sinal detectado com o tempo, por meio da seqüência multi spin-eco. Também se pode observar o decaimento da amplitude do sinal ao longo dos ecos regida pelo tempo de relaxação T2. Figura retirada do De Deene, 2008 [3]. . . . .

3.4.6 Imagens de IRM para uma bobina de cabeça (a) e uma bobina de corpo (b) de um objeto simulador cilíndrico e homogêneo preenchido em gel. Figura retirada de Pavoni, 2009 [4] . . . . . . . . . . . . . . . . .

3.4.7 Dois objetos simuladores escaneados em diferentes direções ilustram deformações relacionadas com a susceptibilidade na interface entre os dois recipientes. As linhas sobre as imagens foram feitas para mostrar a posição real das superfícies dos objetos simuladores. Figura retirada da referencia De Deene, 2008 $[3] \ldots \ldots \ldots \ldots \ldots \ldots \ldots \ldots$

4.2.1 Esquema simplificado do modelo de bandas de energia del proceso de termoluminiscência en una estructura cristalina [5]. . . . . . . . . . . . . .

4.2.2 Curva de brilho: señal lumínica en función de la temperatura de um cristal de TLD [5]. . . . . . . . . . . . . . . . . . . . .

4.5.1 Diagrama de um equipamento convencional de leitura TL. . . . . . . . . .

5.2.1 (a) Fórmula de estrutura da alanina. (b) modelo molecular da alanina. . . .

5.2.2 (a) Estrutura dos três diferentes espécies de radicais formados pela irradiação da alanina. (b) Espectro ESR de um dosimetro de alanina irradiado com elétrons de $11 \mathrm{MeV}$ e uma dose de 10 Gy. Além disso, é mostrado o espectro dos três radicais formados na L- $\alpha$ alanina a partir da irradiação em temperatura ambiente. Figura retirada e modificada do Malinen [6]. . . . . . . . . . . .

5.2.3 Processo de formação do composto paramagnético uma vez feita a irradiação a dosímetro de alanina. Figura retirada e modificada do Guilherme Gonçalves $[7]$

5.3.1 Estados de energia. Figura retirada e modificada do Wertz e Bolton [8]. . . 46

5.3.2 Diagrama básico de um espectrômetro de ressonância de spin-eletrônico [9]. 
6.1.1 Imagem de uma tomografia computadorizada de um paciente. Figura retirada da dissertação de Guilherme Gonçalves [7]. . . . . . . . . . . . . . . . .

6.1.2 (a) Próteses Metálicas de aço inoxidável e o cimento de fixação [7]. (b) Objeto simulador com a pélvis e as próteses femorais. . . . . . . . . . . . . . . .

6.1.3 Abertura cilíndrica que permite a inserção do recipiente que contem o gel magic- $f$. . . . . . . . . . . . . . . . . .

6.2.1 (a) Recipiente utilizado para simulação da região da próstata sem gel. (b) Recipiente com $216 \mathrm{ml}$ inserido na próstata para após feita a irradiação ser lido com IRM. . . . . . . . . . . . . . . . . . . . . . . . . . . .

6.2.2 Tubos de ensaio de calibração cujo fim é fornecer dados para reconstruir a curva de calibração do gel. . . . . . . . . . . . . . . . . . . . . . . . . . .

6.3.1 (a) Objeto simulador deitado no tomógrafo PHILLIPS, mostrando a parte de trás dele. (b) Objeto simulador deitado no tomógrafo onde é visualizado completamente sua forma. . . . . . . . . . . . . . . . . . .

6.3.2 Screenshot do sistema de planejamento do tratamento padrão de próstata. A imagem mostra a localização dos diferentes campos de irradiação, assim como também os valores das doses que devem chegar até cada ponto. Na última imagem da parte inferior direita aparece o histograma Dose-Volume do fêmur direito e esquerdo. . . . . . . . . . . . . . . . . . . .

6.5.1 Suporte feito em acrílico para o phantom e tubos de calibração do gel, visão frontal (a) e lateral (b). O suporte é inserido em um recipiente de plastico contendo uma solução aquosa. . . . . . . . . . . . . . . . . . . . . .

6.6.1 (a) Software desenvolvido em Matlab para determinar taxas de relaxação. (b) Linearização da equação (3.4.9) com o valor de R2 na região de interesse. . .

6.6.2 Interface do programa CERR, mostrando os perfis axial, sagital e coronal. Além disso, apresenta os quatro campos comuns em um tratamento de próstata, e as diferentes estruturas a irradiar. . . . . . . . . . . . . . . . .

6.6.3 (a) Distribuição da dose planejada normalizada pelo valor de máxima dose.

(b) Distribuição de dose medida normalizada pelo valor de máxima dose. . .

6.6.4 Distribuição de pontos aprovados mediante a análise gama (tons cinza). . .

6.8.1 Curva de intensidade relativa da luz vs temperatura para o Harshaw TLD-100 $[5]$. 
6.9.1 Suporte de acrílico com as capsulas farmacêuticas que contem a alanina. . .

6.9.2 (a) Dosímetros marcados do 5-9 distribuídos na parte direita dos diferentes ossos do quadril. (b) Dosímetros do 5-9 localizados na parte esquerda dos ossos do quadril. (c) Dosímetros TL marcados com os números do 1-4 (cor azul) próximos à cabeça do fêmur (d) Dosímetros marcados do 1-4 (cor preto) próximos à cabeça do fêmur. (e) Localização dos dois últimos dosímetros TL no osso sacro. . . . . . . . . . . . . . . . . . . . .

6.9.3 Visão da parte esquerda da próteses femoral com alguns dosímetros aderidos próximo á interface do osso com o implante metalico. . . . . . . . . . .

6.10. Sistema de leitura TLD. (a) Eletromêtro e válvula fotomultiplicadora. (b) Cilindro de nitrogênio usado para não termos oxigênio próximo dos dosímetros quando aquecidos. . . . . . . . . . . . . . . . .

6.12. Forma de embalagem para o teste de calibração. . . . . . . . . . . . . . . 72

6.12.Distribuição dos dosímetros de alanina ao redor do fêmur, quadril e osso sacro. . . . . . . . . . . . . . . . . .

6.15. Espectrômetro de ressonância spin-eletrônico. Operando em Banda X (9 GHz) da marca Jeol. Pode-se ver o magneto, a ponte de microondas e controlador de temperatura. O console de controle do equipamento fica à direita da fotografia. 75

7.1.1 Curva de calibração para o gel magic-f. . . . . . . . . . . . . . . . . . . . 77

7.2.1 Cortes axiais do fantom e dos tubos testes de calibração obtidas na RM. . . 78

7.2.2 Cortes axiais para as duas distribuições de dose. (a) Distribuição de dose do TPS, organizadas em 14 linhas e 9 colunas. (b) Distribuição de dose obtida pelo gel, e se encontra organizada em 11 colunas e 10 linhas. . . . . . . . .

7.2.3 (a) Distribuição de dose (TPS) no plano Axial, Coronal e Sagital. (b) Distribuição de dose do gel com as diferentes visualizações, Axial, Sagital e Coronal. 80

7.2.4 Cortes axiais com as 20 distribuições de doses relativa do volume analisado.

(a) Distribuição de dose TPS para as fatias desde um $\mathrm{Z}=171$ até $\mathrm{Z}=221$.

(b) Distribuição de dose gel para fatias desde um $\mathrm{Z}=44$ até $\mathrm{Z}=63$. . . . .

7.2.5 Cortes axiais do volume analisado mostrando o análise gama para as 20 fatias. 82 
7.2.6 Corte axial analisado com a análise gama 3D, apresenta o valor do índice gama no ponto $\mathrm{X}=42$ e $\mathrm{Y}=41$ de 0,4209 , e além disso, um quadrado vermelho é feito para simular o volume aproximado da próstata. . . . . . . . . . .

7.3.1 Curva de calibração TL. No eixo horizontal temos a dose aplicada e no eixo vertical a dose convertida após a leitura da luz emitida pelo dosímetro. . . .

7.5.1 Curva de calibração da alanina. . . . . . . . . . . . . . . . . . . 89

7.7.1 Cortes axiais para o volume analisado apresentando a análise gama. . . . . . 94

7.7.2 Comparação de doses medidas em pontos aproximadamente iguais em dois tratamentos . . . . . . . . . . . . . . . . . 


\section{Lista de Tabelas}

3.1 Tipos de dosímetros geís poliméricos $[10,11] \ldots \ldots$. . . . . . . 8

3.2 Descrições dos elementos utilizados no Gel MAGIC- $f$. . . . . . . . . . 10

6.1 Composição em massa dos elementos utilizados na fabricação do gel magic-f, ....................... 52

6.2 Valor da sensibilidade para cada um dos TL utilizados. . . . . . . . . . 70

7.1 Valores da taxa de relaxação R2 com os erros associados à medida. . . . . . 77

7.2 Apresentação dos valores de leitura 1 e 2 por meio do equipamento Harshaw, com seus devidos fatores de calibração. . . . . . . . . . . . . . . . . . . . 84

7.3 Valores de leituras 1 e 2 convertidos em dose. . . . . . . . . . . . . . . 85

7.4 Distribuição dos dosímetros Tl no objeto simulador (Phantom) . . . . . 86

7.5 Leitura da dose absorvida por parte dos dosímetros TL localizados ao longo do objeto simulador. . . . . . . . . . . . . . . . . 87

7.6 Valores de dose irradiadas com suas correspondentes amplitudes, determinadas por dosimetria de ESR. . . . . . . . . . . . . . . . . . . 88

7.7 Valores das amplitudes para cada dosímetro localizados na perna direita. $\quad$ • 90

7.8 Amplitudes obtidas por dosimetria ESR para a perna esquerda. . . . . . . . 91

7.9 Valores de dose absorvida para cada dosímetro de alanina localizado na prótese métalica direita. . . . . . . . . . . . . . . . . . . . . . . . . 91

7.10 Valores de dose absorvida para cada dosímetro de alanina localizado na prótese metálica esquerda. . . . . . . . . . . . . . . . . . . 
7.11 Fatores de transmissão para feixes de 4 e 10 MV, para três materiais de pró-

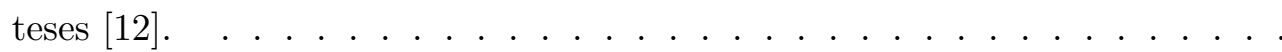

7.12 Comparação das leituras de dose absorvida para os TL e as alaninas para o implante metálico direito. . . . . . . . . . . . . . . . . . . . .

7.13 Comparação das leituras de dose absorvida para os TL e as alaninas para o próteses femoral esquerda. . . . . . . . . . . . . . . . . . . . 97 


\section{Capítulo 1}

\section{Introdução}

O câncer de Próstata é um dos cânceres mais comuns e recorrentes nos homens, afetando $50 \%$ da população masculina com idade acima de 70 anos e praticamente todos com mais de 90 anos [13]. De acordo com as estatísticas da Sociedade Americana de Câncer o número estimado de casos novos para o ano de 2015 foi de 220.800, registrando um número estimado de mortes de 27.540. As taxas de incidência desse tipo de câncer são cerca de seis vezes maiores nos países desenvolvidos quando comparadas com aquelas dos países em desenvolvimento. Pela alta frequência dessa doença é necessário procurar um tratamento com uma boa precisão e que seja além disso eficaz. Portanto, a radioterapia (RT) é uma excelente técnica para o controle do câncer de próstata. Modalidade de tratamento que através do uso de radiações ionizantes combate o crescimento das células cancerosas. O objetivo da RT é a entrega de uma dose de radiação a um volume previamente definido, que deve ser o mais preciso possível evitando assim afetar tecidos sadios vizinhos e produzindo uma melhor qualidade de vida ao paciente. Na radioterapia, há uma exigência rigorosa sobre a dose entregue aos pacientes, pois deve ter uma precisão de $\pm 5 \%$ [14]. Sendo esse o primeiro problema para tratamentos com radiação quando todas as fontes de incertezas do tratamento são tomadas em consideração. A maioria das diretrizes nacionais e internacionais para o controle da precisão na dosimetria de radiação só fornece informações para meios homogêneos; não obstante, nosso corpo é altamente heterogêneo já que possui muitos tecidos de densidade variável. Isso é especialmente certo quando um paciente tem implantes metálicos no corpo tais como placas mandibulares por reconstrução, quadril, perna, e prótese de braço. Geralmente, estes dispositivos tem um número atômico muito alto, alterando significativamente a dose entregada $[14,15]$. 
Como o câncer de próstata é mais comum na população idosa o uso das próteses metálicas no fêmur e na pelve tornou-se mais comum, por isso é importante resolver problemas técnicos associados com o tratamento desses pacientes. É possível ver na distribuição de dose de um tratamento de câncer pélvico, como a dose perto da interface osso-metal aumenta, ao longo do tempo complicações ocorrem em tecidos tumorais adjacentes. Alguns exemplos incluem: necrose óssea e enfraquecimento da fixação do implante. Apesar de que não existe muita informação sobre as complicações causadas pelo uso dos implantes metálicos, problemas futuros são esperados. Portanto, é fundamental detectar estes problemas o mais pronto possível para assim encontrar possíveis soluções. Algumas instituições resolvem o problema por meio da mudança na orientação do feixe para minimizar a irradiação dos implantes. Outras instituições, devido ao aumento da disponibilidade e precisão, usam a Radioterapia de Intensidade Modulada (IMRT) para este tipo de tratamentos [16]. IMRT é uma avançada técnica em radioterapia que permite a entrega de altas doses de radiação ao volume alvo, preservando ao mesmo tempo os tecidos circundantes. Isso é possível pela modulação dos campos de radiação, usualmente feitos por colimadores multilfolhas que conformam os campos de radiação durante a irradiação. Devido à complexidade da distribuição de dose (DD), um adequado controle de qualidade (QA) destes tratamentos é mandatório [17, 18]. A capacidade de fazer um tratamento clínico para resolver uma hipótese é limitada pelo conhecimento das incertezas inerentes dos dados, variações não quantificadas no tratamento podem reduzir a capacidade de um teste para responder às questões que abordam. Os tratamentos clínicos de radioterapia contemporânea têm muitas exigências consideráveis em termos de complexidade e precisão, aumentando de forma mais rigorosa os requerimentos de controle de qualidade (QA) nos tratamentos do paciente [19].

Dosímetros atualmente disponíveis, tais como câmeras de Ionização (IC), arranjos de diodos, dosímetros termoluminescentes (TLDs) e filmes radiográficos fornecem distribuições de doses em um ponto ou em duas dimensões [17]. Em um trabalho recente, Dosimetria de Ressonância de Spin-Eletrônico (ESR) com alanina, que tem uma resposta plana em energia acima de $100 \mathrm{kV}$, foi usada para medir a dose na região da próstata [20]. Para medições de dose em 3D, não obstante, é requerido o uso de muitos dosímetros, resultando em um procedimento muito mais complicado, que ainda não fornece uma alta resolução espacial, exceto no caso dos filmes. Portanto, na atualidade a melhor opção é usar géis poliméricos associados com uma técnica de imagem para 
produzir mapas de doses em 3D [21, 16].

Nosso objetivo é estudar os tratamentos de próstata e a influencia das próteses femorais metálicas na distribuição de dose. Neste estudo, um objeto simulador (Phantom) da região pélvica de um adulto e um inserto cilíndrico na região da próstata foi desenvolvido, com o fim de fazer aplicações em dosimetria 3D usando dosimetria gel magic- $f$. A dose absorvida na região da prótese também será avaliada e para isso, é utilizada a dosimetria termoluminescente e de ESR-alanina. 


\section{Capítulo 2}

\section{Objetivos}

- Estudar tratamentos de próstata e a influência de implantes femorais metálicos na distribuição de dose. Para isso, um objeto simulador da região pélvica de um adulto com duas próteses metálicas e uma inserção cilíndrica na região da próstata foi desenvolvido, com o fim de fazer aplicações em dosimetria 3D, usando como dosímetro o gel magic- $f$.

- Avaliar por meio do sistema de planejamento do tratamento (TPS) a dose nos ossos em proximidade das próteses com dosímetros termoluninescentes e alanina. Essa medidas serão feitas por meio do aquecimento do dosímetro no caso dos TL e por espectroscopia de ressonância de spin-eletrônico (ESR) para as alaninas. 


\section{Capítulo 3}

\section{Dosimetria Gel}

\subsection{Evolução da dosimetria gel}

Durante muitos anos pesquisadores têm se esforçado para medir as distribuições de dose da radiação absorvida utilizando géis. Os dosímetros de gel são feitos a partir de produtos sensíveis à radiação ionizante. Os primeiros pesquisadores que mostraram um tipo de sugestão com respeito à medição da dose de radiação foram Fricke e Morse em 1927. Mas foi somente em 1950 que Day e Stein testaram a mudança da cor no Fenol de Folin pela irradiação [11], não obstante, quatro anos depois, Alexander discutiu os efeitos da radiação ionizante no polimetacrilato que era obtido a partir da polimerização do metacrilato de metila [22]. Posteriormente, em 1957 distribuições de doses de fótons e elétrons em géis Agar foram investigados por meio de espectrofotometria [23]. No ano seguinte, Hoecker e Watkins investigaram a dosimetria pela polimerização induzida em líquidos. Já em 1961, Boni utiliza a poliacrilamida como um dosímetro de radiação gama.

Quase mais de duas décadas se passaram para que um novo avanço na dosimetria gel fosse feito, esse é talvez o avanço mais importante que tem sido dado já que deu inicio à dosimetria que hoje em dia se conhece, a qual esta baseada principalmente nos trabalhos de Gore desenvolvidos em 1984. Ele investigou as propriedades de relaxação dos géis Fricke em RMN e mostrou que as mudanças induzidos pela radiação quando os íons ferrosos $\left(\mathrm{Fe}^{2+}\right)$ são convertidos em íons férricos $\left(F e^{3+}\right)$, podem ser quantificadas por meio das medições de relaxação em RMN. Em 1986, Appleby reportou que as soluções de dosimetria Fricke dispersas através de uma matriz gelatinosa podem ser 
usada para obter informação da distribuição de dose tridimensional (3D) utilizando Imagem por Ressonância Magnética (IRM). Posteriormente foi mostrado que a irradiação do dosímetro gel tipo Fricke não apresentava estabilidade espacial na distribuição de dose devido à difusão de íons dentro do dosímetro. Cinco anos depois, em $1991 \mathrm{Au}-$ det e Schreiner reportaram mudanças nas medições de relaxação transversal em RMN nas medidas de óxido de polietileno irradiados. Em 1992 Kennan et al., mostram resultados de estudos de relaxação longitudinal sobre RMN realizadas em uma solução aquosa irradiada de N,N'-metileno-bis-acrilamida e agarose, a qual mostrou que a taxa de relaxação aumenta com a absorção de dose.

Finalmente, Maryanski em 1993 determinou uma nova formulação de dosimetria gel baseada na polimerização de monômeros de acrilamida dentro de uma matriz de agarose aquosa, aquela solução foi chamada com o acrônimo de BANANA (Bis Acrylamide Nitrous oxide ANd Agarose). Este tipo de dosimetria gel não apresentava as limitações de difusão que foram encontradas no dosímetro Fricke, mas foram outras complicações as que limitam a sua utilização. Como já sabemos, quando o gel é irradiado acontece a radiólise da água e nele são produzidos os radicais livres para posteriormente permitir a polimerização dos monômeros. No momento dessa polimerização pode ocorrer que o gel irradiado contem oxigênio, o que gera erros na resposta do dosímetro. Para corrigir isso, o gel é saturado com óxido nítrico durante sua preparação e assim remover o oxigênio. Como resultado, estes dosímetros de gel tinham de ser fabricados num ambiente livre de oxigênio [11], tal como em uma caixa de luvas bombeado com nitrogénio gasoso. Juntamente com a utilização de produtos químicos potencialmente tóxicos [11], é que nasce uma limitação significativa na introdução da dosimetria de gel em usos clínicos.

Um ano depois, Maryanski e seus colegas fizeram um bom estudo respeito ao dosímetro Fricke cuja formulação deste foi aperfeiçoado, substituindo a agarose por gelatina. O novo dosímetro foi chamado com o acrônimo BANG (bis, acrylamide, nitrogen and aqueous gelatine), o primeiro de uma série de novas formulações de géis poliméricos. Em 1994, esta formulação foi patenteada[24] e começa a ser comercializada através de MGS Research Inc. como $B A N G^{\circledR}$. Posteriormente devido à nomenclatura do produto comercial, o gel de poliacrilamida (PAG) começa a ser o acrônimo do dosímetro gel polimérico de muitos outros autores. Muitas pessoas fizeram mais publicações sobre novas formulações de dosímetros de gel poliméricos alguns das quais foram resumidas por Lepage.

Devido à limitação com os dosímetros gel, por causa dos radicais livres que são sensíveis 
ao oxigênio atmosférico no momento da polimerização, era necessário encontrar uma forma muito mais fácil para remover o oxigênio e assim facilitar a fabricação deles em um ambiente livre deste. Por tal razão, a realização ou elaboração de um dosímetro gel polimérico normóxico era de muita importância. Nessa ordem de ideias um significante desenvolvimento no campo da dosimetria gel ocorreu quando foi feita uma formulação alternativa na dosimetria gel polimérica publicada por Fong em 2001. O novo dosímetro resolveu o problema de inibição do oxigênio permitindo a fabricação dele em condições normais no laboratório, aquele novo gel foi chamado Gel MAGIC.

O gel magic esta composto por gelatina, ácido metacrílico, ácido ascórbico e sulfato de cobre. Nele ocorre uma reação em que um metal bivalente (sulfato de cobre) forma um complexo com o ácido ascórbico, que captura o oxigênio molecular e permite que um elétron se transfira através do complexo para uma espécie externa, gerando assim, um radical livre que pode iniciar a polimerização e removendo o oxigênio da mistura [4]. Subsequentemente, De Deene em 2002, mostrou que outros antioxidantes podem também ser utilizados para fabricações de novos géis normóxidos, ideias que foram base para os trabalhos desenvolvidos em 2006 por Baldock, mostrando que outros antioxidantes como o Hidroximetil e o cloreto de fósforo tem a mesma eficácia na fabricação do gel magic.

Um artigo publicado no 2002 de dosimetria gel fricke com IRM [25], mostrou o desenvolvimento de um objeto simulador com células pequenas, um Favo de Mel (Honeycomb Phantom) feito de polietileno, que tinha como objetivo reduzir os efeitos de difusão dos íons. Em um principio, tubos de calibração com gel fricke foram irradiados para diferentes doses e imagens com diferentes tempos de repetição (TR) foram obtidos, o analise desse processo deixo bons resultados de homogeneidade e boa reprodutibilidade nas imagens de RM. Além disso, o resultado para os efeitos da difusão em $F e^{3+}$ dentro do gel durante $24 \mathrm{hr}$, mostraram que a informação espacial foi constante 24 hr após a irradiação, portanto, o objeto simulador implementado reduz satisfatoriamente aqueles efeitos de difusão de íons. Não obstante, problemas de auto-oxidação no momento do montagem podem levar a erros nas intensidades das imagens, por tal motivo, em nosso trabalho não é considerada a dosimetria gel fricke.

No ano de 2003 uma nova classe de dosimetria polimérica foi apresentava com o nome de PRESAGE, ele não vai ser discutido aqui por não se tratar de um dosímetro que permite a avaliação por IRM, mas funciona muito bem em um sistema ótico.

A seguir são apresentados os diferentes tipos de dosímetros gel poliméricos publicados 
por Senden em 2001.

Tabela 3.1: Tipos de dosímetros geís poliméricos [10, 11].

\begin{tabular}{|c|c|c|}
\hline $\begin{array}{l}\text { Dosímetro } \\
\text { Nórmoxico }\end{array}$ & Referência & Formulação dosímetro gel polimérico \\
\hline MAGIC & {$[18,26,27]$} & $\begin{array}{c}\text { Ácido metacrílico, ácido ascórbico, sulfato de } \\
\text { cobre, gelatina }\end{array}$ \\
\hline MAGAS & {$[27,28]$} & Ácido metacrílico, ácido ascórbico, gelatina \\
\hline MAGAT & {$[27,29,30]$} & Ácido metacrílico, hidroximetil, gelatina \\
\hline nMAG & {$[31]$} & Ácido metacrílico, hidroximetil, gelatina \\
\hline PAGAS & {$[27]$} & $\begin{array}{c}\text { Acrilamida, N,N-metileno-bis-acrilamida, ácido } \\
\text { ascórbico, gelatina }\end{array}$ \\
\hline PAGAT & {$[21,29,32]$} & $\begin{array}{l}\text { Acrilamida, N,N metileno-bis-acrilamida, } \\
\text { hidroximetil, hidroquinona, gelatina }\end{array}$ \\
\hline nPAG & {$[31]$} & $\begin{array}{c}\text { Acrilamida, N,N metileno-bis-acrilamida, } \\
\text { hidroximetil, gelatina }\end{array}$ \\
\hline
\end{tabular}

Desde o ponto de vista de distribuições de doses, a dosimetria gel polimérica é uma técnica superior a outras porque permite obter informação em 3D. É baseada na polimerização do gel devido à reação gerada pela radiação que é iniciada pela radiólise da água. Uma forma de fazer a leitura dos géis uma vez sejam irradiados é por meio de imagem por ressonância magnética utilizando relaxometria, de igual maneira é possível utilizar a tomografia ótica como ferramenta de leitura. A forma como esta constituído o gel permite ser apresentado com um dosímetro ideal pois, é possível conformações adequadas a um objeto simulador antropomórfico com densidade equivalente à água.

Atualmente a dosimetria gel continua em fase de investigação, cujos principais problemas são:

- A fabricação pode ser dispendiosa e complicada. Em alguns casos pode requerir um laboratório especializado devido aos problemas para remover o oxigênio dissolvido no gel. Por tal razão, os géis nórmoxicos são uma boa opção.

- Ainda não é fácil o acesso aos tomógrafos de ressonância e tomógrafos óticos.

Nosso trabalho é baseado em um novo tipo de gel magic desenvolvido pelo grupo [16], onde um composto chamado Formaldeído é incluído para resolver parcialmente os problemas de estabilidade, permitindo um aumento do ponto de fusão. De maneira que, 
o gel foi denominado gel magic- $f$, nossa atenção vai ser focalizada somente neste gel. As caraterísticas físicas e químicas fazem do gel magic- $f$ um excelente candidato para trabalhar com dosimetria das radiações ionizantes em 3D.

\subsection{Propriedades físicas e químicas do gel magic- $f$}

O gel magic-f (Acido Metacrílico, Acido Ascórbico, Gelatina, Sulfato de Cobre com adição de Formaldeído) é o acrônimo de um composto formado por 5 elementos, os quais reação com a radiação ionizante formando monômeros que polimerizam o gel devido aos radicais liberados no momento da radiólise da água. Na tabela (3.2), são mostradas as características de cada elemento utilizado na fabricação dele.

Cada um dos composto utilizados na fabricação do gel tem uma função direta ou indireta no momento da irradiação. Primeiramente, a gelatina tem como função manter o controle no momento da polimerização assim como de fornecer um meio equivalente ao tecido humano. As altas concentrações de gelatina na solução (gel magic- $f$ ) podem reduzir a sensibilidade da relaxometria do gel em seqüências T2 em Ressonância Magnética [3].

O acido ascórbico fornecem a capacidade de formar um complexo com o sulfato de cobre e o oxigênio, reação importante pois, com ela o gel pode ser feito em atmosfera normal.

O ácido metacrílico é o componente principal na fabricação do gel magic- $f$, já que é o monômero que permite a formação do polímero que mede indiretamente a radiação absorvida. O grau de polimerização depende da quantidade de radicais livres que inicialmente foram gerados quando ocorre a radiólise da água. 
Tabela 3.2: Descrições dos elementos utilizados no Gel MAGIC- $f$.

\begin{tabular}{lcc}
\hline Nome & Estrutura química & Propriedades \\
Água Mili-Q & $\begin{array}{c}\text { É um tipo de água deionizada ou } \\
\text { desmineralizada na qual foram retirados os } \\
\text { ions. O sistema Mili-Q combina a produção } \\
\text { da água pura II e ultra pura I em uma mesma } \\
\text { unidade, eliminando a necessidade de um } \\
\text { sistema de pre-tratamento para a obtenção } \\
\text { da água ultrapura. }\end{array}$ \\
Ácido Ascórbico & $\begin{array}{c}\text { É um sólido cristalino de cor branca, inodoro, } \\
\text { hidrossolúvel e pouco solúvel em solventes } \\
\text { orgânicos. Além de isso, é um poderoso } \\
\text { antioxidante cuja função é aprisionar os } \\
\text { radicais livres de oxigênio deixando-os em sua } \\
\text { forma inerte. }\end{array}$ \\
\hline
\end{tabular}

Liquido sem cor ou cristais sem cor, de um cheiro muito forte e desagradável. É uma sustância que polimeriza com facilidade devido a um forte aquecimento ou na

\section{Ácido Metacrílico}<smiles>C=C(C)C(=O)O</smiles>

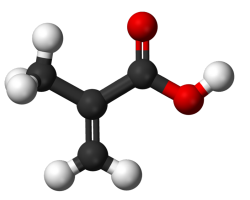

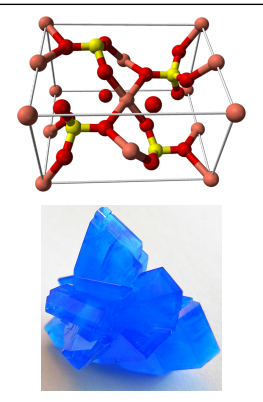

presença de luz, agentes oxidantes, tais como peróxidos, ou a presença de vestígios ácido clorídrico, com perigo de incêndio e explosão.

O Ácido metacrílico é fabricado industrialmente, a uma escala muito grande como um precursor de ésteres, principalmente metacrilato de metilo (MMA) e polimetacrilato de metilo (PMMA).

Composto químico cuja formulação é $\mathrm{CuSO}_{4} 5 \mathrm{H}_{2} \mathrm{O}$, também conhecido por vitríolo azul sendo este o composto mais importante do cobre e a forma mais frequente de ser encontrado. Ele é solúvel em água e metanol e levemente solúveis em etanol e glicerina.

\begin{tabular}{c}
\hline É um composto químico cuja formulação é \\
$H_{2} C=O$, seu nome oficial é Metanal . Gás \\
incolor de um cheiro forte, solúvel na água e \\
ésteres. É uma sustância que polimeriza \\
facilmente portanto, reage com antioxidantes.
\end{tabular}


O formaldeído quando interage com a gelatina transforma a proteína representada pela gelatina. Basicamente, reage com as terminações aminas primárias dos aminoácidos lisina e arginina presentes na gelatina formando finalmente as conhecidas bases de Schiff. Essa base, é produto da reação formada a partir das ligações cruzadas entre os resíduos da gelatina (3.2.1) [4]. As ligações duplas para serem dissolvidas requerem uma energia térmica maior, portanto, o ponto de fusão da gelatina com a adição de formaldeído é mais alto.

$$
\text { Gelatina }-\mathrm{NH}_{2}+\mathrm{CH}_{2} \mathrm{O} \rightarrow \mathrm{Gel}-\mathrm{N}=\mathrm{CH}_{2}+\mathrm{H}_{2} \mathrm{O}
$$

Ao utilizar o formaldeído o ponto de fusão do gel aumenta até $65^{\circ} \mathrm{C}$ e não afeta as diferentes reações dentro do dosímetro. Além disso, a sua sensibilidade é de 10,5\% maior que a dos géis convencionais e apresenta uma redução nos valores de R2 medidos [4].

A agua deionizada é importante pois reduz os níveis de oxigênio, e dessa mesma forma a qualquer outro elemento que possa interromper o processo de polimerização.

Nosso dosímetro gel, é basicamente uma matriz gelatinosa onde os monômeros estão dissolvidos. A seguir serão mostradas as reações químicas que ocorrem dentro do dosímetro gel no momento da irradiação da água.

Em primeiro lugar, o dosímetro é composto de $90 \%$ de água portanto, quando é feita a irradiação ocorre a radiólise e o que acontece é que as moléculas de água se dissociam em muitos radicais livres.

Radiólise da água- propagação dos radicais livres

$$
\begin{gathered}
\mathrm{H}_{2} \mathrm{O}+\text { radiação } \longrightarrow \mathrm{H}_{2} \mathrm{O}^{+}+e^{-} \\
\mathrm{H}_{2} \mathrm{O}^{+} \longrightarrow \mathrm{H}^{+}+\mathrm{OH}^{\cdot} \\
e^{-}+\mathrm{H}_{2} \mathrm{O} \longrightarrow \mathrm{H}_{2} \mathrm{O}^{-} \\
\mathrm{H}_{2} \mathrm{O}^{-} \longrightarrow \mathrm{H}^{\cdot}+\mathrm{OH}^{-} \\
\mathrm{H}^{+}+\mathrm{OH}^{-} \longrightarrow \mathrm{H}_{2} \mathrm{O} \\
\mathrm{H}_{2} \mathrm{O}+\text { radiaçãa } \longrightarrow \mathrm{H}^{\cdot}+\mathrm{OH}^{\cdot}
\end{gathered}
$$


Após a propagação dos radicais livres a probabilidade de que estas partículas se encontrem umas com outras por movimento browniano e reajam em forma de uma reação em cadeia aumenta com o tempo, portanto, o raio de ação dos radicais começa a crescer.

Polimerização: Mecanismo de reação em cadeia por radicais livres.

$$
\mathrm{H}_{2} \mathrm{O}+\text { radiação } \longrightarrow \mathrm{H}^{\cdot}+\mathrm{OH}^{\cdot}
$$

Iniciação: Como sabemos os radicais livres, produtos da radiólise da água, são os encargados de iniciar a polimerização dos monômeros por meio da ligação a um elétron da ligação dupla do monômero. Nesse caso, o monômero utilizado para o gel magic- $f$ é o ácido metacrílico o qual apresenta uma ligação dupla onde o radical é ligado. A iniciação pode ser vista como:

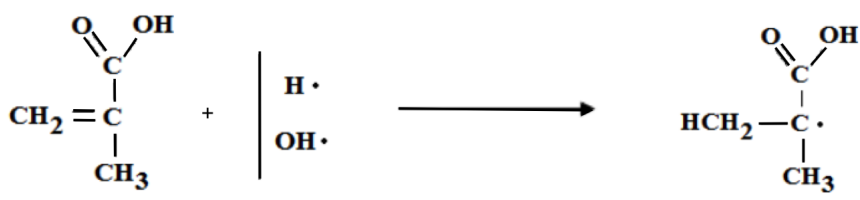

Figura 3.2.1: Fórmula estrutural do monômero presente no gel polimérico, neste caso gel magic- $f$ e o processo de iniciação da polimerização [1].

Em principio, não existe nenhum polímero formado dentro do gel, mas a medida que vai passando o tempo os radicais estão sendo ligados aos monômeros e conseqüentemente grandes cadeias de monômeros são formados por médio de enlaces químicos que em geral são de tipo covalente, para finalmente formar macromoléculas chamadas polímeros. O crescimento da cadeia polimérica ocorre por meio da propagação em cadeia de reações nas quais os radicais monoméricos ou poliméricos reagem com outros monômeros ou polímeros.

Propagação: Os monômeros interagem entre si como uma reação em cadeia. 


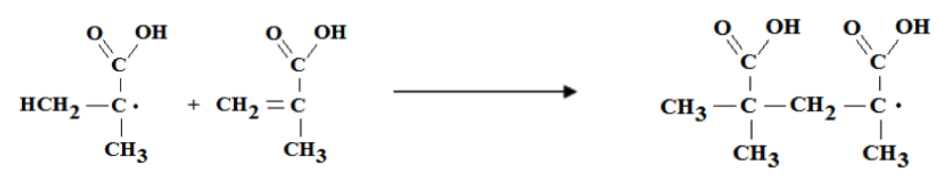

Figura 3.2.2: Fórmula estrutural do crescimento da cadeia polimérica por meio do processo de propagação [1].

Finalmente, a terminação das moléculas do ácido metacrílico é completada formando o polímero:

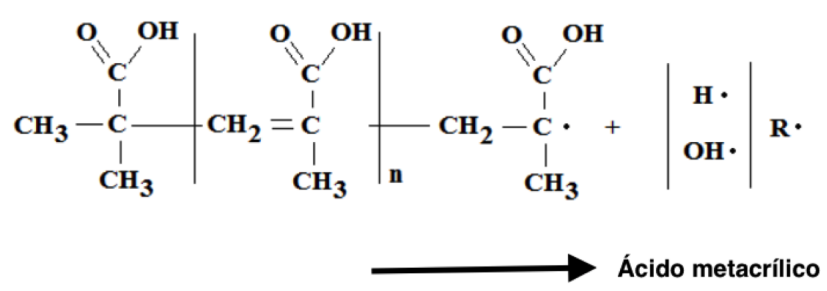

Figura 3.2.3: Fórmula estrutural do processo de terminação da polimerização [1].

\subsection{Características dos dosímetros géis poliméricos}

\subsubsection{Efeitos do oxigênio}

O processo de polimerização é iniciado por meio da liberação dos radicais livres produtos da radiólise da água na fabricação do gel magic- $f$. Estes radicais livres combinados com os monômeros formam um reativo. Não obstante, as moléculas de oxigênio que ficam no meio ambiente atuam como um agente eliminador dos radicais livres e consequentemente o processo de polimerização não é realizado com êxito [33, 34, 24, 35]. Assim, mesmo pequenas quantidades de moléculas de oxigênio circulando na mistura do gel podem afetar o dosímetro, diminuindo a sua eficiência. Uma parte importante na fabricação do dosímetro gel polimérico é remover o oxigênio dos frascos onde é armazenada a solução que irá se gelificar. Portanto, é de vital importância assegurar que não exista difusão de oxigênio para dentro dos frascos. A manutenção de um ambiente hipóxico foi a principal desvantagem na fabricação dos dosímetros em seus estudos iniciais, tornando difícil 
o processo de implementação no ambiente clinico. Com a inclusão da dosimetria gel polimérica normóxida descrita previamente, o ambiente hipóxico deixa de ser necessário, porém os avanços até o momento são muito incipientes e ainda temos um longo trabalho para poder implementar essa disimetria na prática clinica.

\subsubsection{Efeitos da luz}

Como já sabemos o processo de polimerização deve ser feito unicamente por meio da radiólise da água que geralmente leva à criação dos radicais livres. Não obstante, outros fatores influenciam na polimerização, como por exemplo, a luz intensa, mais exatamente a energia solar ou outras fontes de luz que contenham radiação ultravioleta, que poderia iniciar a fotopolimerização do gel antes de ser feita a irradiação com o acelerador linear. Se isso acontece, a sensibilidade do gel é degradada. Uma solução imediata para que não ocorra uma diminuição da sensibilidade do gel é, uma vez seja feita a irradiação o gel deve ser armazenado longe de fontes de luz muito fortes.

\subsubsection{Temperatura}

Um cuidado especial na mistura do gel com a água deve ser tomado em consideração, para isso, é conveniente utilizar uma temperatura maior para ter certeza que a gelatina seja completamente dissolvida. Inicialmente a adição da gelatina deve ser feita com a água à temperatura ambiente, de modo que o crescimento de qualquer aglomerado que possa prejudicar o procedimento de manufatura seja removido. Uma vez que a gelatina é diluída completamente dentro da água, a mistura não deve exceder os $50^{\circ} \mathrm{C}$ para ter maior garantia que a gelatina esteja completamente dissolvida dentro da água [10]. Um aumento na temperatura pode significar um dano na polimerização pois poderia aumentar o risco de que aconteça uma pre-polimerização. Seguindo com o processo de manufatura, a temperatura do gel deve ser baixada para ser armazenado nos respectivos recipientes. Basicamente, um erro na temperatura pode afetar as reações de polimerização dentro do dosímetro gel e isto leva a uma incorreta calibração das imagens da dosimetria gel. Para fazer uma diminuição dos efeitos causados pelos artefatos sobre os mapas de dose é de vital importância ter um maior controle no tamanho, forma e temperatura dos dosímetros.

Durante a aquisição de imagem de ressonância magnética a temperatura tem um efeito 
considerável sobre a sensibilidade da dose R2. Muitos autores encontraram um aumento na sensibilidade da dose como na taxa de relaxação $\mathrm{R} 2[36,17]$. Isso pode ser o resultado de uma alteração na mudança das taxas de relaxação de prótons no gel quando a temperatura é modificada, como a temperatura diminui o movimento dos prótons da água começa a ser mais lento [30]. O aumento na temperatura de ao menos $1^{\circ} \mathrm{C}$ dentro de seu respectivo simulador pode gerar incertezas nos mapas de dose de aproximadamente 50 cGy. Devido a que o gel é submetido a processos de imagens de ressonância magnética mudanças nas taxas de relaxação acontecem, e portanto, um controle na temperatura dos dosímetros é requerido. Os dosímetros que uma vez sejam irradiados devem ser mantidos a uma temperatura controlada durante pelo menos 24 horas, antes de fazer a imagem de ressonância magnética para assim permitir o equilíbrio de temperatura dos dosímetros com o ambiente.

\subsubsection{Concentração dos monômeros}

A sensibilidade da dose R2 do gel pode ser aumentada pelo aumento total dos monômeros do gel. Maryanski descreve que o aumento típico da concentração dos monômeros da ordem de $3 \%$ aumenta a sensibilidade em $6 \%$ ampliando o ponto de saturação [1]. O incremento da saturação é gerado por dois mecanismos: Reatividade dos monômeros e das propriedades de relaxação do gel as quais dependem da sua composição e concentração. É importante saber que o gel tem um ponto de saturação (a saturação faz referencia a que o gel responde linearmente até uma dose limite, depois desse ponto o gel já não tem resposta alguma) o qual devemos conhecer.

É conveniente ter presente que algumas vezes quando se trabalha com dosimetria gel polimérica é utilizado como monômero um ácido forte (neste caso o ácido metacrílico), portanto, concentrações elevadas podem afetar negativamente à gelatina no dosímetro gel com o tempo. O que leva a problemas futuros da sensibilidade na dose R2 do gel.

\subsubsection{Envelhecimento do gel}

Os géis tipo fricke mostravam problemas de difusão com os íons férricos respeito ao tempo gerando problemas de resolução espacial. Mas, com o uso de dosimetria gel polimérica os problemas de limitações de tempo não são um fator significativo. 
Na dosimetria polimérica o tempo de polimerização não é definido mas a estimativa do tempo para ocorrer a polimerização total fica dentro de um intervalo de 12 ou talvez 24 horas após feita a irradiação. De acordo com estudos feitos por De Deene et al., sobre a estabilidade da estrutura do dosímetro gel polimérico, erros significativos após 12 horas da irradiação foram encontrados [30]. Não obstante, para tempos a partir de 12 horas é detectada uma melhor estabilidade temporal.

\subsubsection{Toxicidade}

No caso de utilizar géis com um monômero de acrilamida é importante estar atento na manipulação deste, pois apresenta perigo neurotóxico produzindo problemas no sistema nervoso central. No caso dos géis que utilizam o ácido metacrílico este é irritante e corrosivo, deve ser manipulado em uma capela e com os equipamentos de segurança adequados.

\subsection{Avaliação da dosimetria gel polimérica}

Uma vez feita a irradiação o processo de leitura da dose depositada nos dosímetros deve ser realizado. Para isso, é necessária a obtenção de imagens para produzir mapas de distribuição de dose absorvida. A avaliação desses dosímetros pode ser executada por métodos tais como: IRM, tomografia computadorizada com raios $\mathrm{x}$, tomografia ótica computadorizada e ultrassom. É fundamental que a técnica escolhida tenha uma precisão e uma capacidade de detecção das mudanças da radiação induzida nos dosímetros géis.

A técnica mais usada até o momento é a IRM, que também foi a primeira a ser desenvolvida para a leitura dos dosímetros géis poliméricos. Não obstante, IRM foi prontamente reconhecida como uma técnica promissora, mas devido a suas limitações quanto ao acesso aos tomógrafos de ressonância magnética e ao fato que é muito complexo a optimização do protocolo de imagem baseados, principalmente, em técnicas óticas vem sendo desenvolvidas novos métodos de imagem. 


\subsubsection{Imagens por ressonância magnética}

A primeira vez que foi proposto o uso de imagem de ressonância magnética como método de leitura de distribuição de dose absorvida aconteceu em 1984 por Gore et al., [3] e anos mais tarde na "5th International Conference on Radiotherapy Gel Dosimetry", foi publicada uma revisão dos princípios quantitativos de ressonância magnética para dosimetria gel [3]. Portanto, o descrito em baixo é feito baseado na compreensão do leitor do mesmo.

\subsubsection{Princípios básicos na imagem de ressonância magnética}

Os principais componentes em um scanner de ressonância magnética são:

- Um magneto criogênico que proporciona um campo magnético homogêneo e de alta intensidade, típica $1.5 \mathrm{~T}$ ou $3 \mathrm{~T}$. Onde a maior campo magnético maior vai ser a razão sinal-ruído [3].

- Bobinas de gradiente de campo magnético capazes de criar um campo magnético que ficam na mesma direção que o campo magnético principal mas tem variação de intensidade dependendo de sua direção.

- Bobinas de Radiofrequências (RF), basicamente são as responsáveis de produzir ou receber uma onda eletromagnética.

Além dos três principais componentes do scanner, cabe ressaltar que eles também possuem bobinas de ajuste de homogeneidade do campo magnético e gaiola de Faraday. De modo que, quando o sinal é obtido este passa a ser digitalizado e armazenado, de tal forma que enquanto a seqüência se repete gradientes do campo magnético são aplicados e o sinal é codificado espacialmente. Durante a codificação estão sendo aplicadas as transformadas de fourier para reconstruir finalmente a imagem.

No entanto, para ter coerência e continuidade um pequeno resumo sobre o que acontece em RM será discutido a seguir.

O processo de RM, como o nome sugere, envolve a interação de um núcleo atômico com um campo magnético. Quantidades de núcleos diferentes apresentam o fenômeno, entre os quais temos: Carbono 13, o Azoto 15, Flúor 19, Sódio 23 e Fósforo 31. Além 
disso, a água e as gorduras que são os constituintes principais em amostras biológicas também exibem o fenômeno. Nesse contexto, as propriedades do spin fazem que o núcleo de hidrogênio comporte-se como uma diminuta barra magnética (Figura 3.4.1a), cujo campo magnético é descrito como dipolar (Figura 3.4.1b). Esse momento magnético dipolar $^{1}$ é associado ao campo dipolar e descreve como ocorre a alienação dipolar, o seja, o dipolo é alinhado com o campo magnético externo. De modo que, o núcleo encontra-se interatuando com o campo magnético externo como se fosse uma agulha de bússola [2].

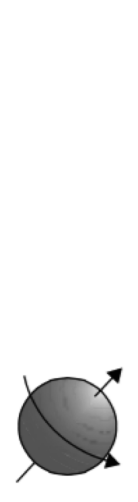

(a)

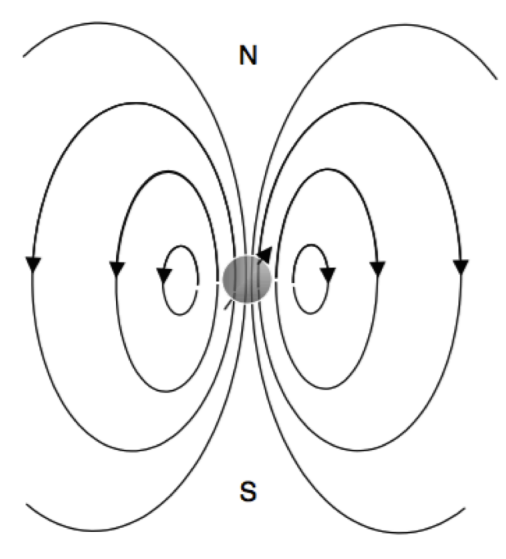

(b)

Figura 3.4.1: (a) Propriedades do spin. (b) Campo magnético dipolar pode ser associado com um campo magnético externo aplicado, permitindo que os prótons se alinhem como este campo externo. A figura foi retirada do Tofts, 2003 [2].

Em ausência de um campo magnético os momentos dipolares magnéticos são posicionados em direções aleatórias. Quando os prótons são submetidos a um campo magnético externo o efeito Zeeman acontece, gerando dois possíveis estados de energia do núcleo de hidrogênio, usualmente representado pelo símbolo $\triangle E$ : o primeiro estado é quando os spins apresentam o seu momento magnético paralelo ao campo aplicado, que corresponde a um estado de maior energia. O segundo estado é quando os spins mostram o seu momento magnético antiparalelo ao campo aplicado o qual corresponde a um estado de menor energia (Figura 3.4.2)[4]. A equação que representa os dois níveis de energia é

\footnotetext{
${ }^{1} \mathrm{O}$ momento magnético dipolar é gerado a partir da rotação dos prótons de carga positiva.
} 


$$
\triangle E=\gamma \cdot B_{0}
$$

sendo $\gamma$ a razão giromagnética, e $B_{0}$ o campo magnético aplicado externamente.

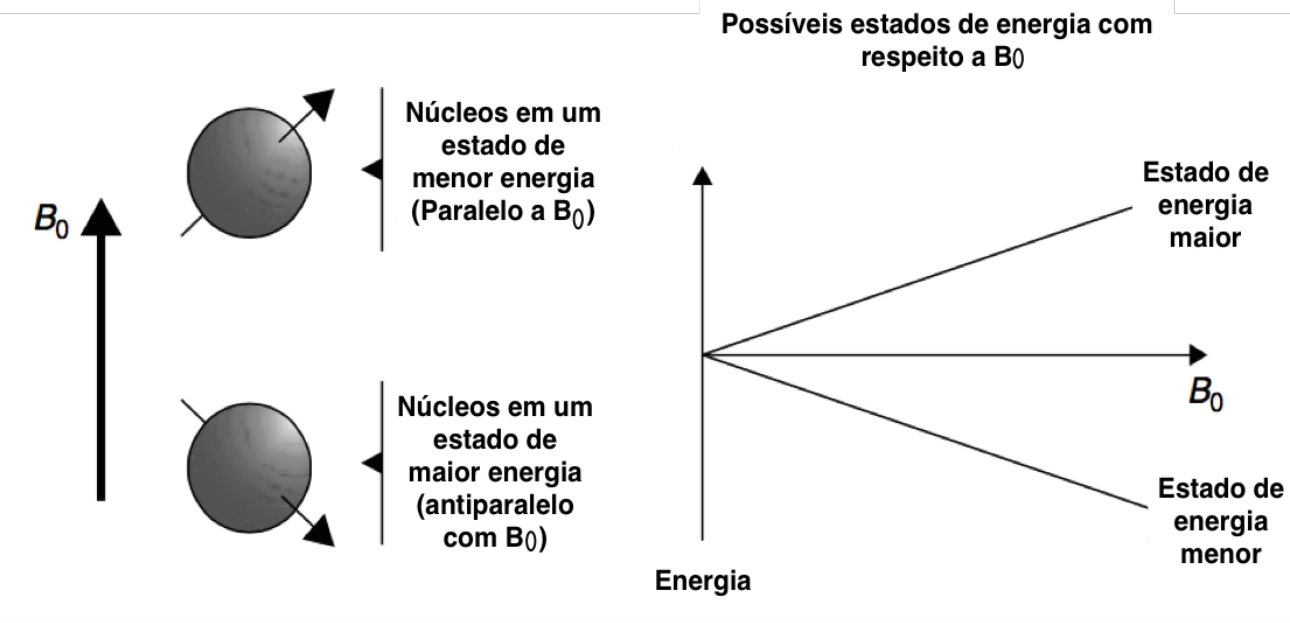

Figura 3.4.2: Na parte esquerda da imagem temos os possíveis estados onde pode existir o próton: estado de menor energia com tendência a seguir a direção do $B_{0}$ e um estado de maior energia que tende a estar em contra do campo $B_{0}$. O lado direito, mostra que a diferença de energia entre os dois estados aumenta à medida que a força do campo $B_{0}$ aumenta [2]. Figura retirada e modificada do Tofts, 2003 .

No sistema macroscópico em equilíbrio as distribuições de spins paralelos $\left(N_{\text {Paralelo }}\right)$ e antiparalelos $N_{\text {antiparalelo }}$ são regidos pela estatística de Boltzmann:

$$
\frac{N_{\text {Paralelo }}}{N_{\text {Antiparalelo }}}=e^{\frac{\triangle \mathrm{E}}{k T}},
$$

com $\triangle \mathrm{E}$ sendo os dois níveis de energia mostrados acima na equação $(3.4 .1), k$ como a constante de Boltzamann cujo valor é $1,38064852(79) \times 10^{-23} \mathrm{~J} / \mathrm{K}$ e T a temperatura.

Em presencia de um campo magnético externo $B_{0}$, o momento magnético associado à rotação dos prótons, se acopla com $B_{0}$, pelo que os spins dos prótons começam a expe- 
rimentar um torque. Aquele torque faz que o spin faça um movimento de precessão ao redor do campo externo com uma frequência característica conhecida como a freqüência de Larmor dado por (3.4.3) (Figura 3.4.3).

$$
f_{R F}=\frac{\gamma}{2 \pi} B_{0}
$$

onde $\gamma$ é a razão giromagnética, cujo valor é especifico dependendo do tipo de núcleo (para os prótons de hidrogênio $\gamma=267.54 \mathrm{~s}^{-1} T^{-1}$ ) e $B_{0}$ o campo magnético no núcleo.

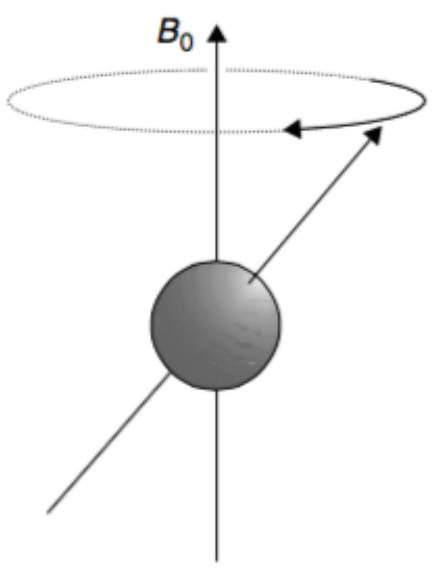

Figura 3.4.3: Movimento de precessão do próton na direção do campo magnético externo $B_{0}$. Figura retirada do Tofts, 2003 [2].

Nesse contexto, em um sistema de prótons de hidrogênio que estão sendo submetidos a um campo magnético externo $B_{0}$ pode ser dada uma magnetização nuclear. Se é aplicado um pulso RF com valor próximo à freqüência de Larmor (3.4.3), acontece uma excitação dos prótons mudando do estado menor de energia a estado de maior energia, esta excitação provoca uma mudança na direção do vetor magnetização, pela mudança no ângulo em que o vector magnetização precessiona na direção do campo magnético aplicado [4]. O ângulo sobre o qual é mudado os spins dependem do tempo de duração e da intensidade do pulso de radiofrequência. Uma vez feita a excitação o movimento de precessão resulta em uma onda eletromagnética que induz uma corrente nas bobinas receptoras para produzir o sinal de IRM.

Após da perturbação, o sistema se relaxa voltando a seu estado de equilíbrio, liberando a energia que foi colocada nele. A recuperação da magnetização longitudinal $\mathrm{M}_{z}$ é ex- 
ponencial e a forma como esta se recupera é descrita por meio da constante T1, que é chamada tempo de relaxação longitudinal ou spin-rede. Essa recuperação é causada principalmente pelos campos magnéticos flutuantes; principalmente derivados dos movimentos dos núcleos e elétrons vizinhos ao redor dos momentos magnéticos. A equação que descreve este tipo de processo é

$$
\mathrm{M}_{z}=\mathrm{M}_{0}\left(1-e^{-\frac{t}{T 1}}\right)
$$

onde $\mathrm{M}_{0}$ é a magnetização inicial do campo magnético estático, T1 tempo de relaxação. T1 governa a taxa de restabelecimento da magnetização longitudinal $\left(\mathrm{M}_{z}\right)$, após um tempo T1, $63 \%$ da magnetização $\mathrm{M}_{0}$ é restabelecida.

Se um pulso de RF com exatamente o mesmo valor da freqüência de Larmor (3.4.3) fosse aplicado no plano x,y iniciaria uma rotação dos spins em torno da direção z, mas com o passar do tempo os spins começam a defasar-se e alguns deles voltam a sua posição inicial. Aquele desfasamento acontece pelas inomogeneidades do campo, o que faz que cada pacote de spins gire com diferente freqüência de Larmor. A constante de tempo que descreve o movimento de restauração dos spins a seu estado inicial de equilíbrio da magnetização transversa, $\mathrm{M}_{x, y}$, é chamada tempo de relaxação transversal T2 ou Spin-Spin e está dada por:

$$
\mathrm{M}_{x y}=\mathrm{M}_{x y_{0}} e^{-\frac{t}{T 2}}
$$

onde $\mathrm{M}_{x y_{0}}$ é a magnetização inicial transversal.

Dois fatores contribuem no decaimento da magnetização transversal, as interações moleculares, e as variações no campo magnético $B_{0}$. A combinação destes dois efeitos é chamada como tempo de relaxação $\mathrm{T} 2 *$ que envolve o T2 intrínseco mais todas as inomogeneidades do campo. É representada através da equação:

$$
\frac{1}{T 2^{*}}=\frac{1}{T 2}+\frac{1}{T 2_{\text {inomogeneidades }}} .
$$

A geração de imagem em ressonância magnética depende de vários componentes, a primeira delas é a densidade dos prótons e a segunda, são os tempos de relaxação T1 e T2. A principal diferencia entre T1 e T2 é a capacidade de ponderar o contraste dependendo da estrutura envolvida. Como por exemplo, quando a imagem é ponderada para T1, o valor do pixel ou do sinal vai depender somente de T1, isso porque a intensidade do 
sinal em T1 é predominante com respeito ao resto. No caso de uma imagem ponderada para T2, o valor do pixel depende em certa parte da densidade dos prótons e do valor de T1 mas, normalmente o sinal predominante nesta seqüência é T2.

Em dosimetria gel polimérica é possível utilizar qualquer dos dois tempos de relaxação apresentados acima, pois as mudanças devidas à polimerização induzida pela radiação podem ser detectadas tanto por T1 como por T2. Não obstante, a técnica que tem sido implementada durante os últimos anos é a constante de relaxação spin-spin T2, pois T1 envolve troca de energia e como interações físicas que envolvem troca deste tipo precisam de mais tempo de relaxação, e a aquisição das imagens torna-se mais demorada. Múltiplas características fazem que T2 seja uma melhor alternativa de uso, varias delas são: sensibilidade e a faixa dinâmica da Taxa de relaxação R2, que é correlacionado com a dose absorvida. Além disso, apresenta outras características como eficiência e exatidão nas medições.

\subsubsection{Como determinar T2}

O valor de T2 é determinado a partir de duas seqüências: seqüência spin-eco (SSE) ou multi spin-eco, a primeira utiliza mais tempo de aquisição entre uma imagem e outra, enquanto que, com seqüência multi spin-eco múltiplas imagens são adquiridas com vários ecos. Uma descrição mais formal é feita a seguir.

\section{- Seqüência spin-eco (SSE)}

A seqüência spin-eco (SSE) foi desenvolvida por Erwin Hahn em 1950, e ajuda a melhorar os tempos de obtenção das imagens. Inicialmente, nesta seqüência é aplicado um pulso de excitação de $90^{\circ}$ que gira o vetor magnetização $\mathrm{M}_{z}$, após um pequeno tempo $(\tau)$ um pulso de $180^{\circ}$ é enviado e coloca novamente em fase ao vetor magnetização. Os spins se encontram de novo juntos, devido às suas diferentes frequências de precessão fornecendo uma magnetização transversa que produz um sinal nas bobinas de detecção. O tempo transcorrido entre o pulso de $90^{\circ}$ e a metade do eco, quando a sinal é máximo é conhecido como tempo de eco (TE), relacionada com T2, e o tempo que transcorre entre um pulso e outro é denominado como tempo de repetição (TR) [1]. Na figura a seguir são mostrados os diferentes pulsos de radiofrequência e do sinal detectado em cada etapa da seqüência de spin-eco. 


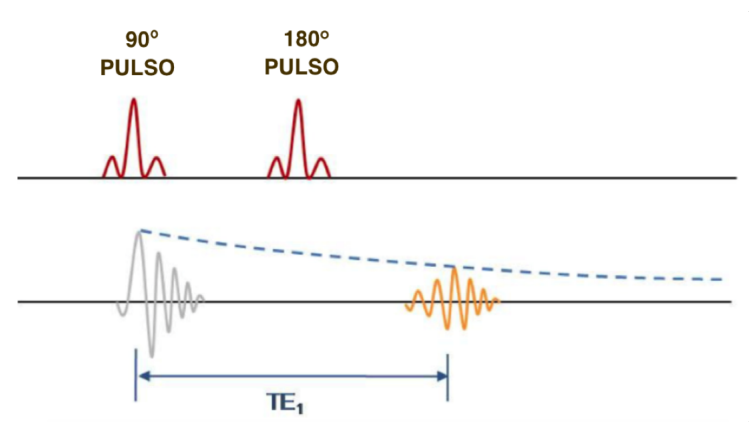

(a)
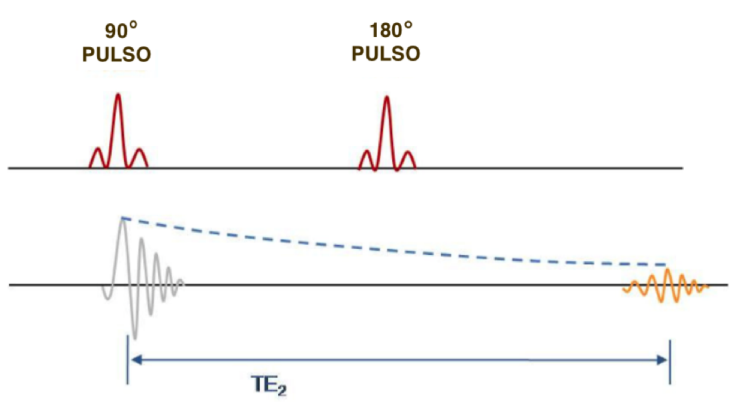

(b)

Figura 3.4.4: Esquema da seqüência spin-eco repetida duas vezes com dois tempos de eco diferentes produz informação suficiente para fazer a reconstrução de um mapa de R2. a) Tempo entre o primeiro pulso curto com respeito ao pulso de $180^{\circ}$. b) Tempo entre o primeiro pulso longo com respeito ao pulso de $180^{\circ}$. Figura retirada do De Deene, 2008 [3].

$\mathrm{O}$ valor de R2 em cada pixel no mapa de R2 pode ser determinado a partir das intensidades de cada pixel das imagens ponderadas obtidas em T2. O sinal de eco (SSE) obtida em uma seqüência spin eco é modelado pelas equações a seguir.

- No caso da figura (3.4.4a) com um primeiro tempo de eco adquirido, a equação que modela este comportamento é :

$$
S\left(T E_{1}\right)=S_{0} \cdot e^{-R 2 \cdot T E_{1}},
$$

com $S_{0}$ é o sinal que deveria ser adquirido a partir da magnetização longitudinal em equilíbrio $\left(\mathrm{M}_{0}\right), T E_{1}$ o tempo de eco e $S\left(T E_{1}\right)$ como a intensidade do pixel da primeira seqüência spin-eco (SSE).

- Agora para o segundo tempo de eco da figura (3.4.4b) a equação que modela o sinal é: 


$$
S\left(T E_{2}\right)=S_{0} \cdot e^{-R 2 \cdot T E_{2}}
$$

com $T E_{2}$ tempo de eco e $S\left(T E_{2}\right)$ é o sinal medido no tempo $T E_{2}$ da segunda seqüência spin-eco (SSE).

Com as duas equações descritas anteriormente (3.4.7), (3.4.8) é possível determinar uma nova equação que permita descrever a taxa de relaxação R2 para duas imagens obtidas a partir de diferentes tempos eco, como se mostra a seguir

$$
\begin{aligned}
\frac{S\left(T E_{1}\right)}{S\left(T E_{2}\right)} & =e^{-R 2\left(T E_{1}-T E_{2}\right)} \\
\operatorname{Ln} \frac{S\left(T E_{1}\right)}{S\left(T E_{2}\right)} & =\operatorname{Ln} e^{-R 2\left(T E_{1}-T E_{2}\right)} \\
R 2\left(T E_{2}-T E_{1}\right) & =\operatorname{Ln} \frac{S\left(T E_{1}\right)}{S\left(T E_{2}\right)} \\
R 2 & =\frac{1}{\left(T E_{2}-T E_{1}\right)} \operatorname{Ln} \frac{S\left(T E_{1}\right)}{S\left(T E_{2}\right)} .
\end{aligned}
$$

A principal vantagem da seqüência de spin-eco (SSE) é que basicamente todos os scanners tem disponível o seu uso, o que facilita a obtenção das taxas de relaxação R2.

Suas desvantagens são: deslocamento de qualquer imagem com respeito à outra dando lugar a um erro no cálculo do mapa de R2, outra é respeito ao tempo de aquisição das imagens pois nesta seqüência existe uma grande quantidade de tempo morto (tempo que é primordial para que ocorra a recuperação de T1 e a relaxação de T2) que não esta sendo utilizado durante a aquisição da sinal. Com tempos de medições longos é suficiente para se obter ruído no sinal e consequentemente gerar erros nos mapas de dose, ou em outras palavras uma precisão intrínseca baixa.

Não obstante, é possível aplicar vários pulsos de $180^{\circ}$ para obter múltiplos ecos, a seqüência que faz uso disto é chamada multi spin-eco (MSE). A seguir é feita a descrição.

\section{- Seqüência multi spin-eco (MSE)}

A seqüência multi spin-eco é baseada na seqüência spin-eco convencional, adquirindo mais de dois ecos durante cada pulso de excitação emitido. A principal característica dessa seqüência é a possibilidade de aquisição de várias imagens da mesma região anatômica obtidas com diferentes ecos depois de cada pulso, permitindo preencher os espaços vazios com distintas ponderações fazendo uma melhor reconstrução da imagem em um 
tempo menor. O equipamento de ressonância magnética utilizado normalmente produz entre 4 e 32 ecos, e são denominados como Echo Train.

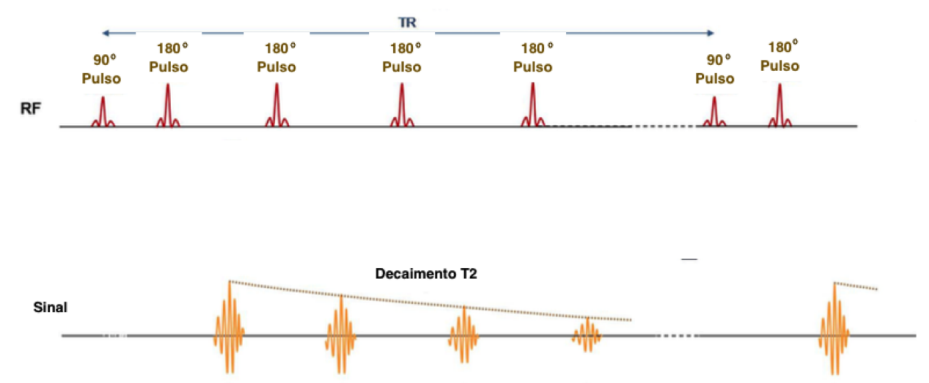

Figura 3.4.5: Esquema da seqüência multi spin-eco. A primeira imagem mostra uma seqüência multi spin-eco produzindo vários ecos durante um mesmo tempo de repetição. Todos os ecos obtidos durante o mesmo tempo de repetição tem a mesma codificação de fase. Na segunda imagem se observa o decaimento do sinal detectado com o tempo, por meio da seqüência multi spin-eco. Também se pode observar o decaimento da amplitude do sinal ao longo dos ecos regida pelo tempo de relaxação T2. Figura retirada do De Deene, 2008 [3].

Na dosimetria gel polimérica, particularmente a seqüência mais utilizada nos tratamento de radioterapia é a multi spin-eco. Pois, o poder de aquisição de múltiplos ecos durante um mesmo tempo de repetição ajuda a reduzir a indução da sinal-ruído comparado com a seqüência spin-eco (SSE) [17].

\subsubsection{Possíveis erros na realização das seqüências de imagem}

O principal objetivo da dosimetria gel polimérica para radioterapia de alta precisão é verificar as variações ao redor de 2-3\% da dose máxima nas regiões de dose homogênea e na parte do erro espacial de $2 \mathrm{~mm}$ nas regiões com heterogeneidades como já foi citado. Não obstante, limitações técnicas relacionadas com a precisão da distribuição de dose determinada por IRM leva a variações da temperatura durante a digitalização. Imagens de artefatos gerados em um scanner de RM podem causar erros no mapeamento da dose e são classificados como falta de exatidão na dose ou como deformações dos mapas de dose. Portanto, foi necessário encontrar diferentes estratégias de compensação. De Deene et al., demostram que a precisão espacial na distribuição de dose é afetada por distorções geométricas causado por problemas de inomogeneidades no campo magnético e pelas inomogeneidades do gradiente do campo magnético [37]. As complicações citadas 
anteriormente usando rotinas com IRM e dosimetria gel polimérica fazem que a inserção delas seja dificultosa.

\subsubsection{Falta de uniformidade nas imagens}

As imagens obtidas por ressonância magnética podem apresentar problemas de inomogeneidade de campo, mostradas em áreas de intensidade do sinal não uniforme. No caso de dosimetria gel, resultados de não uniformidade são devidas a uma sobre ou sub-dosagem.

Para imagens T1, usando dosimetria gel fricke foram encontradas diversas não nuniformidades quando é aplicado uma seqüência de spin-eco com múltiplos tempos de repetição (TR). Como durante a obtenção das imagens de T1 são aplicados pulsos de radiofrequência erros de uniformidades podem ser atribuídos ao campo não uniforme $B_{1}$, assim como também às diferenças inerentes na relaxação de T1 para os diferentes tempos de relaxação. Para imagens T2, usando dosimetria gel polimérica com seqüência multi spin-eco e bobina de cabeça, foi encontrado nos mapas de R2 uma uniformidade de aproximadamente $120 \mathrm{~cm}$ de área no centro das bobinas, mas diminuiu consideravelmente perto das bordas da bobina [3]. Quando é utilizada uma bobina de corpo as uniformidades diminuem o que resulta em mais uniformidade para o mapa de R2, por outro lado, é gerada uma perda da sinal-ruído (Figura 3.4.6 ).

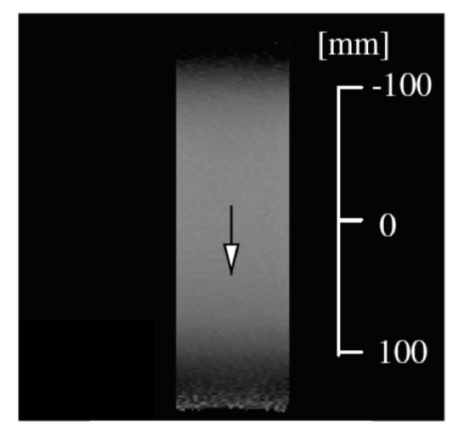

(a)

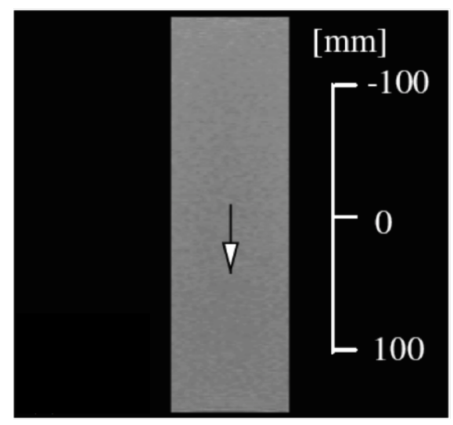

(b)

Figura 3.4.6: Imagens de IRM para uma bobina de cabeça (a) e uma bobina de corpo (b) de um objeto simulador cilíndrico e homogêneo preenchido em gel. Figura retirada de Pavoni, 2009 [4].

Existem muitas fontes que podem proporcionar diferentes não uniformidades nas imagens obtidas com seqüência spin-eco. Algumas dessas são: inomogeneidades do campo 
$B_{1}$, heterogeneidade do campo estático entre outras, mas a maioria delas têm um efeito proporcional à intensidade da imagem e consequentemente são cancelados no ajuste quantitativo de R1 ou R2. Não obstante, alguns desses artefatos não desaparecem completamente das imagens por causa da interferência de outras seqüências, sendo a inomogeneidade do campo $B_{1}$ um destes artefatos. De tal maneira que, em um escâner de RM clínico as fontes de não uniformidade nas imagens T1 e T2 são originadas pelas inomogeneidades do campo $B_{1}$.

Testes quantitativos de T1 mostraram que devido à inomogeneidade do campo $B_{1}$ é produzida uma excitação incompleta em diversas partes do objeto simulador fazendo que a restauração da componente longitudinal da magnetização seja diferente para vários tempos de repetição. Para resolver o problema de excitação incompleta, quando a uniformidade em imagens T1 excede 2-3\% nas sequiências spin-eco é conveniente usa seqüências de inversão recuperação de spin [38].

No caso de T2 a não uniformidade é causada pelas inomogeneidade do campo $B_{1}$ e em combinação com os ecos estimulados. Por conseguinte, o ângulo de inclinação dos momentos magnéticos nucleares depois da emissão de um pulso de reorientação não é igual em todo o volume do objeto simulador. Portanto, a historia da magnetização do spin durante uma seqüência de tipo multi spin-eco vai depender da posição dos momentos nucleares nos cortes fazendo que o desvio dos valores de $\mathrm{R} 2$ dependam também da posição [3].

Outra fonte de não uniformidade pode ser devido ao aumento não homogêneo da temperatura do objeto simulador durante o processo de aquisição das imagens. Por causa da absorção de potência das ondas de RF acontece um aumento de $1-3^{\circ}$ da temperatura, e além disso, o objeto simulador está em continuo contato com o ar da sala de simulação durante o processo de obtenção das imagens o que gera um aumento de temperatura não uniforme. De maneira que, erros entre 3 a $10 \%$ relativos à dose máxima são esperados.

É de grande importância um controle das não uniformidades nas imagens pois, elas podem levar a erros graves na dose que podem estar sujeitos a acontecer em distribuição de dose 3D. É também importante desenvolver várias estratégias de compensação para manter o nível de incerteza aceitável com respeito à falta de uniformidade. 


\subsubsection{Distorções nas imagens}

A distorção da forma geométrica do objeto simulador aparece como uma deformação nos mapas de dose. Aquelas deformações podem ser de toda a imagem ou pode ser somente em algumas partes dela, aparecem especialmente quando se tem inclusões de outros materiais do objeto simulador tais como: cavidades de ar ou objetos com baixa densidade. Os tomógrafos com campo magnético baixo podem ser mais propensos a sofrer problemas de distorção da imagem que os de magnetos criogênicos.

A codificação espacial da sinal de ressonância magnética é baseada na correlação entre a intensidade de campo magnético e da frequência dos pulsos de radiofrequência determinada pela frequência de Larmor (3.4.3). Quando é alterado o gradiente de campo magnético nas três direções ortogonais durante a seqüência de aquisição da sinal, é obtida uma codificação nas três direções. As distorções das imagens aparecem devido a que o gradiente de campo magnético produzido pelas bobinas de gradiente pode se desviar de sua linearidade. Além disso, como o campo magnético principal $B_{0}$ não é completamente homogêneo produz uma deformação na imagem criada. Outros erros similares acontecem durante a codificação de fase e no momento da seleção do corte.

Outro tipo de distorção de imagem pode ocorrer quando materiais com diferentes densidades eletrônicas são inseridos no objeto simulador como por exemplo, os objetos simuladores que incluem cavidades de ar no caso de um estudo de perda de equilíbrio. No geral esses materiais tem uma suscetibilidade magnética diferente o que resulta em uma suscetibilidade relacionada com a distorção nas imagens iniciais e nas imagens finais. A distorção é inversamente proporcional à largura da banda do receptor . Por outro lado, a inclusão de materiais com diferentes compostos químicos como líquidos orgânicos e gorduras no gel podem causar um desvio químico desses objetos na direção de codificação da frequência.

Na figura (3.4.7) é mostrado um exemplo de susceptibilidade relacionado com artefatos. A imagem mostra como dois objetos são colocados ao mesmo tempo em um escâner de ressonância magnética cujo campo magnético e direção de codificação da frequência são localizados acima da imagem, pode ser visto claramente como existe uma distorção das interfaces entre os dois objetos simuladores. De modo que, quando os objetos simuladores são localizados perpendicularmente ao campo magnético os artefatos desaparecem $[4]$. 


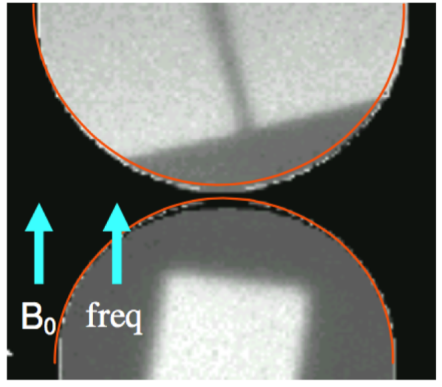

(a)

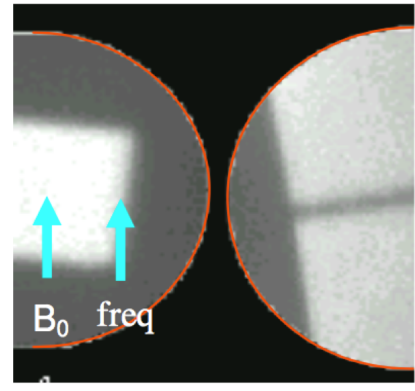

(b)

Figura 3.4.7: Dois objetos simuladores escaneados em diferentes direções ilustram deformações relacionadas com a susceptibilidade na interface entre os dois recipientes. As linhas sobre as imagens foram feitas para mostrar a posição real das superfícies dos objetos simuladores. Figura retirada da referencia De Deene, 2008 [3].

\section{- Estratégias de compensação}

Uma das estratégias de compensação mais usuais para determinar algum tipo de deformação nas imagens ou deslocamentos nos cortes escolhidos é colocar marcas fiduciárias ao redor ou sobre o objeto simulador. Portanto, no momento de fazer a sobreposição das imagens do planejamento com as de qualquer outra técnica dosimétrica as irregularidades imersas são visíveis, detectando erros de escala nas imagens do objeto simulador.

No caso das distorções causadas pelo tomógrafo, um controle de qualidade muito rigoroso utilizando um objeto simulador deve ser feito. Com a obtenção de um mapa de distorção uma matriz de correção nos mapas de dose pode ser usada, assim como é feito na neurocirurgia estereotáxica guiada pela RM.

\subsubsection{Erros na dose}

Os erros na dose não podem ser vistos simplesmente com uma inspeção direta da imagem ou nos mapas de dose, mas sim por meio de comparação, ou seja, é necessário utilizar os valores medidos da dose com respeito aos valores de dose medidos com outro tipo de técnica dosimétrica. É possível que em algumas seqüências, como as seqüências de Multi spin-eco, a curva de dose resposta dependa da orientação de aquisição das imagens e de outros parâmetros tais como o campo de visão (FOV- Field of View). O problema aumenta quando são usados equipamentos que contenham elevados gradientes, assim 
como também, no uso de tempos de eco curtos. Os valores da taxa de relaxação R2 dependem da temperatura e portanto, se os géis não são submetidos a uma regulação de sua temperatura, o seja, se eles não entram em equilibrou térmico com a sala antes de ser passados pelo tomógrafo de RM para a aquisição das imagens de ressonância magnética, erros na dose aparecem. Outros erros podem acontecer quando a aquisição das IRM dos tubos de calibração são realizadas em diferentes circunstâncias e com diferentes parâmetros de imagem.

Efeitos de volume parcial mostram que podem levar muitas discrepâncias na dose em pixels adjacentes a uma fonte pontual como acontece em um experimento de braquiterapia. Um cuidado especial deve ser mantido em conta na excitação das imagens de múltiplos cortes, assim como também, com a excitação alternada das fatias que podem levar a uma interferência cruzada entre as imagens e portanto, um problema com a dose pode aparecer.

\subsubsection{Tomografia ótica computadorizada}

Quando um dosímetro gel polimérico é submetido a irradiação suas propriedades óticas mudam e é possível implementar técnicas de leitura que consigam ler a dose absorvida dentro de tais dosímetros, portanto, o uso de métodos óticos e correlação com a densidade ótica faz com que seja possível medir a dose com essa abordagem. Utilizando um sistema de tomografia ótica computadorizada se pode reconstruir a imagem da distribuição de dose dentro do dosímetro [39, 40, 41, 42]. O TCO funciona da seguinte maneira, um feixe de laser HeNe $(634 \mathrm{~nm})$ atravessa os diferentes ângulos que cercam o dosímetro e com ajuda de alguns espelhos os dados da projeção são capturados por um fotodiodo. A obtenção das imagens para diferentes fatias são determinadas pela movimentação vertical do objeto simulador e pela aquisição das projeções. Para a obtenção dos mapas 2D os coeficientes de atenuação óticos são obtidos por meio de algoritmos de reconstrução semelhantes aos da TC.

Uma das principais vantagens em um sistema TCO para leitura dos dosímetros gel é o baixo ruído que apresenta pois, se fosse comparado com imagens IRM a relação de sinalruído é superior neste caso. Além disso, o sistema TCO é um equipamento de baixo custo e com a capacidade de produzir mapas de dose 3D com uma boa resolução espacial, exatidão e precisão, corrigindo assim os problemas de espalhamento da luz. Oldman et al., em 2001 fizeram uma investigação sobre o uso de TCO para dosimetria gel 
polimérica, verificando planejamentos de tratamentos complexos como em radiocirurgia e IMRT [41]. Encontrando-se mapas de dose em 3D em menos de uma hora com resolução espacial submilimétrica, com parâmetros de exatidão de $3 \%$ e uma precisão de não menos de $1 \%$.

Não obstante, existem significativas limitações no uso de um TCO, devido a que uma diminuição do sinal pode acontecer ao redor do dosímetro causadas pela reflexão e refração do laser do escâner. Também, a profundidades muito maiores no recipiente do gel podem provocar problemas de atenuação da luz reduzindo fortemente a obtenção de informação necessária para uma boa leitura. Adicionalmente, a densidade ótica do objeto simulador não deve exceder um máximo pois deve estar dentro de uma faixa dinâmica do sistema de detecção de luz e seu correspondente SNR [30].

\subsubsection{Tomografia computadorizada com raios $\mathrm{x}$}

Diferentes estudos acerca do uso da tomografia computadorizada de raios x para avaliação da dosimetria gel polimérica já foram publicadas. As mudanças nos dosímetros gel poliméricos causados pela radiação induzida são responsáveis pelas mudanças de densidade, além disso, também são afetados os coeficientes de atenuação linear dos raios x. Estudos demostraram uma correlação entre as unidades Hounsfield (HU) nos equipamentos de raio x com a dose absorvida, essas mesmas investigações mostram que existe algum tipo de relacionamento entre o coeficiente de atenuação linear de raios x com a dose absorvida induzindo mudanças dentro dos dosímetros.

Uma das principais vantagem do uso deste tomógrafo com respeito a um IRM é basicamente sua economia e acessibilidade, sendo de muita utilidade para as pessoas do serviço de radioterapia pois o equipamento é fundamental na hora de fazer o planejamento do tratamento tridimensional. Em 2002 Audet et al., realizaram testes usando um tomógrafo computadorizado com raios x com o fim de avaliar distribuições de dose complexas em géis poliméricos, para isso, a entrega da dose foi planejada como em um tratamento estereotáxico usando dosímetros gel poliméricos. Os resultados mostraram que os dosímetros de tipo polimérico poderiam ser necessários para delimitar as regiões irradiadas dentro de um volume de gel não irradiado produzindo bons resultados, pois os valores da distribuição de dose medida eram iguais à dose planejada [43].

Recentemente, novas investigações foram focalizadas na utilização de géis normóxidos usando como método de leitura TC de raios x. Em 2004 Brindha et al., investigou 
o coeficiente linear para dosímetros gel poliméricos normóxidos, particularmente foi uma investigação baseada no uso de géis PAGAT e MAGAT encontrando-se que a dose resposta no TC foi linear até 15 Gy para o PAGAT e para o MAGAT até 10 Gy. Portanto, se conclui que os dois dosímetros são aptos para fazer dosimetria gel. Por outro lado e continuando com o estudo dos géis normóxidos, Hilt et al., fizeram trabalhos com respeito à dose resposta do gel Magic usando TC de raios x com doses de até 150 Gy. Em resumo, a dosimetria gel polimérica normóxida combinada com TC de raios x para controle de qualidade é valida, mostrando que pode ser incluída nas rotinas clinicas.

Não obstante, se é bem sabido que uma técnica como a TC de raios x é uma boa forma de leitura dos dosímetros géis poliméricos normóxidos, também é necessário estar à par das limitações que a técnica possui. A primeira restrição é : pouco sensível à dose e à relação contraste-ruído (CNR) pois é baixa comparada com a relação sinal-ruído em IRM. A CNR pode ser corrigida com uma média de múltiplos imagens, mas fazer isso leva a um aumento no tempo de leitura e sobrecarga do tubo. Por outra parte, também aumenta o valor do trabalho associado à dosimetria gel de imagem. Uma segunda limitação é a região de resposta linear da TC de raios x pois essa é relativamente menor quando comparado com a IRM, sendo linear até 10 Gy.

\subsubsection{Ultrassom}

É uma técnica utilizada para determinar as estruturas dos materiais. Os parâmetros ultrassônicos mais utilizados são: atenuação ultrassônica, velocidade ultrassônica de propagação e impedância ultrassônica [44]. O ultrassom tem a capacidade de estudar as estruturas poliméricas [44, 45] e de determinar as mudanças que ocorrem durante a irradiação. Maryanski et al., em 1999 foram os primeiros em sugerir o uso de ultrassom como método de medição para os dosímetros gel poliméricos.

Avaliações da técnica foram feitas por Mather et al., velocidade de propagação, atenuação e a intensidade transmitida do ultrassom foram medidas em função da dose, mostrando uma grande variação na dose absorvida de até 15 Gy. Para os controles de qualidade usando ultrassom os dosímetros expostos foram do tipo PAG e géis poliméricos normóxidos MAGIC. Os resultados obtidos não são nada alentadores, já que na correlação da velocidade de ultrassom para o dosímetro PAG aumenta com o aumento da dose absorvida enquanto que para o MAGIC a velocidade ultrassônica diminui. Isso 
ocorre devido às diferenças na dependência das propriedades elásticas do gel com a dose em frequências ultrassônicas. A partir desta investigação foi possível construir um protótipo de um sistema de ultrassom capaz de visualizar a distribuição de dose dos dosímetros gel poliméricos.

Pode-se concluir que, o uso do ultrassom como técnica de leitura da dose em dosímetros gel poliméricos está em desenvolvimento, portanto, estudos básicos e testes de reprodutibilidade para determinar todo tipo de inconsistências encontradas nos valores absolutos da velocidade ultrassônica e de atenuação nos dosímetros devem ser feitos [46]. 


\section{Capítulo 4}

\section{Dosimetria Termoluminescente}

Neste capítulo, descreve-se o modelo simples da termoluminescência com a finalidade de entender o processo de emissão luminosa que ocorre no aquecimento de certos materiais previamente expostos à radiação. Assim como também são descritas algumas características essenciais dos dosímetros termoluminescentes e sua aplicação na física médica.

\subsection{Introdução}

Durante muito tempo o principal interesse da física médica na área das radiações ionizantes é poder determinar a quantidade de energia absorvida por um material, aquela energia é conhecida como dose. Essa dose pode ser determinada por meio da dosimetria por termoluminescência. Em principio, no ano 1663 Robert Boyle foi o primeiro em reportar o fenômeno de termoluminescência, encontrado em um pedaço de diamante natural. Anos mais tarde, em 1953 Daniels desenvolveu as bases físicas do fenômeno ocorrido na TL, e forneceu os aspectos fundamentais na aplicação do fenômeno cujos objetivos principais são a detecção e a dosimetria.

Os dosímetros termoluminescentes são amplamente utilizados na radioterapia para medir a dose absorvida em pacientes que estão sendo submetidos a tratamentos radioterapêuticos. Aquela informação que é obtida por meio desses dosímetros é importante já que pode ser usada como um controle de qualidade do tratamento, assegurando uma maior eficiência no controle da doença.

As principais vantagens do TLD são: 
- Tamanho pequeno dos detectores.

- Ampla faixa de resposta de doses (10 uGy-100 kGy).

- Número atômico equivalente ao tecido humano na maioria dos detectores.

- Reutilizáveis com pequenas variações.

- Resposta independente da distribuição angular da radiação.

Não obstante, a maior desvantagem dos TLD é a demora na leitura bem com a perda do sinal após o processo de leitura.

\subsection{Fundamentos teóricos}

O fenômeno de termoluminescência é a propriedade que tem alguns materiais de converter energia de radiação a uma radiação de diferente comprimento de onda, geralmente no espectro visível. Esse fenômeno é classificado como fosforescência e é baseado na emissão de luz de um material semicondutor ou isolante, que inicialmente foi exposto à radiação ionizante ou não ionizante e que após isso é submetido ou estimulado com energia térmica, não se deve confundir com o fenômeno de fluorescência pois, neste a emissão de luz se dá quase imediatamente ou durante a exposição dos materiais à radiação.

A termoluminescência é explicada através do modelo de bandas para os níveis de energia dos elétrons nos sólidos [47]. Em geral, os materiais termoluminescentes são, cristais iônicos nos quais a banda de valência se contra repleta de elétrons e a banda de condução esta vazia, se encontram separadas por uma faixa larga de estados energéticos proibidos aos elétrons, conhecidos como a banda proibida ou estado metaestável denominados como armadilhas.

Quando os materiais termoluminescentes são expostos à radiação ionizante, essa radiação incidente transfere a energia aos elétrons fazendo que eles mudem da banda de valência à banda de condução. Durante o processo de mudança de banda é possível que os elétrons sejam capturados em estados metaestáveis de energia devido às impurezas no cristal, permanecendo nesse durante um tempo, pois quando a energia térmica é 
transferida para o cristal os elétrons do estado metaestável voltam à banda de condução novamente, e depois decaem para o estado fundamental emitindo luz, fenômeno conhecido como fosforescência (Figura 4.2.1).
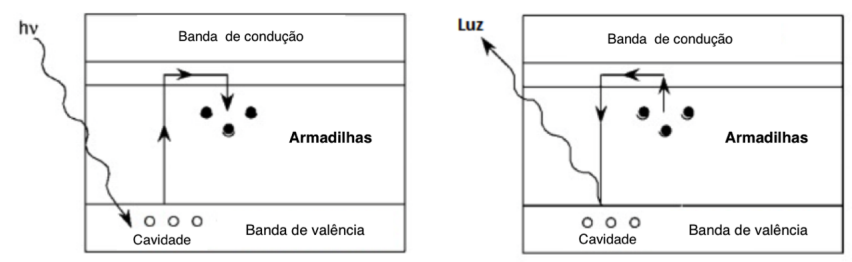

Figura 4.2.1: Esquema simplificado do modelo de bandas de energia del proceso de termoluminiscência en una estructura cristalina [5].

Para cada material termoluminescente é possível determinar uma curva de emissão sabendo que a TL é convertida em corrente elétrica por uma válvula fotomultiplicadora, com essa corrente é possível fornecer uma curva da intensidade luminosa em função da temperatura ( Figura 4.2.2). À baixas temperaturas a intensidade luminosa dessa curva é praticamente nula já que os elétrons não tem suficiente energia cinética para sair do poço de potencial e recombinar-se. De modo que, à medida que a temperatura começa a aumentar a probabilidade de liberação desses elétrons é muito muito maior, não obstante, existe um ponto de saturação onde a intensidade luminosa diminui, isso é devido à pouca quantidade de elétrons localizados nas armadilhas.

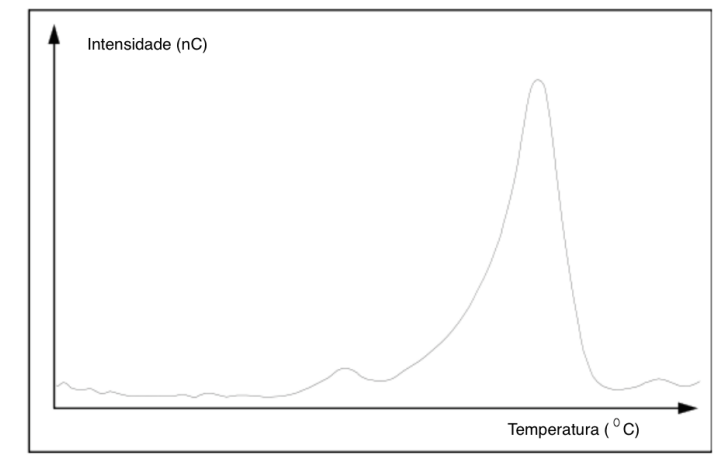

Figura 4.2.2: Curva de brilho: señal lumínica en función de la temperatura de um cristal de TLD [5]. 


\subsection{Materiais termoluminescentes}

Uma quantidade grande de materiais apresentam propriedades termoluminescentes, no entanto, para poder ser considerado um dosímetro, o material TL deve apresentar as seguintes características:

- Resposta linear para uma ampla faixa de doses

- Sensibilidade

- Estabilidade

- Curva de emissão

- Reprodutibilidade

\subsubsection{Linearidade}

A curva de resposta de um dosímetro TL em função da dose é determinada por três regiões: região linear, supralinear e de saturação. Em nosso caso, a região de interesse é a linear pois permite uma maior exatidão nas medidas. A linearidade em materiais como o LiF é até uma dose de 1 Gy, após isso se torna supralinear. Nessa região supralinear a resposta do TL deixa de ser proporcional à dose. Portanto, para resolver o problema uma formula para corrigir a supralinearidade é aplicada:

$$
\mathrm{R}_{\text {supralinear }}=\left(1+0.0278 D-0.000265 D^{2}\right)^{-1} \text {, }
$$

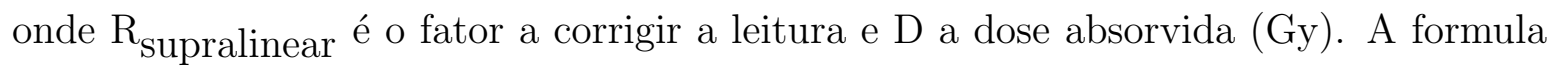
funciona bem até valores de dose de $20 \mathrm{~Gy}$.

Para valores acima de $10^{5}$ Gy a curva de resposta da maioria dos dosímetros TL é saturada. O que possivelmente acontece é uma diminuição do número das armadilhas disponíveis para a captura dos elétrons.

\subsubsection{Sensibilidade}

O termo sensibilidade indica a quantidade de luz emitida por unidade de massa do material termoluminescente e de exposição. 


\subsubsection{Estabilidade}

A uma temperatura T, a probabilidade de liberação de um elétron da armadilha esta dada pela seguinte expressão

$$
\mathrm{P}=\left(s . e^{-\frac{E}{k T}}\right)
$$

onde E é a profundidade da armadilha em energia contada a partir da banda de condução, s como o fator de frequência, k constante de Boltzmann e T a temperatura.

De maneira que, para uma certa temperatura T, P mede a instabilidade da armadilha, isso é, a maior E, maior é a estabilidade pois, menor será a probabilidade do elétron ser liberado.

\subsubsection{Curva de emissão}

A curva de emissão representa a intensidade de luz emitida de um material TL em função da temperatura ou do tempo de aquecimento utilizado. A curva pode apresentar diferentes picos de emissão, dependendo do número de armadilhas presentes nos materiais e suas profundidades. A altura de cada pico depende da dose absorvida ou da exposição, portanto, ela pode ser utilizada para leitura da dose, uma vez seja feita a calibração.

\subsubsection{Reprodutibilidade}

O sinal que é obtido quando são feitas várias medidas em iguais condições deve ser reprodutível, portanto, o material implementado deve cumprir com esse requerimento.

\subsection{Materiais}

Os materiais termoluminescentes mais comuns na dosimetria são : $\mathrm{LiF}, \mathrm{CaSO}_{4}, \mathrm{CaF}_{2}$, $\mathrm{Al}_{2} \mathrm{O}_{3}$, e $\mathrm{Li}_{2} \mathrm{~B}_{4} \mathrm{O}_{7}$. Esses materiais dependem de seu numero atômico efetivo, $Z_{e f}$, pois dependendo dele, o desempenho será melhor em uma área determinada. Por exemplo, os materiais com número atômico efetivo baixo $\left(7<Z_{e f}<9\right)$, tem uma resposta praticamente independente da energia mas com baixa sensibilidade, como $\mathrm{LiF}$ e $\mathrm{L}_{2} B_{4} \mathrm{O}_{7}$. 
No caso de materiais com alto número atômico efetivo $\left(15<Z_{e f}<18\right)$, a resposta é dependente da energia a baixas energias $(E<150 \mathrm{keV})$, como $\mathrm{CaSO}_{4}, \mathrm{CaF}_{2}, \mathrm{Al}_{2} \mathrm{O}_{3}$. Neste trabalho foi utilizado dosímetros compostos de LiF.

\subsubsection{Fluoreto de lítio, LiF: Ti, mg}

O fluoreto de lítio é um halogênio de densidade $2.6 \mathrm{~g} / \mathrm{cm}^{3}$ com número atômico efetivo de 8.2 que comparado com o valor de $7-7.5$ do tecido humano é bastante similar, além disso, não é solúvel em água. As diferentes características que este apresenta fazem que seja usado em aplicações médicas. O LiF: Ti, Mg, é a fusão homogênea de fluoreto de lítio, fluoreto de magnésio, crioleto de lítio e fluoreto de lítio e titânio que dá como resultado uma substancia contendo no máximo 180 ppm de manganésio e 10 ppm de titânio como impurezas ativadoras [48].

\subsection{Equipamento de leitura dos dosimetros TL}

Um equipamento convencional de TLD é formado essencialmente por três partes:

1. O sistema de aquecimento do dosímetro.

2. Uma válvula fotomultiplicadora destinada a transformar a luz emitida em corrente elétrica.

3. Circuito de medida, indicando a dose recebida pelo dosímetro em uma escala graduada.

O cálculo da dose é realizada a partir da luz emitida pelo dosímetro entre dois instantes de tempo, multiplicado pelo fator de calibração que vai depender da energia utilizada na radiação. Os TLDs são aquecidos em uma atmosfera inerte durante o processo de leitura, geralmente de gás nitrogênio. 


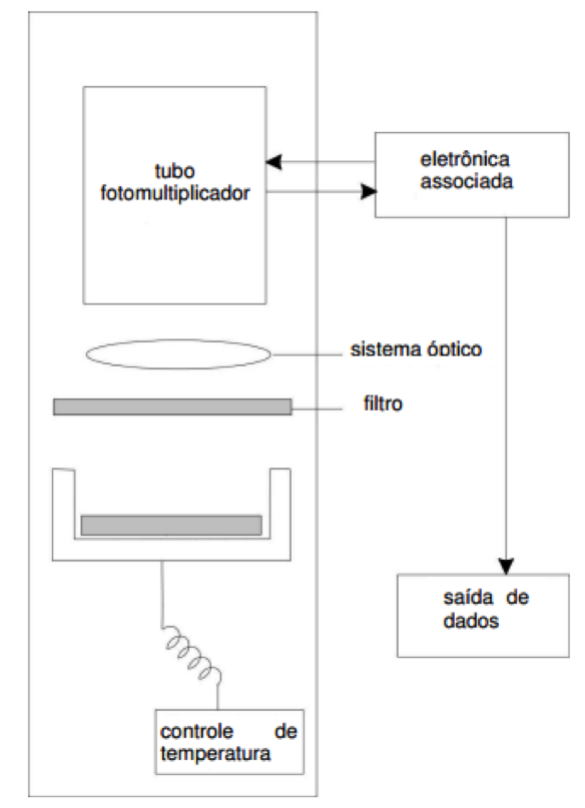

Figura 4.5.1: Diagrama de um equipamento convencional de leitura TL.

Como todo método de medida existem algumas limitações, neste caso, a emissão termoluminescente do material é usualmente complexa e se encontra afetada pela existência de outras contribuições não termoluminescentes como a radiação de fundo e a triboluminescência. Essa última contribuição se refere ao fenômeno ótico que é gerado quando algumas espécies químicas e determinados materiais são submetidos a um processo de trituração, tensão, agitação ou algum tipo de procedimento que leve à quebra de ligações químicas. Além disso, existem outros fatores que limitam o uso desta dosimetria que estão associados com a mesma técnica de medida como é a falta de reprodutibilidade no aquecimento e com os gradientes térmicos. 


\section{Capítulo 5}

\section{Dosimetria por Ressonância Spin-Eletrônico de Alanina}

\subsection{Introdução}

Os métodos tradicionais usados em dosimetria são baseados nos efeitos da radiação em substâncias como por exemplo: ionização em ar (dosimetria de ions), deposição de calor no grafite e metais (calorimetria), descoloração da solução de sulfato ferroso (dosimetria fricke), luminescência em sólidos (dosimetria termolunicente). O método utilizado neste trabalho é feito de componentes orgânicos, particularmente aminoácidos, cuja importância biológica e quantitativa aos efeitos da radiação é a produção de radicais livres.

Os radicais livres em biomoléculas cristalinas são produtos relativamente estáveis de uma seqüência de eventos que, como no tecido, começa pela absorção de energia inicial da radiação. A análise quantitativa desses radicais é utilizada como dosimetria. Não obstante, são muitos os estudos feitos acerca do comportamento dos radicais livres para irradiações de feixes $\gamma$ em substâncias orgânicas cristalinas, dentro desses, os compostos que apresentam melhor resposta são os aminoácidos. Uma possível forma de identificação e determinação da concentração dos radicais livres é realizada por meio da espectroscopia de ressonância de spin eletrônico (ESR), implementada para fótons, nêutrons e feixes de elétrons. 


\subsection{Moléculas orgânicas}

A maioria das moléculas orgânicas contem um número par de elétrons, portanto elas são diamagnéticas e o seu momento magnético resultante é zero. O momento magnético líquido de cada par de elétrons envolvidos na formação da ligação também é zero, sempre e quando as ligações sejam formadas com elétrons de spins opostos. Quando é utilizada a radiação ionizante ligações são interrompidas dando como resultado duas partes paramagnéticas com um elétron desemparelhado cada uma. Essas partes são chamados radicais livres, e como exemplo temos ao átomo de hidrogênio $\mathrm{H}$ pois é o radical mais simples. A estabilidade dos radicais livres dependem do meio ambiente circundante e particularmente da rigidez da matéria. Em soluções ou em materiais orgânicos aquosos o tempo de vida média dos elétrons desemparelhados é muito menor. No entanto, existem também alguns outros materiais como os materiais cristalinos que à temperatura ambiente podem existir por muitos anos. O tipo e quantidade de radicais livres formados pela radiação ionizante geralmente depende da estrutura cristalina e da temperatura [49].

O acoplamento entre um elétron radical e o spin nuclear (principalmente prótons) em um ambiente molecular provoca interações hiperfinas e se a separação hiperfina é anisotrópica, ou seja, se fosse um monocristal a forma do espectro obtido com ESR iria variar de acordo com a orientação do cristal em relação ao campo magnético. Agora, no caso de amostras em pó com cristais orientados aleatoriamente, o espectro ESR é a média sobre todas as direções, o que quer dizer que não depende do campo magnético aplicado.

Por outro lado, os radicais em materiais biológicos geram normalmente resolução baixa do espectro ESR, cujas sinais paramagnéticos eletrônicos são ampliadas por diversas razões por exemplo, a poli-orientação, interação spin-rede e a sobreposição de espectros de diferentes tipos de radicais. De modo que, moléculas orgânicas que apresentam excelentes resultados são os aminoácidos. Elas pertencem a uma sustância biológica

que após a irradiação mostra espectros bem resolvidos. É importante estudá-los pelas seguintes razões:

- Os aminoácidos são componentes de proteínas que podem ser purificados na forma cristalina.

- Monocristais estão prontamente disponíveis. 
A aplicação dos aminoácidos em um método dosimétrico de radicais livres é bastante eficiente e é dependente da magnitude do rendimento radical pela unidade de dose absorvida e do tempo de vida dos radicais. Portanto, um aminoácido que preenche esses critérios é a alanina.

\subsubsection{Alanina}

Alanina é o nome comum para o ácido 2-aminopropanóico. Contém um grupo metila que proporciona um caráter hidrofóbico e de acordo com essa característica é classificado como um aminoácido alifático. Por sua estrutura é também classificado como um dos aminoácidos mais simples, só superado pela glicina que é a mais simples. Sua estrutura molecular é composta por um grupo carboxílico (COOH), um grupo amino (NH2) e um grupo metil (CH3). É uma molécula apolar e hidrofóbica.

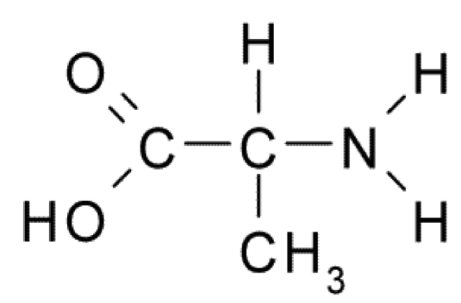

(a)

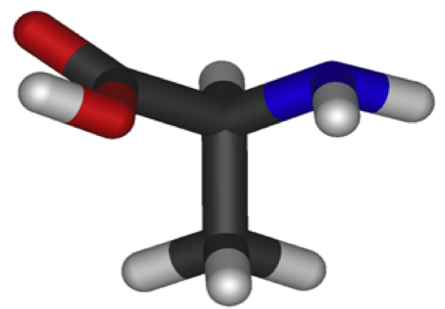

(b)

Figura 5.2.1: (a) Fórmula de estrutura da alanina. (b) modelo molecular da alanina.

A alanina pode ser encontrada em dois tipos de composições moleculares D-alanina e L-alanina denominadas enantiômeros ou isômeros ópticos, chamados dessa forma devido às diferenças que apresentam quanto à polarização da luz (L-alanina produz uma polimerização à esquerda e D-alanina uma polimerização à direita). Ambos enantiômeros D-alanina e L-alanina são produzidos de forma natural, embora a que D-alanina se encontra somente na parede celular de algumas bactérias, é formada a partir das L-alanina por meio da enzima isômerase.

Quando a alanina forma parte de uma proteína não é um aminoácido muito reativo devido à limitação de reatividade do grupo metilo em condições fisiológicas. Apesar da pouca reatividade química, a alanina pode ter funções de reconhecimento de substratos ou reguladores alostéricos em sítios ativos ou de regulação em enzimas. 


\subsubsection{Alanina-ESR}

O aminoácido L- $\alpha$ alanina pode ser usado como um dosímetro padrão secundário para dose alta e dosimetria de transferência, com uma faixa de dose bastante ampla implementando para esse fim pela espectroscopia por ESR. Essa ferramenta de pesquisa permite o monitoramento de concentrações de radicais formados em materiais sólidos, já que geralmente os radicais produzem um spin desemparelhado após feita a exposição à radiação ionizante. O sistema funciona bem e proporciona boas respostas, pois possui uma estabilidade alta do sinal induzido pela radiação. Estudos recentes mostraram que a irradiação das moléculas de alanina formam pelo menos três diferentes espécies de radicais livres R1, R2, R3 (Figura 5.2.2a). Na figura (5.2.2b), é mostrado o espectro típico obtido no espectrômetro por ESR de um dosímetro de alanina, usualmente a amplitude da linha do pico central é usada para determinar a dose de radiação.

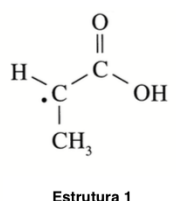

Estrutura

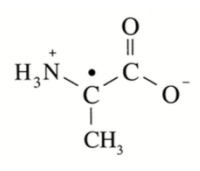

Estrutura 2

(a)

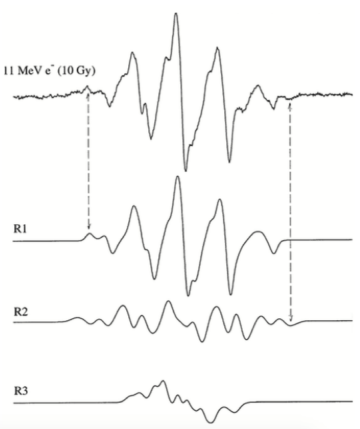

(b)

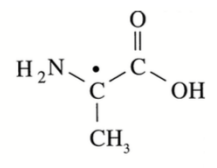

Estrutura 3

Figura 5.2.2: (a) Estrutura dos três diferentes espécies de radicais formados pela irradiação da alanina. (b) Espectro ESR de um dosimetro de alanina irradiado com elétrons de $11 \mathrm{MeV}$ e uma dose de 10 Gy. Além disso, é mostrado o espectro dos três radicais formados na L- $\alpha$ alanina a partir da irradiação em temperatura ambiente. Figura retirada e modificada do Malinen [6].

Quando é irradiada uma amostra de alanina, a ligação covalente entre o carbono $\alpha$ 
e o grupo amino NH2 é quebrada, nesse processo um elétron queda desemparelhado, formando um composto paramagnético como se mostra na figura (5.2.3).

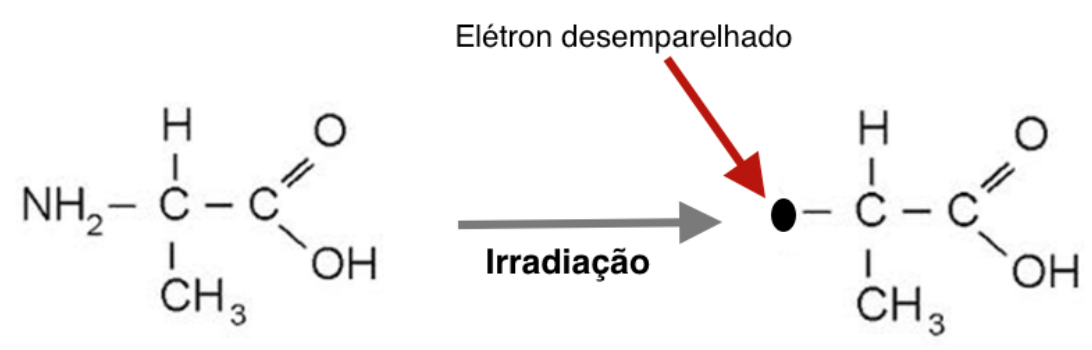

Figura 5.2.3: Processo de formação do composto paramagnético uma vez feita a irradiação a dosímetro de alanina. Figura retirada e modificada do Guilherme Gonçalves [7].

Esse elétron desemparelhado se encontra no estado de energia $E_{0}$ e devido à presença de um campo magnético externo se divide em dois estados de energia $E_{1}$ e $E_{2}$ como foi descrito anteriormente. Aqueles níveis de energia se dividem em cinco subníveis cada um. Cada uma dessas transições são representadas pelas lineais espectrais que caracterizam o espectro de alanina usando como forma de leitura a ESR.

\subsection{Espectroscopia por ressonância de spin eletrô- nico (ESR)}

A espectroscopia por ressonância de spin eletrônico (ESR) é uma técnica não destrutiva para detectar e, com as circunstâncias adequadas, identificar radicais livres. Este processo consiste na absorção da energia de micro-ondas em substâncias paramagnéticas pela transição de spins de um elétron desemparelhado entre os níveis de energias, em presença de um campo magnético externo. O campo é necessário para ter um controle na orientação dos centros paramagnéticos, portanto, eles irão se comportar como pequenas bússolas deixando somente prevalecer um campo magnético resultante, quando eventualmente algum campo magnético externo impuser uma direção preferencial.

Os níveis de energia para um elétron desemparelhado em um campo magnético externo são $E_{1}$ e $E_{2}$ cuja diferença de energia $\triangle \mathrm{E}$ é proporcional ao fator de Landé $g$, o magneton 
de Bohr $\mu_{b}$, e a campo magnético B.

$$
\triangle \mathrm{E}=E_{2}-E_{1}= \pm \frac{1}{2} \mu_{b} g \mathrm{~B}=h \nu,
$$

o fator de Landé $g$ é adimensional e depende do momento angular total do eléctron. $h \nu$ fóton de micro-ondas

As diferenças de energia na espectroscopia ESR são principalmente devido aos spins dos elétrons desemparelhados da amostra imersa em um campo magnético externo ${ }^{1}$, mais conhecido como efeito Zeeman. Os níveis gerados a partir da aplicação do campo magnético são denominados, os níveis de Zeeman e estão determinados por um primeiro nível correspondente ao estado de menor energia $E_{1}$ cujo spin eletrônico é $\mathrm{m}_{s}=-\frac{1}{2} \mathrm{e}$ um segundo nível $E_{2}$ correspondente a um estado de maior energia, com spin eletrônico $\mathrm{m}_{s}=+\frac{1}{2}$, onde essa diferença de energia é dada pela equação (5.3.1) (Figura (5.3.1)).

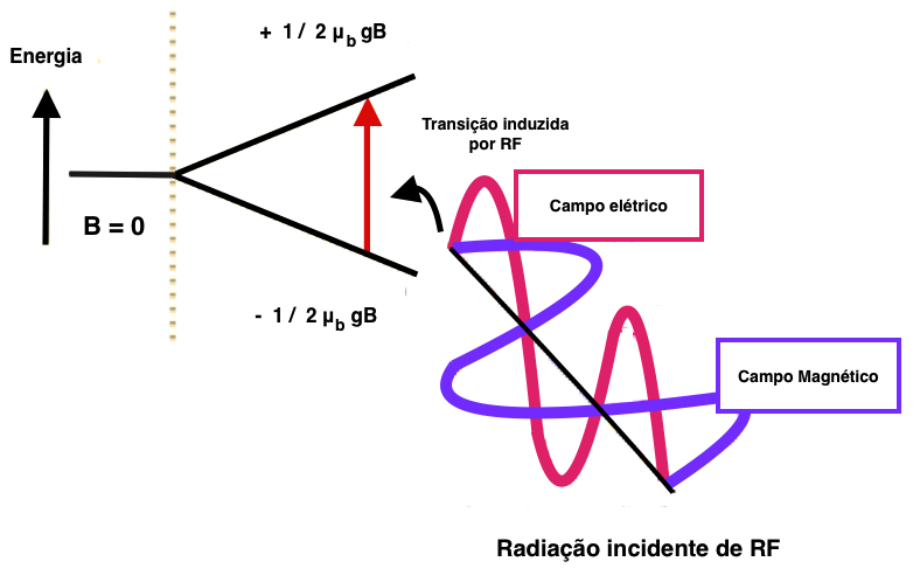

Figura 5.3.1: Estados de energia. Figura retirada e modificada do Wertz e Bolton [8].

Um número maior de spins é encontrado no estado de menor energia $E_{1}$ [50], pois, no caso de equilíbrio térmico os níveis de Zeeman serão determinados a partir da distribuição de Boltzmann, como se mostra a seguir:

$$
\frac{N_{+}}{N_{-}}=e^{-\frac{\Delta E}{k_{b} T}}
$$

com $N_{+}$e $N_{-}$as populações dos spins $\mathrm{m}_{s}=-\frac{1}{2}$ e $\mathrm{m}_{s}=+\frac{1}{2}$ respectivamente, $k_{b}$ como

\footnotetext{
${ }^{1}$ Campo magnético que no caso de ESR é gerado pelos eletroímãs.
} 
a constante de Boltzmann e T temperatura.

Então, quando um fóton atinge com energia igual à diferença de energias entre os níveis de energia, o seja $h \nu$, o eléctron vai absorver a energia do fóton mudando do estado de menor energia até o estado máximo de energia. A absorção de fótons é descrita pela ressonância de spin eletrônico, e permite determinar a quantidade de elétrons desemparelhados em um material paramagnético por meio da leitura da energia absorvida em função do campo magnético [50].

\section{- Elementos essenciais em ESR}

O processo de reconstrução de dose em ESR em amostras, é baseado em 4 itens:

1. Irradiação das amostras

2. Medição ESR.

3. Reconstrução da dose.

4. Interpretação dos resultados.

\subsubsection{Equipamento de leitura}

Para levar a cabo o procedimento descrito anteriormente é necessário dispor de um equipamento que gere e meça a absorção de ondas eletromagnéticas em uma determinada amostra. O equipamento que faz tudo isso é o espectrômetro de ressonância de spin-eletrônico (Figura 5.3.2), que como se pode ver na figura abaixo contem características tais como uma fonte de microondas, detetor, campo magnético B (eletroímãs) e na parte do centro dos dois eletroímãs encontra-se a cavidade ressonante onde é inserida a amostra. O tubo de medição que contem amostra é posicionado em um campo magnético de alta homogeneidade. 


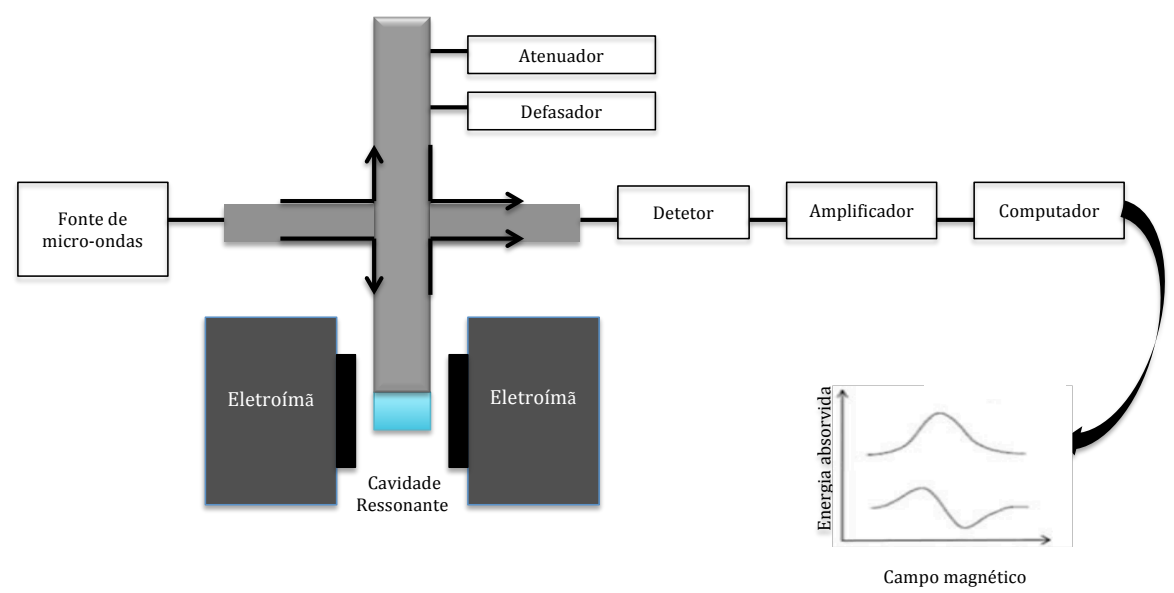

Figura 5.3.2: Diagrama básico de um espectrômetro de ressonância de spin-eletrônico [9].

Em um espectrômetro de ESR as microondas são produzidas por um gerador e posteriormente são enviadas através de uma guia de ondas até as amostras. De tal maneira que, quando ocorre a absorção dessa energia a intensidade de microondas diminui e é detectada pelo sistema eletrônico transformando essa informação em um espectro de intensidade com respeito ao campo magnético [9]. 


\section{Capítulo 6}

\section{Materiais e Métodos}

\section{Parte I - Manufatura, acondicionamento, irradiação e aquisição das IRM obtidas com o gel magic- $f$}

\subsection{Manufatura do objeto simulador}

O objeto simulador (Phantom) é composto de cilindros e elipsoides acrílicos que permitem a inserção da pélvis e as próteses femorais. Ele foi construído com as medidas reais de um ser humano. Tais medidas foram obtidas por meio de uma tomografia computadorizada (TC) de um paciente como é mostrada na figura (6.1.1) [7]. 


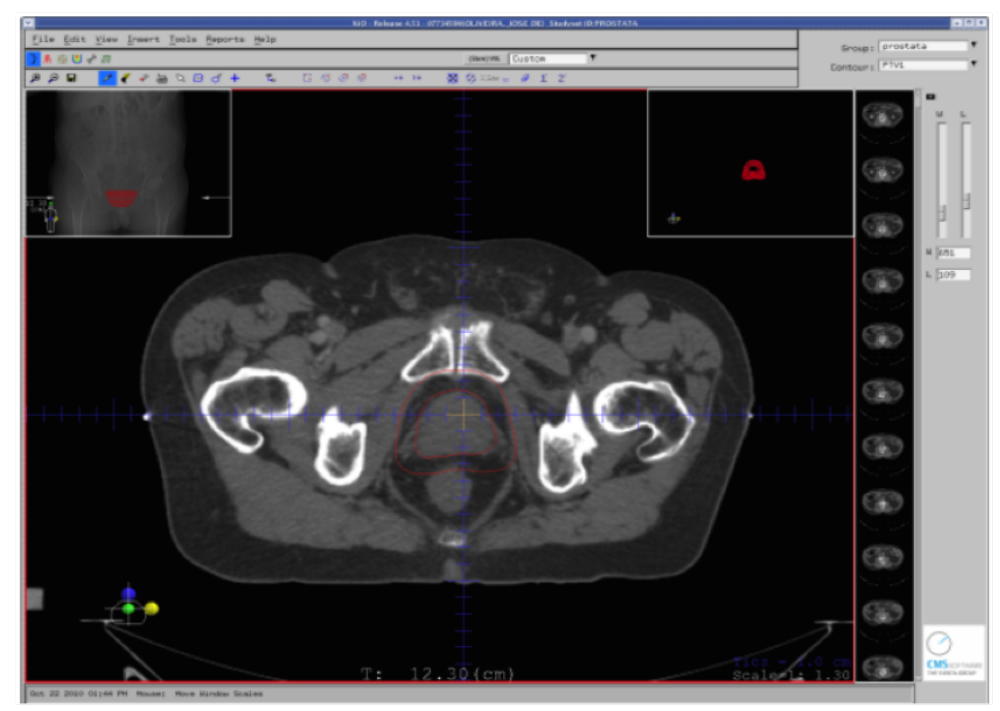

Figura 6.1.1: Imagem de uma tomografia computadorizada de um paciente. Figura retirada da dissertação de Guilherme Gonçalves [7].

Os ossos utilizados para a simulação, são ossos humanos e foram cedidos pelo departamento de cirurgia e anatomia da FMRP-USP. As próteses utilizados são próteses cimentadas compostas por um componente acetabular de polietileno, um haste femoral cimentada de aço inoxidável, o cimento ósseo composto por metil/polimetil metacrilato e um agente radiopaco para fixação, as quais foram doadas pela empresa baumer [7], mostradas na figura (6.1.2a). Após o posicionamento dos ossos, o objeto simulador foi preenchido com água normal para simular o tecido mole ao redor dos ossos, (Figura 6.1.2b), pois a combinação de acrílico e água funciona muito bem como simulador do tecido mole humano. Também foi adicionado um litro de água sanitária (solução de hipoclorito de sódio) para se evitar a formação de fungos quando o objeto simulador foi usado por um período de mais de uma semana. 


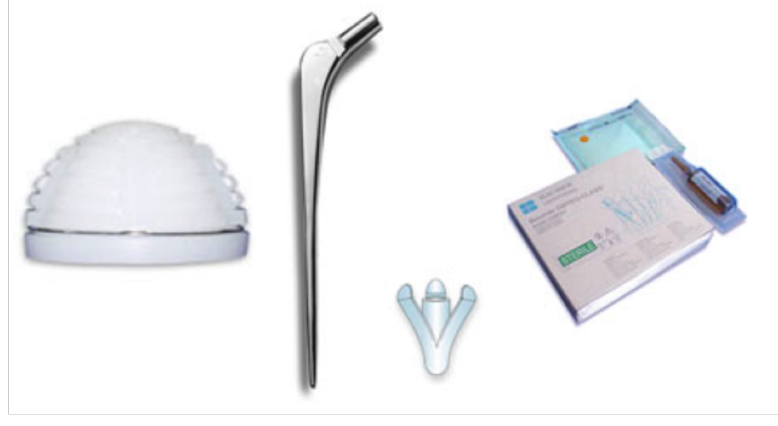

(a)

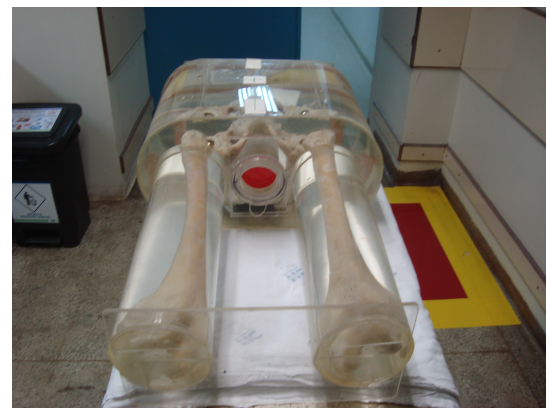

(b)

Figura 6.1.2: (a) Próteses Metálicas de aço inoxidável e o cimento de fixação [7]. (b) Objeto simulador com a pélvis e as próteses femorais.

Acondicionar o objeto simulador é uma das etapas mais importantes neste trabalho, pois os resultados obtidos dependem da precisão com que foi construído, portanto, depois de inserir a pélvis e as próteses femorais no acrílico é necessário determinar o volume que contém a próstata. Em um trabalho anterior desenvolvido pelo Guilherme Gonçalves [7], chamado "Influência das próteses metálicas na radioterapia de próstata através de dosimetria por ESR", foi elaborado uma cavidade cilíndrica de $4.4 \mathrm{~cm}$ de diâmetro e $5.0 \mathrm{~cm}$ de comprimento na região da próstata. Nesse caso, foram utilizados dosimetros de alanina, em nosso caso em vez da alanina é colocado o recipiente que contem o gel magic- $f$, mas como o recipiente utilizado agora é significativamente maior modificações tiverem que ser feitas. Por essa razão, a cavidade foi modificada a uma abertura cilíndrica de $6.3 \mathrm{~cm}$ de diâmetro e consequentemente o recipiente do gel pode ser introduzido como pode-se ver na figura (6.1.3).

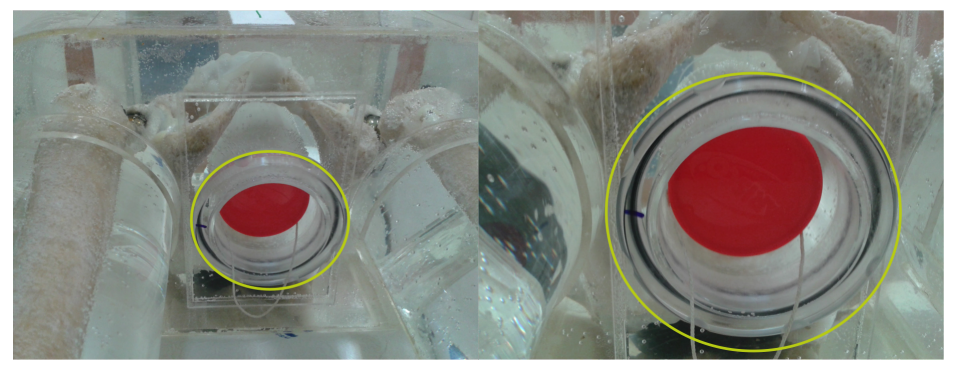

Figura 6.1.3: Abertura cilíndrica que permite a inserção do recipiente que contem o gel magic- $f$. 


\subsection{Manufatura dos dosímetros}

O processo de confecção dos dosímetros consiste em duas etapas: uma primeira onde é feita a elaboração do gel magic- $f$ e uma segunda parte chamada como acondicionamento do gel magic- $f$ realizadas no laboratório de ressonância magnética do departamento de física da Universidade de São Paulo - RP.

\subsubsection{Elaboração do gel}

O processo de fabricação do gel magic- $f$ deve ser feito com a maior precisão possível já que disso depende a reprodutibilidade de sua resposta, pois sabemos que erros na elaboração produzem complicações no momento da irradiação afetando o processo de polimerização no gel [26].

O gel magic- $f$ foi desenvolvido em nosso grupo com uma composição que aumenta o ponto de fusão do gel. A tabela (6.1) mostra a composição em massa dos elementos que constituem o gel.

Tabela 6.1: Composição em massa dos elementos utilizados na fabricação do gel magic- $f$,

\begin{tabular}{cc}
\hline Elementos & Porcentagem em massa (\%) \\
\hline Água mili-Q & 82.3 \\
Gelatina Bovina (250 Bloom) & 8.33 \\
Ácido metacrílico & 6.00 \\
Ácido ascórbico & 0.03 \\
Sulfato de cobre & 0.02 \\
Formaldeído & 3.00 \\
\hline
\end{tabular}

O processo de manufatura do gel é iniciado adicionando a gelatina à água a temperatura ambiente, utilizando para isso um agitador magnético que aquece à água até $50^{\circ} \mathrm{C}$. Durante o processo de aquecimento a gelatina é adicionada ao poucos para evitar a formação de bolhas dentro da matriz gelatinosa, nesse momento, a solução deve ficar de cor transparente e homogênea, essa etapa dura apenas uns 35 minutos. Imediatamente depois disso, o aquecimento é desligado e o recipiente que contem a gelatina é resfriado até $35^{\circ} \mathrm{C}$, uma vez é conseguida essa temperatura o ácido ascórbico e o sulfato de cobre são adicionados. Após uns 5 minutos é adicionado o ácido metacrílico e uns minutos depois é adicionado o último elemento, o formaldeído. Deixamos a solução 
em constante agitação durante alguns minutos mais e em seguida acondicionamos o gel nos diversos recipientes para finalmente serem levados à geladeira a uma temperatura de $12^{\circ} \mathrm{C}$, permanecendo pelo menos 12 horas nessa temperatura para a gelificação da preparação.

Existem muitas possíveis fontes de erros nos passos de fabricação do gel como por exemplo, a historia térmica da preparação do gel e a pureza dos produtos químicos utilizados, por isso, é recomendado fazer uma calibração separada de cada lote do gel preparado. Tubos menores são preenchidos com o gel e gelificados nas mesmas condições e uma vez feito isso, as amostras são levadas para serem irradiadas com diferentes doses conhecidas, após isso as imagens da ressonância magnética são obtidas e uma análise dos valore de $\mathrm{R} 2$ é feita e, um gráfico com $\mathrm{R} 2$ versus dose é montado para que desta forma sejam calibrados os demais dados experimentais.

\subsubsection{Acondicionamento do gel}

No processo de acondicionamento do gel um cuidado especial deve ser tido, pois uma vez que o gel tem gelificado não pode ter contato com o oxigênio já que a resposta do dosímetro é afetada significativamente. A escolha do recipiente depende do tipo de trabalho que se está pesquisando pois diferentes geometrias podem ser utilizadas, como por exemplo, no caso de medidas de dose na profundidade cujo recipiente deve ser longo para que possa cobrir toda a profundidade a ser medida.

\subsubsection{Recipientes para verificação de dose 3D}

No recipiente a seguir vai ser feito a simulação do tratamento de câncer de próstata. Como se trata da próstata um adequado recipiente deve ser rigorosamente escolhido pois, é necessário ter um volume acorde ao tamanho da região da próstata e assim fazer a simulação da mesma. Além disso, esse recipiente dever estar em condições ótimas para evitar que o ar se armazene no interior do recipiente. Nosso caso, o gel magic$f$ foi vertido em um recipiente de plástico feito de Tereftalato de Polietileno (PET), hermético, mostrado na figura (6.2.1). Aquele recipiente é inserido na região da próstata do objeto simulador. As medidas desse recipiente são $6.3 \mathrm{~cm}$ de diâmetro e $10.5 \mathrm{~cm}$ de comprimento, onde um total de $216 \mathrm{ml}$ do gel magic- $f$ é acondicionado em somente um recipiente. Um total de 3 recipientes foram usados, cada um com $216 \mathrm{ml}$ do gel. 
Os recipientes contém dentro três barras com diferentes formas geométricas (circular, quadrada e trinagular ) para funcionarem como marcas fiduciárias nos diferentes planos.

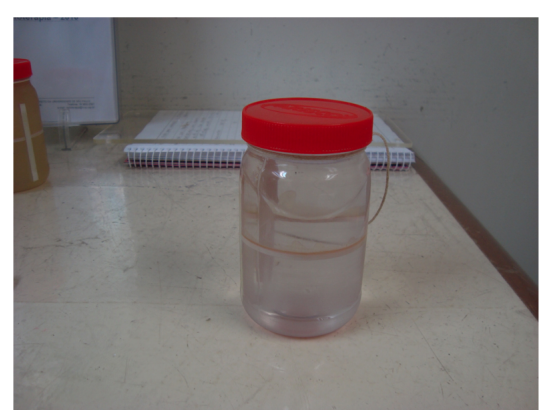

(a)

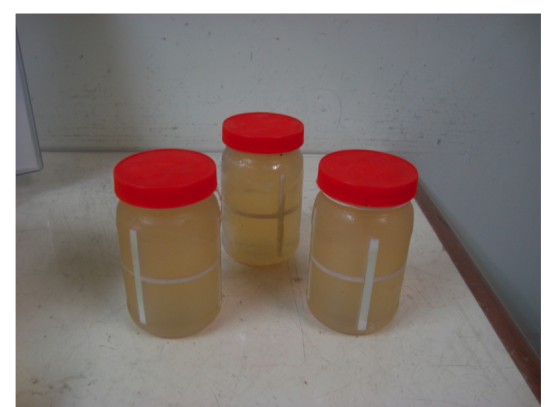

(b)

Figura 6.2.1: (a) Recipiente utilizado para simulação da região da próstata sem gel. (b) Recipiente com $216 \mathrm{ml}$ inserido na próstata para após feita a irradiação ser lido com IRM.

\subsubsection{Tubos de ensaio usados para calibração}

Existem diferentes formas de fazer a calibração do dosímetro gel magic- $f$ com por exemplo, calibração por meio de vários feixes, calibração por meio de vários frascos, e o método da dose na profundidade entre os quais o que é mais ajustável a nossos requerimentos é o de calibração por meio de vários frascos com um único feixe de radiação ionizante. Foi escolhida essa técnica já que a quantidade do gel é pequena e o processo experimental para a calibração é relativamente fácil. No momento da escolha dos tubos testes é primordial encontrar o tamanho mais adequado deles, pois quando são usados recipientes grandes erros na dose absorvida no interior dos tubos podem ser gerados a futuro ${ }^{1}$. Então, os melhores tubos testes devem ser de um volume pequeno para assim obter menos variações na dose absorvida.

Antes de fazer qualquer irradiação de um lote de dosímetros é necessário fazer uma calibração destes. Portanto, no mesmo lote do gel utilizado para simulação do tratamento de câncer de próstata, oito tubos de ensaio de calibração de vidro de $9 \mathrm{ml}$ foram preenchidos com o gel ( Figura 6.2.2). Esses tubos nos permitem um analise estatístico ótimo da dose absorvida no interior de cada dosímetro.

\footnotetext{
${ }^{1}$ Tubos de ensaio para calibração de volume pequeno são usados para evitar problemas de decaimento da radiação com a profundidade.
} 


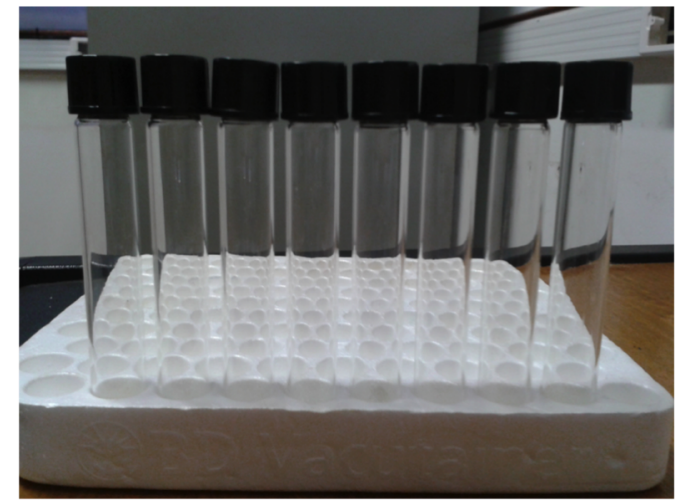

(a)

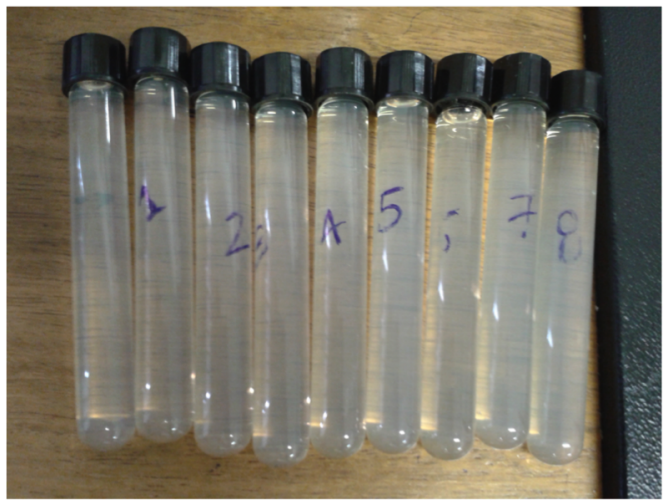

(b)

Figura 6.2.2: Tubos de ensaio de calibração cujo fim é fornecer dados para reconstruir a curva de calibração do gel.

\subsection{Planejamento do tratamento e irradiação do gel magic- $f$}

\subsubsection{Planejamento}

A aquisição das imagens do objeto simulador foi realizada por meio de uma tomografia computadorizada, com um tomógrafo PHILLIPS do hospital das clinicas da faculdade de medicina de ribeirão preto. Na aquisição de imagens foi usado o objeto simulador da pelve com as próteses femorais metálicas preenchidas de água no container de acrílico (Figura 6.3.1), e com o recipiente de simulação (Figura 6.2.1) inserido na região da próstata preenchido com água para facilitar as coisas e evitar um gasto desnecessário de gel. No entanto, nessa tomografia também são incluídos os dosímetros TL. Posteriormente essas imagens CT são importadas para o sistema de planejamento CMX XIO (Elekta) da unidade de radioterapia do hospital das clinicas da faculdade de medicina de ribeirão preto. A localização do isocentro foi feita por meio de três objetos radiopacos chamados "bibs" fornecidos pelos físicos médicos no mesmo momento da CT. 


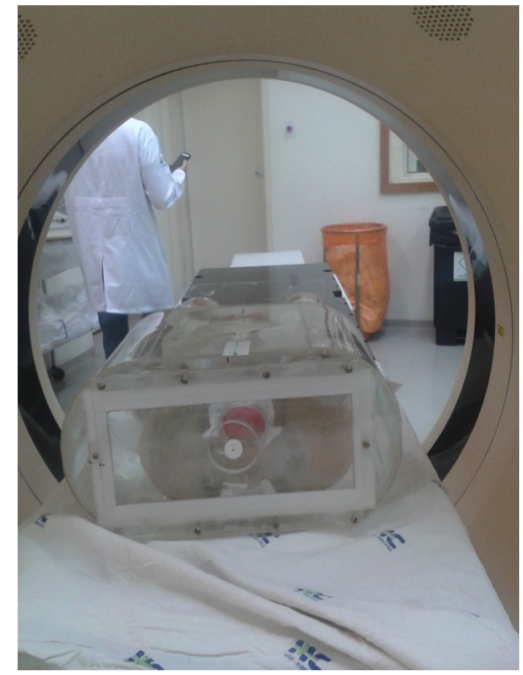

(a)

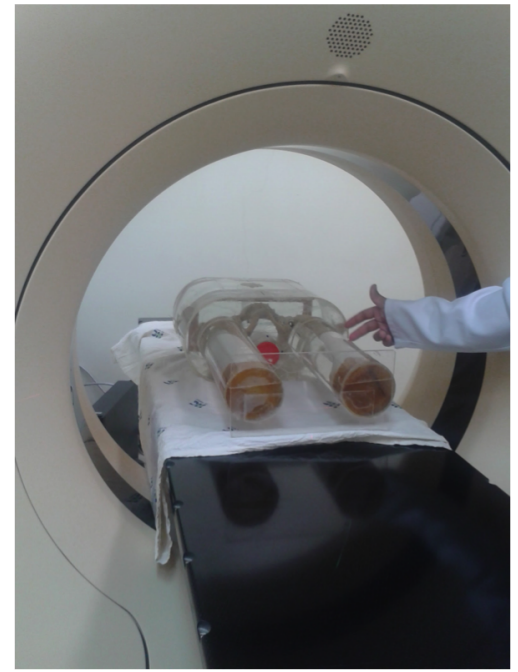

(b)

Figura 6.3.1: (a) Objeto simulador deitado no tomógrafo PHILLIPS, mostrando a parte de trás dele. (b) Objeto simulador deitado no tomógrafo onde é visualizado completamente sua forma.

O protocolo implementado foi o padrão para próstata, utilizando quatro campos cujas distribuições de dose foram avaliadas até conseguir uma distribuição de dose homogênea. Uma dose total de 70 Gy foi planejada em 35 sessões de 2 Gy cada uma. Esse protocolo esta incluído no sistema computacional do tomógrafo, onde aproximadamente 90 imagens com formato DICOM foram exportadas para um CD com a finalidade de serem importadas ao CERR (cujas tradução ao português é "ambiente computacional para a pesquisa em radioterapia" ). O CERR é uma plataforma de software para desenvolver e compartilhar os resultados de pesquisa no planejamento de um tratamento em radioterapia. Esta escrito em linguagem de programação de MATLAB permitindo o fácil acesso, diminuindo o custo de visualização e analise ${ }^{2}$. Uma screenshot do planejamento foi obtida e é apresentada a seguir:

\footnotetext{
${ }^{2} \mathrm{O}$ CERR oferece múltiplas vantagens já que permite a criação de uma base de dados do planejamento para vários tipos de pesquisas, incluindo a analise dose-volume-resultado e comparações do planejamento com IMRT.
} 


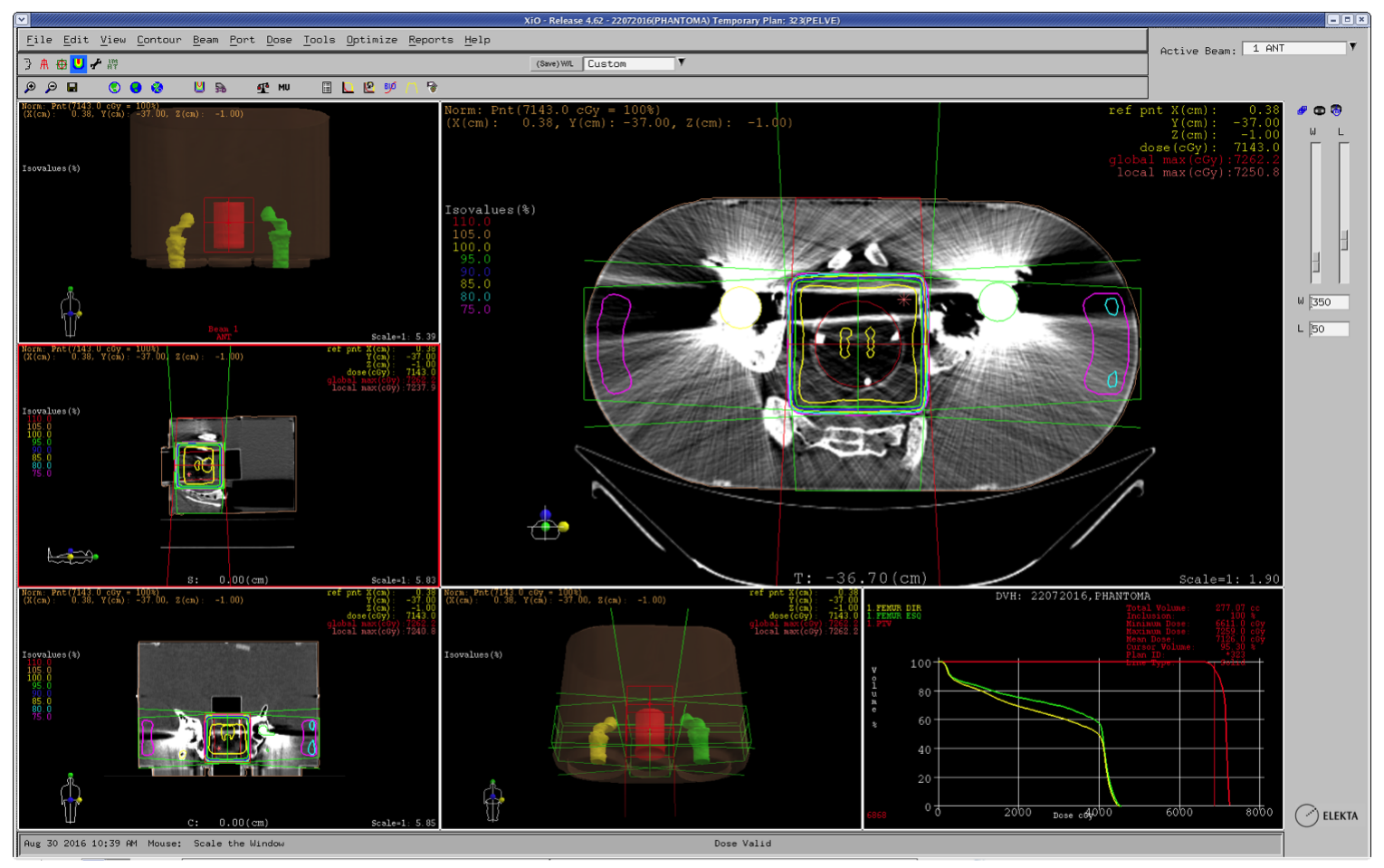

Figura 6.3.2: Screenshot do sistema de planejamento do tratamento padrão de próstata. A imagem mostra a localização dos diferentes campos de irradiação, assim como também os valores das doses que devem chegar até cada ponto. Na última imagem da parte inferior direita aparece o histograma Dose-Volume do fêmur direito e esquerdo.

\subsection{Irradiação do gel magic- $f$}

\subsubsection{Irradiação do objeto simulador}

As irradiações do objeto simulador com o recipiente de simulação inserido na região da próstata foram feitas na unidade de radioterapia do hospital das clinicas de ribeirão preto, com um acelerador Siemens Primus LINAC usado um feixe de $6 \mathrm{MV}$. Uma dose total de 2 Gy foi entregada em quatro campos com ângulos de 0, 90, 180, 270 graus. Em principio o objeto simulador preenchido de água com as duas próteses metálicas é colocado deitado na mesa, como foi previsto no planejamento. Para alinhar o objeto simulador aos lasers de posicionamento foram feitas três marcas em forma de cruz nas partes laterais e na parte superior deste. Essa marcas são utilizadas tanto para o CT de planejamento como para a irradiação. 


\subsubsection{Irradiação dos tubos teste usados para calibração}

As irradiações desses tubos foram feitas no mesmo lugar que para o objeto simulador da pelve. Os tubos teste para calibração foram irradiados usando um feixe único com uma distancia fonte- superfície de $100 \mathrm{~cm}$, distancia padrão em radioterapia externa. Além disso, foi utilizado um campo de $20 \times 20 \mathrm{~cm}^{2}$, com doses de $0,5,1,0,1,5,2,0,2,5$, 3,0, 4,0 Gy. Os tubos testes foram posicionados na profundidade de máxima dose em um fantom de acrílico, e uma camada de $10 \mathrm{~cm}$ de acrílico foi também posicionada na parte de trás dos tubos para simular a radiação de retro-espalhamento.

\subsection{Aquisições das imagens de ressonância magné- tica}

A aquisição das imagem por ressonância magnética foram feitas com um PHILIPPS Achieva 3T do HCRP-USP. Vinte e quatro horas após a irradiação, a medida de distribuição de dose foi avaliada por meio de um mapa de relaxometria R2 (1/T2 ). Para evitar variações nas taxas de relaxação R2 é importante deixar o objeto simulador e os tubos testes de calibração algumas horas antes na sala do tomógrafo de ressonância magnética para permitir que entrem em equilíbrio térmico com o meio. Além disso, o tempo de espera possibilita que a polimerização seja completada com sucesso.

Para evitar artefatos nas IRM dos tubos testes e do objeto simulador foi construído um suporte de acrílico que deixa fixos cada um desses elementos (Figura 6.5.1). Esse suporte é inserido em um recipiente preenchido com uma solução de água mili-Q (99\% de massa), cloreto de sódio ( $0.2 \%$ de massa) e com cloreto de manganês ( $0.3 \%$ de massa). No entanto, esse suporte também é construído com a ideia de reduzir o tempo de uso na ressonância pois, devido a sua forma permite adquirir as imagens dos tubos e do objeto simulador de maneira junta. 


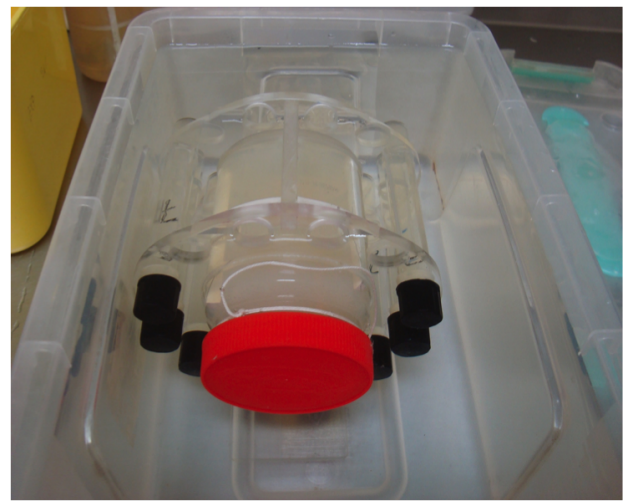

(a)

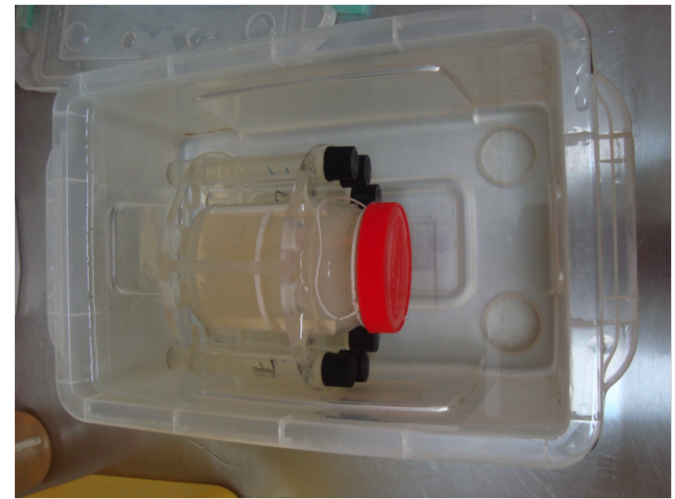

(b)

Figura 6.5.1: Suporte feito em acrílico para o phantom e tubos de calibração do gel, visão frontal (a) e lateral (b). O suporte é inserido em um recipiente de plastico contendo uma solução aquosa.

Como a aquisição das IRM para os elementos já mencionados acima foram feitas em conjunto a seqüência usada é a mesma. Uma seqüência Multi Spin Echo (MSE), com uma duração de aproximadamente 25 minutos é utilizada para cada phantom. Os principais parâmetros são:

1. Sequência com 8 ecos, igualmente espaçados em múltiplos de 35 ms (35 70105 $140175210245280)$

2. Tempo de repetição de $1000 \mathrm{~ms}$

3. Tamanho do Voxel de $0.6 \times 0.6 \times 2 \mathrm{~mm}$

4. Tamanho da matriz de aquisição $224 \times 224 \times 60$

5. FOV (Field of View)

- $\mathrm{AP}=130$

- $\mathrm{RL}=130$

- $\mathrm{FH}=120$ 


\subsection{Leitura das IRM}

Para determinar as taxas de relaxação R2 das imagens, é utilizado um software desenvolvido pelo nosso grupo de pesquisa que usa como ferramenta Matlab.

\subsubsection{Programa de relaxometria}

O programa permite carregar as IRM em formato DICOM, e também permite selecionar a região de nosso interesse, conhecida como ROI (Region of Interest), e assim determinar os valores de R2. Com base nos dados dos tempos de eco e da intensidade do sinal, o cálculo de R2 é feito por meio da linearização da equação (3.4.9), ver figura (6.6.1).

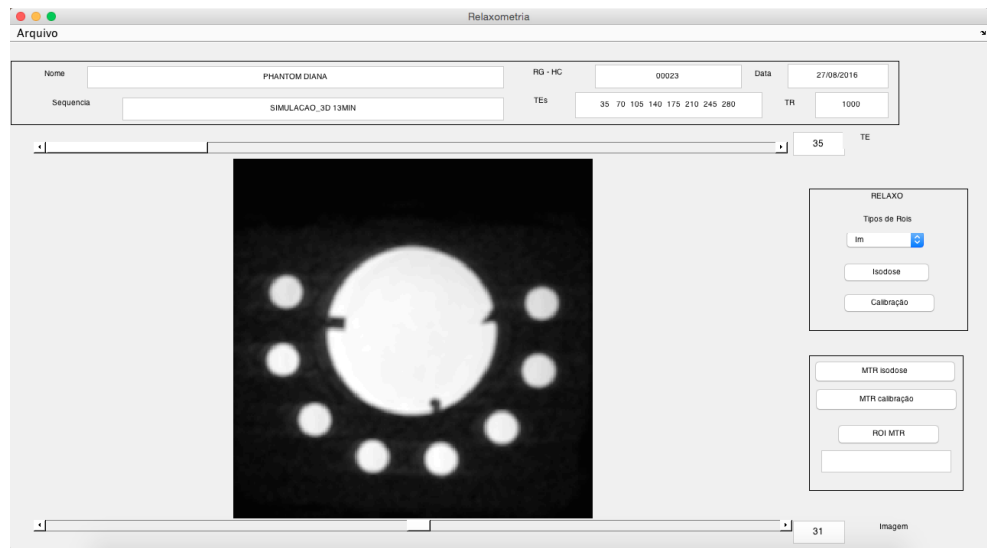

(a)

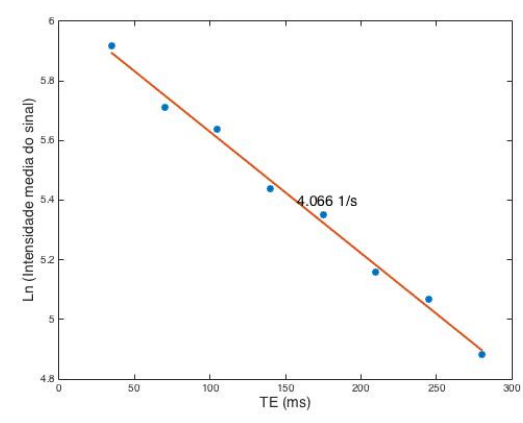

(b)

Figura 6.6.1: (a) Software desenvolvido em Matlab para determinar taxas de relaxação. (b) Linearização da equação (3.4.9) com o valor de R2 na região de interesse.

\subsubsection{Análises das distribuições de dose}

Antes de fazer a comparação entre as imagens do planejamento com as adquiridas por ressonância é necessário fazer alguns ajustes, como por exemplo de tamanho, espaçamento, e isocentro. Em princípio as imagens do TPS foram exportadas em formato DICOM-RT, para ser lidas pelo programa CERR. Nesse programa se pode visualizar perfeitamente os campos a ser irradiados e as diferentes estruturas como, paciente, PTV, fêmur direito e fêmur esquerdo (Figura 6.6.2). Além disso, as matrizes da dose planejada, CT, e as posições das estruturas podem ser extraídas em MatLab. 


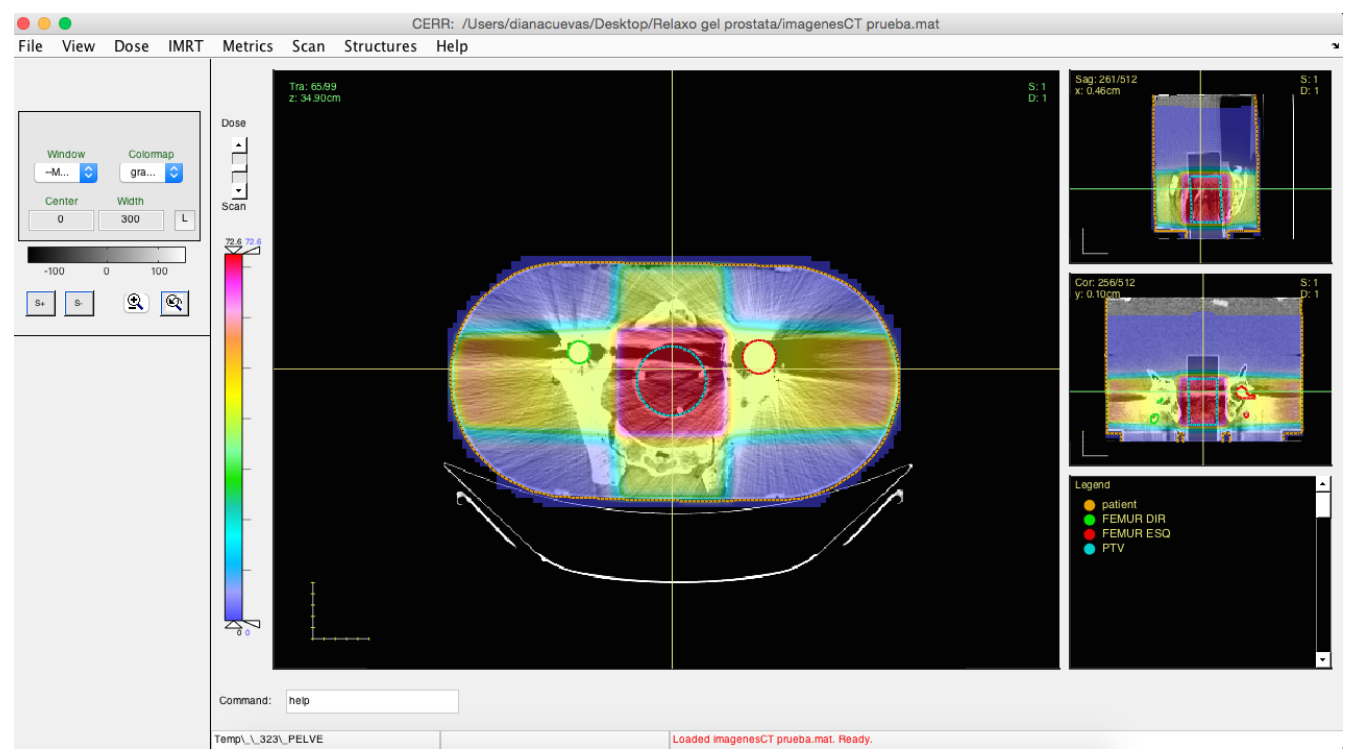

Figura 6.6.2: Interface do programa CERR, mostrando os perfis axial, sagital e coronal. Além disso, apresenta os quatro campos comuns em um tratamento de próstata, e as diferentes estruturas a irradiar.

O registro das imagens foi feito por meio das marcas inseridas dentro do recipiente que contem o gel magic- $f$, localizadas como o isocentro tanto pelo CT no planejamento como para as imagens da ressonância. Durante o registro das imagens foram feitas diversas modificações tais como, interpolações de dados, rotações e reescalamento de matrizes.

\subsubsection{Comparação das imagens do TPS e adquiridas pela ressonância}

A comparação entre os mapas de R2 da dose planejada e a dose medida é avaliada ao longo da região do fantom, com aproximadamente 80 fatias, com espaçamento de $1 \mathrm{~mm}$ entre elas, sendo esse nosso PTV. Cada mapa de R2 é analisado em valores relativos pois, existem alguns problemas associados com a calibração do dosímetro gel, baseados nos tubos de calibração. Por isso, neste trabalho se optou pelo critério de normalização de máxima dose para os valores de $\mathrm{R} 2$ e de dose, em principio, foi selecionada uma região homogênea localizada próximo ao isocentro. A distribuição de R2 é normalizada por um ponto de uma região homogênea, e da mesma forma para a distribuição de dose do TPS. 


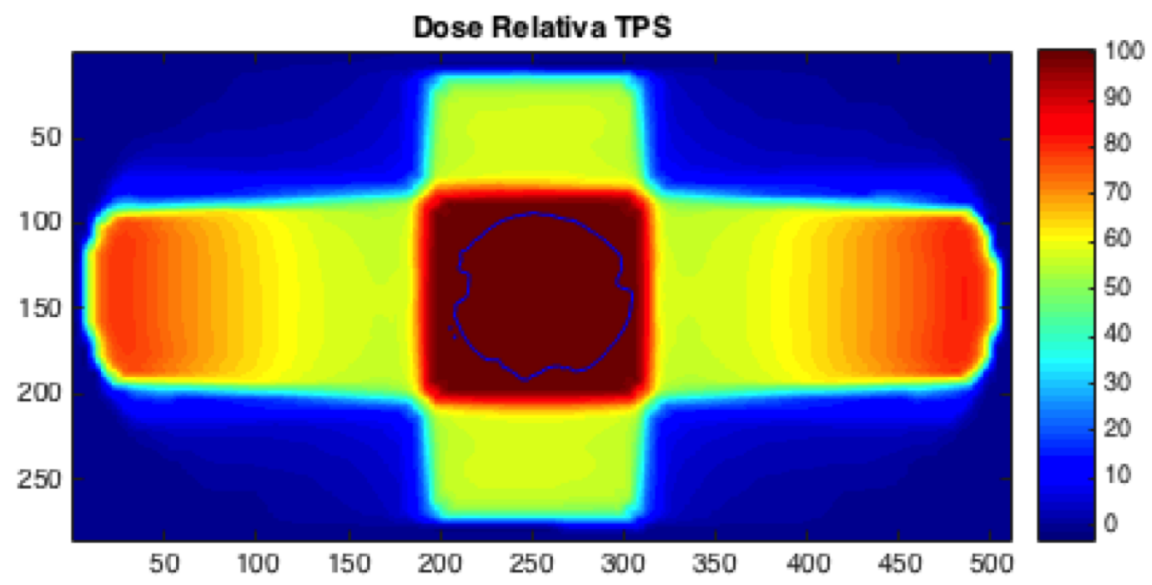

(a)

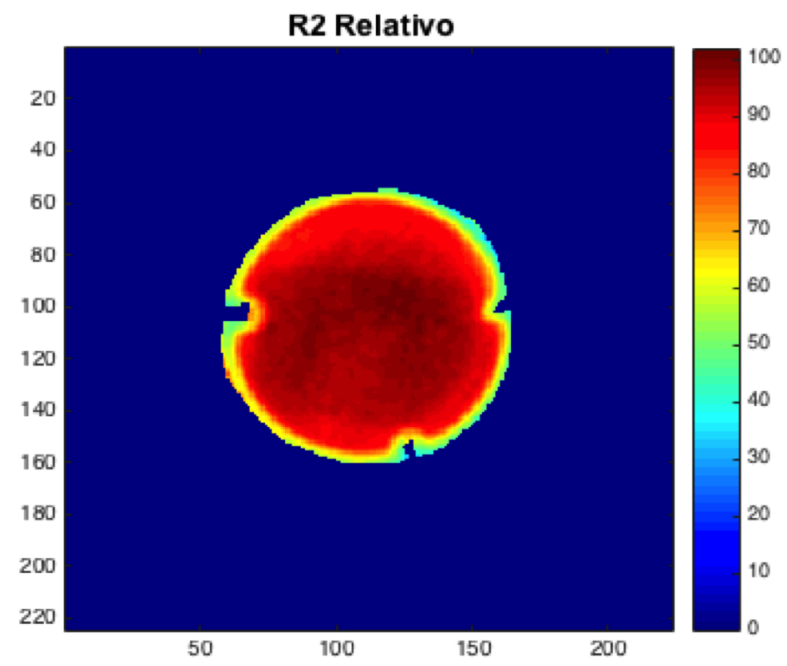

(b)

Figura 6.6.3: (a) Distribuição da dose planejada normalizada pelo valor de máxima dose. (b) Distribuição de dose medida normalizada pelo valor de máxima dose.

A análise gama permite fazer a comparação entre as duas distribuições de dose 3D. Essa análise foi desenvolvida no ambiente MatLab por nosso grupo [4]. A análise gama se caracteriza por avaliar de maneira simultânea a diferença percentual de dose, e a distância de concordância (DTA), encontrando o índice gama $\gamma$ entre duas distribuições de dose. Finalmente o que o programa mostra é a porcentagem de pontos aprovados no volume analisado, e além disso, também mostra a porcentagem de pontos aprovados em cada imagem que compõe o volume. Os critérios de aceitação adotados para a análise 
gama 3D, é 3\% de diferença percentual de dose e $3 \mathrm{~mm}$ de distancia de concordância (DTA).

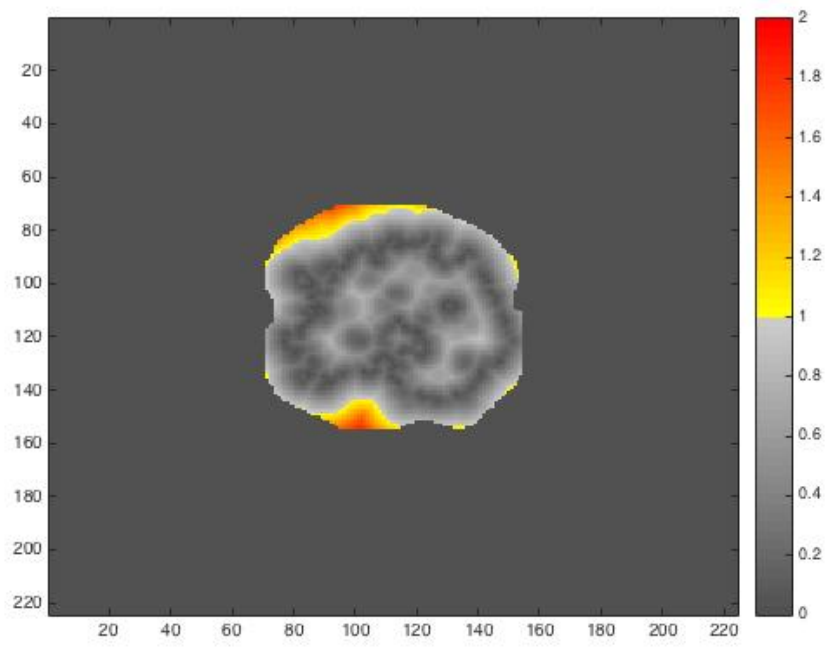

Figura 6.6.4: Distribuição de pontos aprovados mediante a análise gama (tons cinza).

Para que se considere aprovado o planejamento incialmente se deve ter uma aprovação na análise gama superior ao $90 \%$ dos pontos avaliados.

\section{Parte II - Manufatura, tratamento térmico, irradia- ção e leitura da dose absorvida nos dosímetros de TL por aquecimento}

\subsection{Manufatura}

Os dosímetros TL são obtidos e calibrados por parte do grupo de Dosimetria (CIDRA) do programa de Física aplicada à medicina e biologia da faculdade de Filosofia Ciências e Letras de Ribeirão Preto, da Universidade de São Paulo. O material termoluminescente usado é o fluoreto de Lítio ( $\mathrm{LiF}$ ) dopado com manganésio e titânio. Um lote de 40 dosímetros foram coletados, cuja geometria é similar à de um chip com medidas: diâmetro 3,2 mm, espessura de 0,89 mm, número atômico efetivo 8.2. 


\subsection{Tratamento térmico}

A resposta do $\mathrm{LiF}: \mathrm{Ti}, \mathrm{Mg}$ é muito sensível aos diferentes processos térmicos que envolvem seu uso, de maneira que, é mais importante a repetição e reprodutibilidade desses procedimentos que a dos mesmos valores de temperatura padronizados [51]. Em nosso caso, o TLD-100, o tratamento térmico é tratado em três etapas:

1. Tratamento térmico pré irradiação à alta temperatura.

2. Tratamento térmico pré irradiação à baixa temperatura.

3. Tratamento térmico após irradiação.

\section{Tratamento térmico pré-irradiação à alta temperatura}

Com a finalidade de restaurar a sensibilidade, o dosímetro TL é aquecido em um forno a $400^{\circ} \mathrm{C}$ por aproximadamente 1 hora. Diversos estudos comprovaram a viabilidade desse procedimento que confirma a dependência da sensibilidade do LiF : Ti, Mg como uma função da temperatura de aquecimento durante 1 hora[52].

\section{Tratamento térmico pré-irradiação à baixa temperatura}

Uma vez finalizado o procedimento de aquecimento a $400^{\circ} \mathrm{C}$, o lote de dosímetros é mudado de forno para ser aquecido durante 2 horas a uma temperatura de $100^{\circ} \mathrm{C}$. Procedimento feito para reduzir o desvanecimento, reduzindo a contribuição dos picos de baixa temperatura 1, 2 e 3 ( Figura 6.8.1). Finalizado esses dois processos, os dosímetros são levados para embalagem. Eles são cobertos na totalidade com plástico de não mais do que $1,5 \mathrm{~cm}$ de comprimento, e finalmente podem ser levados para irradiação. 


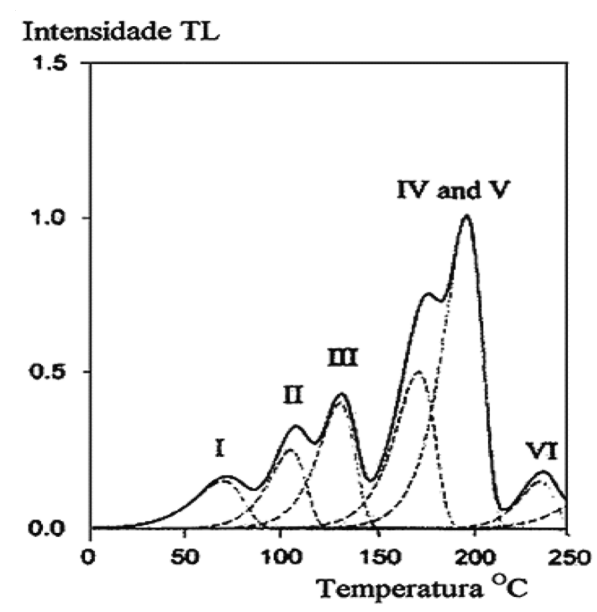

Figura 6.8.1: Curva de intensidade relativa da luz vs temperatura para o Harshaw TLD-100 $[5]$.

\section{Tratamento térmico após irradiação}

Uma das questões mais importantes na dosimetria termoluminescente, é a forma de leitura deles. Essa leitura deve fornecer resultados de forma rápida e eficiente que garanta a estabilidade do dosímetro durante o processo. Uma vez irradiados os dosímetros, as 20 pastilhas de fluoreto de lítio foram aquecidas em um forno a $100^{\circ} \mathrm{C}$ por 10 minutos, e em seguida são resfriadas sobre uma superfície refrataria até a temperatura ambiente. O procedimento de leitura é especificado nas seções a seguir.

\subsection{Irradiação}

\subsubsection{Irradiação das pastilhas de calibração}

Para a irradiação com fins de calibração, é realizada com ajuda de um suporte de acrílico retangular de $33,8 \mathrm{~cm}$ de comprimento, espessura $0,8 \mathrm{~cm} \mathrm{~cm}$ no suporte base, e uma tampa de acrílico de $0,5 \mathrm{~cm}$ de espessura, com capacidade para aproximadamente 70 dosímetros de $2 \mathrm{~cm}$ de comprimento e $0,5 \mathrm{~cm}$ de diâmetro os quais são divididos em 7 linhas cada uma com capacidade para 10 dosímetros, como se pode ver na figura (6.9.1). São usados 20 pastilhas de fluoreto de lítio, colocando duas por cada embalagem e cada embalagem é irradiado com doses de $0,5,1,0,2,0,2,5,3,0,4,0,6,0,8,0$ e 10,0 Gy. O 
tipo de feixe, campo de irradiação e distancia fonte-superfície são da mesma forma que para as cápsulas de alanina e os tubos teste do gel.

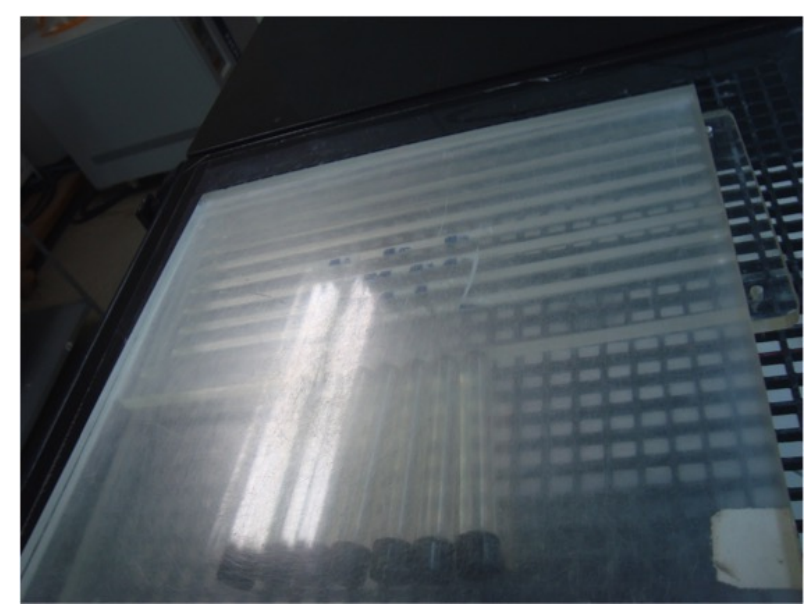

Figura 6.9.1: Suporte de acrílico com as capsulas farmacêuticas que contem a alanina.

\subsubsection{Irradiação do objeto simulador com os TL}

Os 20 dosímetros TL foram distribuídos nas regiões do quadril, osso sacro e nas próteses femorais metálicas. Foram incluídos 20 dosímetros TL cuja distribuição é da seguinte forma: Na parte perna direita, 4 dosímetros são localizados próximos à cabeça do fêmur, marcados cada um com números do 1-4 de cor azul (Figura 6.9.2c), os dosímetros marcados do 5-9 são distribuídos nos ossos do quadril (Ísquio, Ílio e Púbis). Exatamente assim, um deles no ramo ísquio púbico, dois na linha pectínea e dois perto da tuberosidade isquiática, como se mostra na figura (6.9.2a). Na parte esquerda é feito o mesmo procedimento de distribuição dos dosímetros com uma diferencia no cor das marcas dos tubos de Eppendorf que neste caso é preto (Figura (6.9.2b)(6.9.2d)). No total há 18 tubos designados nas regiões citadas, os dois tubos restantes estão na parte inferior do osso sacro (Figura 6.9.2e). 


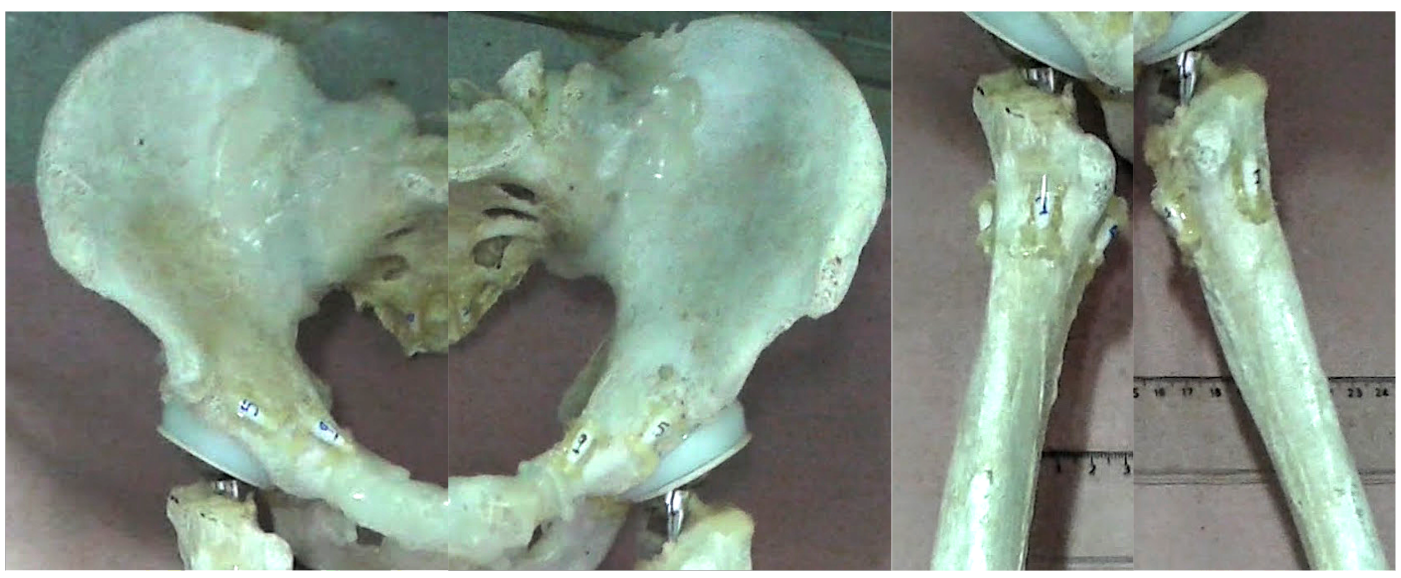

(a)

(b)

(c)

(d)

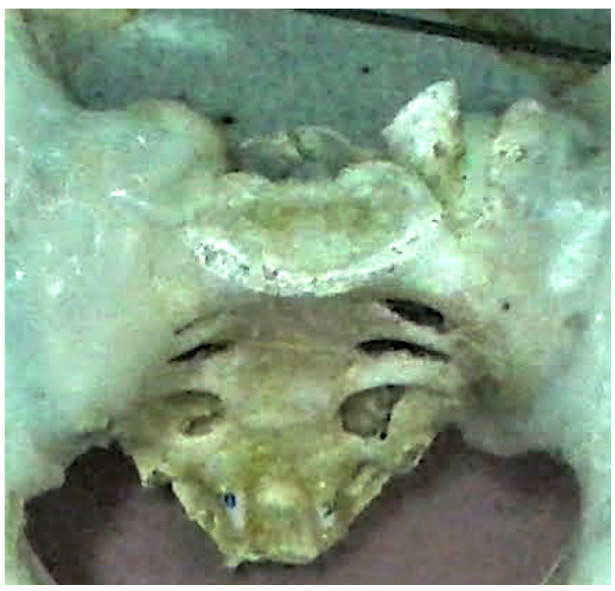

(e)

Figura 6.9.2: (a) Dosímetros marcados do 5-9 distribuídos na parte direita dos diferentes ossos do quadril. (b) Dosímetros do 5-9 localizados na parte esquerda dos ossos do quadril. (c) Dosímetros TL marcados com os números do 1-4 (cor azul) próximos à cabeça do fêmur (d) Dosímetros marcados do 1-4 (cor preto) próximos à cabeça do fêmur. (e) Localização dos dois últimos dosímetros TL no osso sacro.

De acordo com o sistema de planejamento (TPS) descrito na seção $\mathbf{6 . 3}$, a quantidade de dose que chega até essas regiões é de 1 Gy por cada 2 Gy em um tratamento normal de próstata. Essas pastilhas foram irradiadas com um acelerador Siemens Primus LINAC, com feixe primário de $6 \mathrm{MV}$ e um campo de irradiação de $10 \times 10 \mathrm{~cm}^{2}$. São feitas duas sessões cada uma com $2 G y$, portanto e de acordo com o TPS a dose que deve chegar até as próteses é da ordem de 2 Gy. 


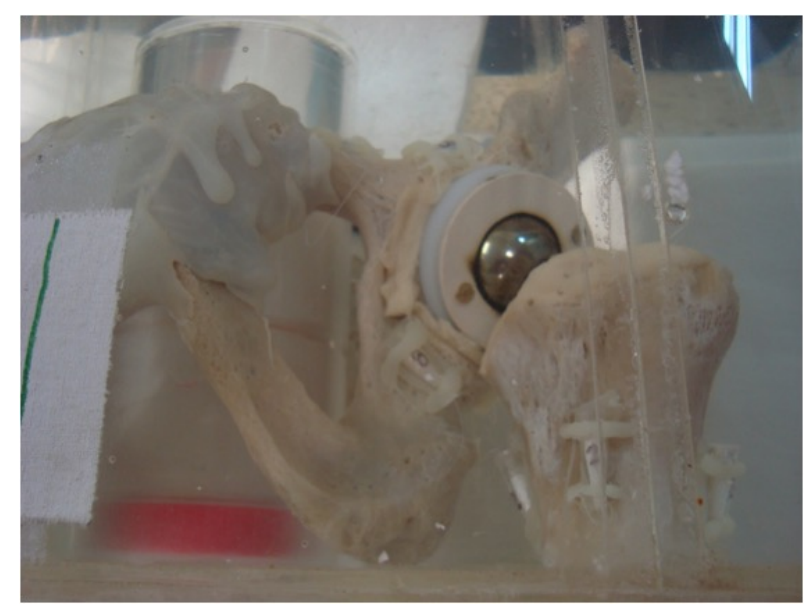

Figura 6.9.3: Visão da parte esquerda da próteses femoral com alguns dosímetros aderidos próximo á interface do osso com o implante metalico.

\subsection{Leitura}

Durante o processo de leitura do dosímetro TL, realiza-se um tratamento térmico após irradiação a uma temperatura abaixo da temperatura de avaliação, com a finalidade de eliminar os picos 1, 2 e 3, já que estes apresentam dependência com a temperatura ambiente gerando uma instabilidade neles. As 40 amostras são colocados na placa de acrílico e posteriormente são levadas a forno a $100^{\circ} \mathrm{C}$ por 10 minutos.

O equipamento usado para a leitura dos TL é um leitor HARSHAW 2000, e possui um compartimento com uma prancheta metálica para acomodação do TL (Figura 6.10.1); tendo uma função de resistência elétrica que aquece o TLD e seu refrigeração é feita em uma atmosfera de nitrogênio gasoso. 


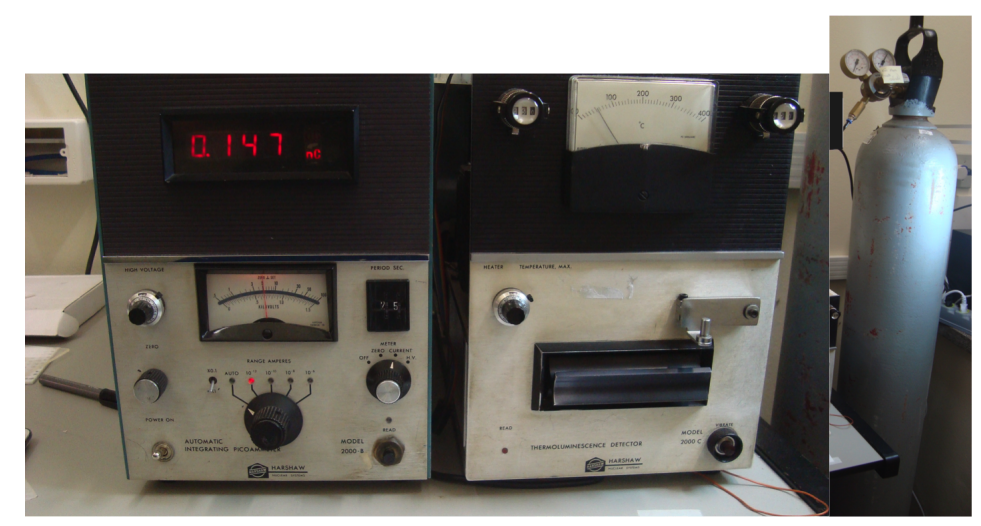

(a)

(b)

Figura 6.10.1: Sistema de leitura TLD. (a) Eletromêtro e válvula fotomultiplicadora. (b) Cilindro de nitrogênio usado para não termos oxigênio próximo dos dosímetros quando aquecidos.

Antes de fazer qualquer leitura com o equipamento é necessário calibrar o aparelho. Essa calibração esta dividida em dois diferentes testes, teste de prancheta e teste de luz de referência. No primeiro teste, se considera a leitura produzida pelo leitor quando é aplicado o aquecimento na prancheta sem haver nenhum material termoluminescente. A medida é feita com o compartimento completamente fechado, simulando a leitura de algum dosímetro TL e deve ter o valor de $0,14 \mathrm{nC}$. O teste de luz de referência consiste na leitura com o compartimento do dosímetro completamente aberto. Aquele procedimento posiciona uma fonte de luz estável, constituída de $\mathrm{Nal}(\mathrm{Tl})$ ativado com C-14 existente no interior do leitor a qual recebe diretamente um fluxo de fótons constantes. Esse último teste deve ser feito para cada série de leitura pois, os valores das leituras devem ser normalizadas com relação a uma única série de leituras escolhidas. Posteriormente da calibração se procede à leitura de cada pastilha, inicialmente a cada dosímetro é aplicado um fator de calibração $F_{c a l}$, dado pela equação $(6.10 .1)$.

$$
F_{C a l}=\frac{D_{R e f}(\mathrm{mGy})}{S(\mathrm{nC})}
$$

nosso caso, esse valor de $D_{\text {Ref }}$ foi obtido para Kerma, no césio 137 com um valor de 8,084 mGy, $S$ como a sensibilidade, e depende do número do dosímetro TL utilizado durante a exposição à radiação. Portanto, a seguir é apresentada uma tabela com os valores de sensibilidade para o lote 3 . 
Tabela 6.2: Valor da sensibilidade para cada um dos TL utilizados.

\begin{tabular}{|c|c|}
\hline Detector & Sensibilidade \\
\hline 34 & 15,1 \\
\hline 35 & 14,3 \\
\hline 36 & 14,7 \\
\hline 37 & 13,8 \\
\hline 39 & 11,3 \\
\hline 43 & 13,4 \\
\hline 45 & 13,1 \\
\hline 46 & 14,1 \\
\hline 47 & 15,6 \\
\hline 48 & 13,2 \\
\hline 49 & 13,6 \\
\hline 50 & 13,9 \\
\hline 53 & 14 \\
\hline 54 & 13,2 \\
\hline 56 & 13,2 \\
\hline 57 & 13,2 \\
\hline 58 & 13,7 \\
\hline 59 & 13,4 \\
\hline 61 & 13,6 \\
\hline 71 & 13,1 \\
\hline 72 & 13,8 \\
\hline 73 & 13,9 \\
\hline 74 & 14,6 \\
\hline 75 & 12,7 \\
\hline 78 & 13,3 \\
\hline 79 & 14,4 \\
\hline 80 & 12,9 \\
\hline 81 & 12,8 \\
\hline 82 & 14,4 \\
\hline 84 & 13,5 \\
\hline 85 & 12,6 \\
\hline 86 & 14,3 \\
\hline 87 & 14,4 \\
\hline 88 & 13,3 \\
\hline 89 & 12,4 \\
\hline 90 & 12,8 \\
\hline 91 & 14 \\
\hline 92 & 13,7 \\
\hline 93 & 15 \\
\hline
\end{tabular}


A estimativa da dose é realizada a partir da luz emitida pelo dosímetro (Leitura (nC)) entre 50 e $250{ }^{\circ} \mathrm{C}$, que por sua vez é multiplicada pelo fator de calibração anteriormente determinado, como se mostra na seguinte equação :

$$
D_{\text {Lida }}=\text { Leitura }(\mathrm{nC}) \times F_{C a l}
$$

\section{Parte III - Manufatura, acondicionamento, irradia- ção e leitura da dose absorvida nos dosímetros de alanina por meio de espectroscopia ESR}

A partir de aqui são apresentados cada um dos passos utilizados para o desenvolvimento da dosimetria com alanina. Em principio é descrito o processo de manufatura da alanina, após isso, são embalados e colocados no objeto simulador. Finalmente se descreve como é feita a leitura de cada um dos dosímetros.

É importante aclarar que as medidas feitas com dosimetria ESR não foram realizadas em conjunto com o gel magic- $f$ e os dosímetros TL. Portanto, uma nova tomografia computadorizada é feita, cujas imagens foram importadas para o sistema de planejamento TPS, da unidade de radioterapia do hospital das clinicas.

\subsection{Manufatura dos dosímetros de alanina}

O processo de fabricação dos dosímetros começa com a elaboração da mistura em forma de pó da alanina, que é composta de L- alanina e Polivinil álcool (PVA) com um porcentagem de $95 \%$ e 5\% respectivamente, feita no laboratório de Ressonância Magnética do Departamento de Física. Além disso, para fins de pesquisa um lote de alanina já elaborada foi compactada manualmente em pastilhas cilíndricas de aproximadamente 1 cm de comprimento e 0,3 de diâmetro, realizada também no Laboratório de Ressonância Magnética. Onde 30 pastilhas foram utilizadas para o teste de calibração e para a avaliação do tratamento. 


\subsection{Acondicionamento dos dosímetros de alanina}

A escolha de um recipiente o suficientemente pequeno que possa conter a alanina em pastilhas cilíndricas foi feita minuciosamente pois, se deve minimizar ao máximo o uso de diferentes matérias no objeto simulador que possam levar a problemas de equilíbrio eletrônico. As pastilhas de alanina utilizadas para calibração foram inseridas em cápsulas farmacêuticas, as quais são pequenos containers gerados principalmente de gelatina (Figura 6.12.1). O acondicionamento dos dosímetros usados para comparação entre a dose planejada e a dose medida foi feito de plástico preto de aproximadamente $2 \mathrm{~cm}$.

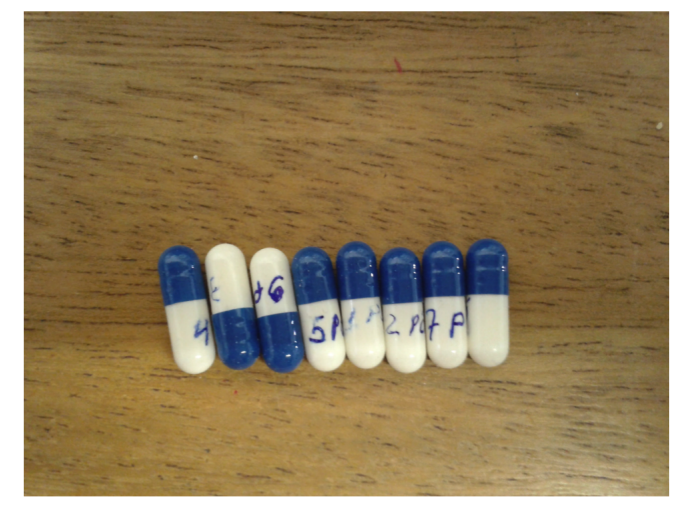

Figura 6.12.1: Forma de embalagem para o teste de calibração.

Uma vez feito o acondicionamento, 20 dosímetros são colocados no objeto simulador da pélvis (Figura 6.1.2b) ao redor do fêmur, o quadril e o osso sacro. A localização dos dosímetros de alanina no fantom é assim, na perna direita ao redor da cabeça do fêmur são distribuídos 4 dosímetros, na região do quadril direito 5 mais deles são posicionados e por último na região do osso sacro é colocado o dosímetro número 10. Na perna esquerda é repetido o mesmo procedimento. 


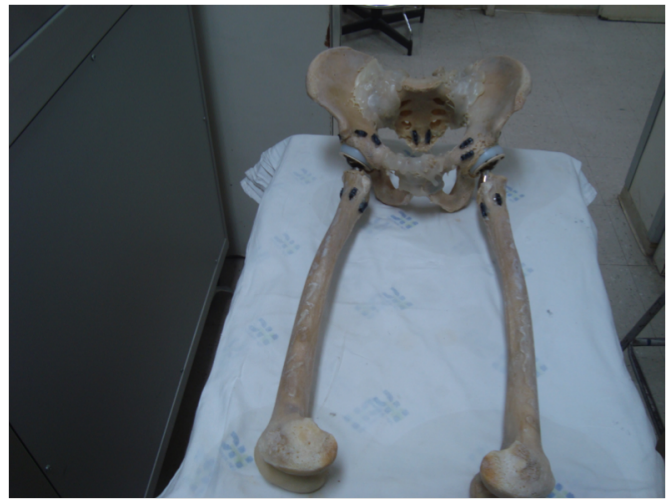

(a)

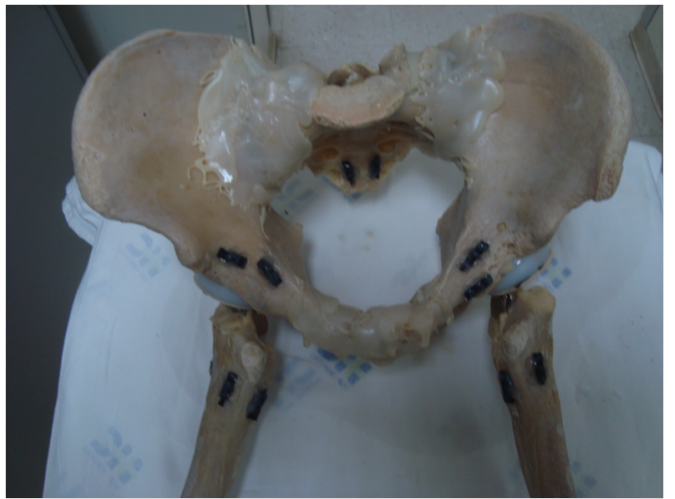

(b)

Figura 6.12.2: Distribuição dos dosímetros de alanina ao redor do fêmur, quadril e osso sacro.

\subsection{Irradiação dos tubos de ensaio com alanina usados para calibração}

Para a irradiação dos dosímetros é usado o mesmo suporte de acrílico dos TL ( Figura 6.9.1). Foram utilizadas 10 cápsulas farmacêuticas objetivando a construção da curva de calibração. Cada um dessas cápsulas são preenchidas com aproximadamente $134 \mathrm{mg}$ de alanina, cuja irradiação é feita usando um feixe único a uma distancia Fonte-Superfície de $100 \mathrm{~cm}$ em um campo $20 \times 20 \mathrm{~cm}^{2}$. As doses determinadas para cada tubo são: 5,0, 7,0, 9,0, 11,0, 13,0, 15,0, 17,0, 19,0, 21,0 Gy, deixando um tubo sem irradiar correspondente ao valor de 0,0 Gy. Esse processo foi realizado na unidade de Radioterapia do Hospital das Clinicas de Ribeirão Preto.

\subsection{Irradiação do objeto simulador contendo os do- símetros de alanina}

Quando se trabalha com câncer de próstata as doses que chegam até o volume alvo não devem exceder uma dose máxima de 2 Gy, já que regiões vizinhas como o reto e a bexiga são suscetíveis a essa radiação, o que produz danos significativos no corpo do paciente. No entanto, como é conhecido a alanina funciona bem para doses altas, 
gerando em nosso caso uma desvantagem. Para resolver isso, é feita uma primeira irradiação na unidade de radioterapia do hospital das clinicas de ribeirão preto, cujo fim é determinar a resposta dos dosímetros quando são submetidos a doses baixas. As doses inicialmente aplicadas foram 0,5, 1,0, 1,5, 3,0, 4,0, 6,0, 8,0, 10,0 Gy, com essas doses foi possível medir um sinal no espectrômetro de ESR, o que resolveu o problema. Posteriormente, o objeto simulador da pélvis com os dosímetros de alanina incluídos é submetido a uma tomografia computadorizada. Neste caso, nossa preocupação era saber quanta dose conseguia chegar até os dosímetros de alanina pois, se a dose era demasiada baixa não seria possível obter algum tipo de sinal na leitura deles. Com o sistema de planejamento CMX XIO (ELEKTA) sabemos que um total do 55\% da dose vai chegar até esses dosímetros, de modo que, ao redor de 1 Gy da dose esta sendo depositada neles, dose suficiente para obter um sinal. Um total de 6 Gy foi entregado. Após feito o planejamento a irradiação dos dosímetros de alanina é realizada na unidade de Radioterapia do Hospital das Clinicas de Ribeirão Preto, com um acelerador Siemens Primus LINAC, usando um feixe de $6 \mathrm{MV}$ e um Campo de radiação de $10 \times 10 \mathrm{~cm}^{2}$. Inicialmente, o objeto simulador que contém o recipiente que simula a próstata, e a alanina, é colocado deitado na mesa do acelerador como se fosse uma pessoa real.

\subsection{Leitura da dose absorvida nos dosímetros por meio de espectroscopia ESR.}

As leituras dos dosímetros foram feitas com um espectrômetro de banda $\mathrm{X}$ da marca JEOL, modelo JES-FA 200 (9.5 GHz), pertencente ao laboratório de ressonância magnética aplicada do Departamento de Física. Os parâmetros utilizados são um campo magnético de 344,536 mT, um total de 4 varreduras, amplitude de 6,00 x 100, amplitude de modulação de $0,5 \times 10 \mathrm{mT}$, constante de tempo de $0,3 \mathrm{~s}$ e um tempo de varredura de 1 minuto. 


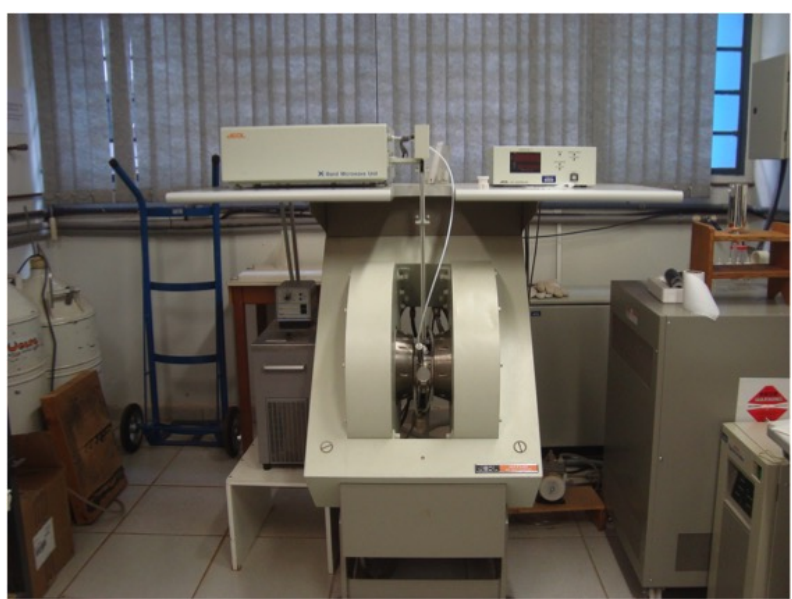

Figura 6.15.1: Espectrômetro de ressonância spin-eletrônico. Operando em Banda X (9 GHz) da marca Jeol. Pode-se ver o magneto, a ponte de microondas e controlador de temperatura. $\mathrm{O}$ console de controle do equipamento fica à direita da fotografia. 


\section{Capítulo 7}

\section{Resultados e Discussões}

Neste capítulo são apresentados os resultados para o controle de qualidade tridimensional usando gel magic- $f$ e as leituras de dose absorvida na região dos implantes metálicos por parte dos dosímetros TL e alanina. Os resultados para cada técnica dosimétrica é separada por partes.

\section{Parte I - Resultados dosimetria gel magic- $f$}

Na parte I é mostrado o resultado correspondente à dosímetria gel magic- $f$, iniciando com o gráfico da curva de calibração e posteriormente se mostram as distribuições de dose 3D analisadas com o programa de relaxometria e a análise gama.

\subsection{Curva de calibração do gel magic- $f$}

A avaliação dos valores de R2 para cada tubo de calibração é feita por meio da seleção da zona de interesse, eliminando as bordas do recipiente de vidro, com a finalidade de evitar erros na medida de R2 causados por artefatos externos. Inicialmente é feita a curva de calibração utilizando os valores de dose e R2 mostrados na tabela (7.1), a curva apresenta um comportamento linear entre a taxa de relaxação R2 e a dose, de modo que, a sensibilidade do gel pode ser determinada e corresponde ao coeficiente angular de cada curva (Figura 7.1.1). 
Tabela 7.1: Valores da taxa de relaxação R2 com os erros associados à medida.

\begin{tabular}{cccc}
\hline Dose (Gy) & R2 $(1 / \mathrm{s})$ & Erro \pm & Desvio padrão \\
\hline 0,5 & 2,6 & 0,18 & 0,41 \\
1,0 & 3,0 & 0,09 & 0,21 \\
1,5 & 3,3 & 0,02 & 0,06 \\
2,0 & 3,7 & 0,06 & 0,14 \\
3,0 & 4,5 & 0,24 & 0,54 \\
\hline
\end{tabular}

\section{Curva de Calibração Gel Magic-f}

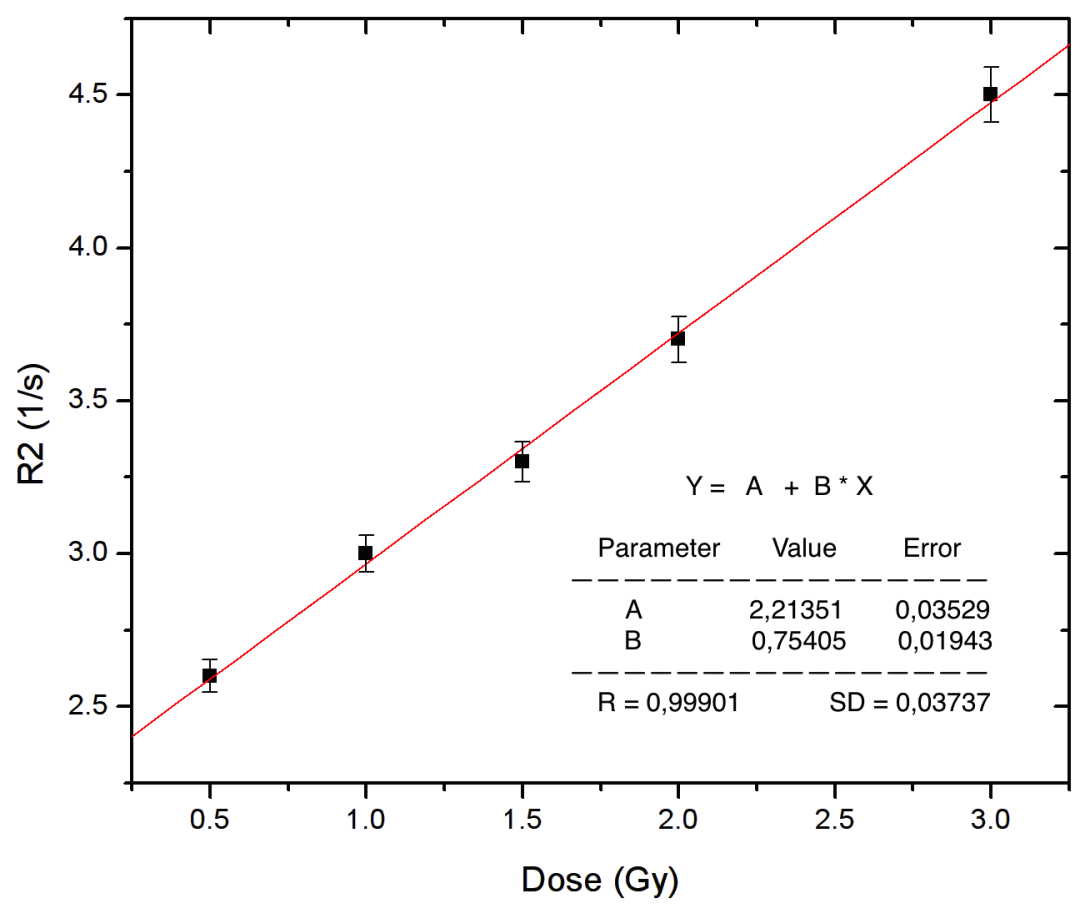

Figura 7.1.1: Curva de calibração para o gel magic-f.

\subsection{Controle de qualidade tridimensional gel magic- $f$}

Para a avaliação tridimensional foi usado como dosímetro o gel magic- $f$, com o fim de avaliar o planejamento ao longo do seu volume. O planejamento é feito para um tratamento padrão de câncer de próstata com quatro campos e uma dose total de 70 
Gy, o equivalente a 35 frações cada uma com 2,0 Gy. A análise começa com a aquisição das IRM e seu posterior processamento. Inicialmente são adquiridos 60 cortes axiais de IRM com espaçamento de $2 \mathrm{~mm}$ entre as fatias. Após isso, se obtém para cada corte um mapa de R2 que pode ser relacionado com a dose absorvida. Um dos problemas ao utilizar IRM , é a possível presença de artefatos nas imagens, causados possivelmente pelas diferenças de susceptibilidades magnéticas entre o fantom e o ar ao redor, por isso, as primeiras e últimas imagens da sequência adquirida são eliminadas e a relaxometria só é analisada para 52 cortes (Figura 7.2.1). No entanto, é importante ter os espaçamentos entre as fatias de $1 \mathrm{~mm}$ em $1 \mathrm{~mm}$, por isso, é realizada uma interpolação entre as fatias intermediárias dos cortes adquiridos.

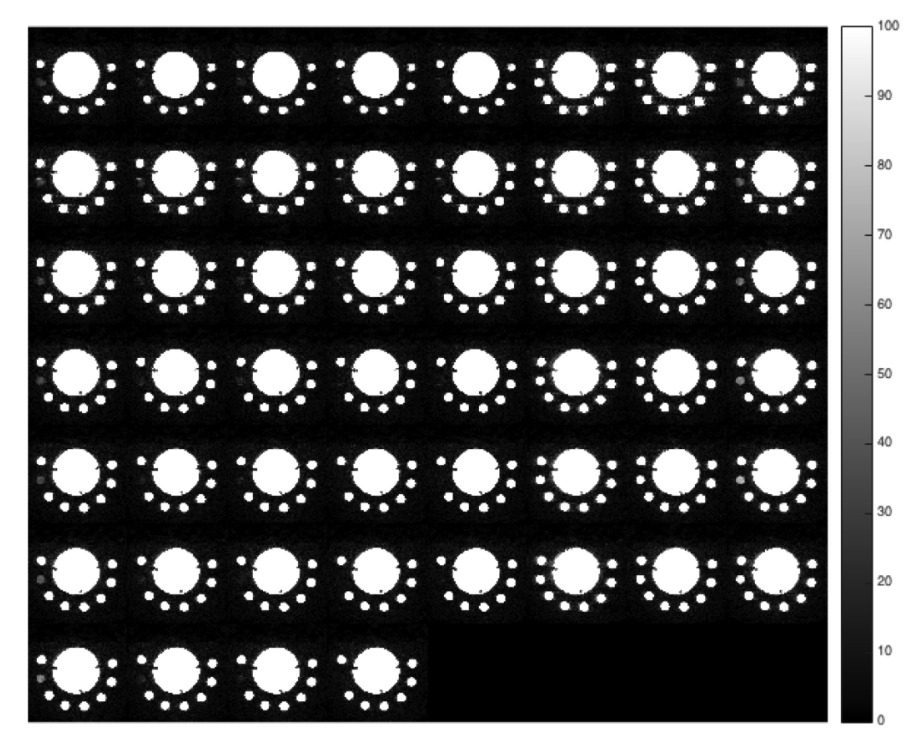

Figura 7.2.1: Cortes axiais do fantom e dos tubos testes de calibração obtidas na RM.

Agora, as imagens de distribuição de dose exportadas pelo TPS foram 74, com um espaçamento entre as fatias de $4 \mathrm{~mm}$. Os cortes de nosso interesse são os localizados desde a imagem $57(Z=57)$ até a $87(Z=87)$, para um total de 31 imagens. Neste caso, é necessário fazer uma interpolação dupla dos valores intermediários entre as fatias. Com essas interpolações ficaríamos com uma matriz de 296 imagens de distribuições de dose. No entanto, todas as 296 imagens não são de nosso interesse já que contém informações adicionais sobre as estruturas do paciente e próteses femorais. De modo que, foram escolhidas apenas 124 imagens correspondentes ao PTV, o seja, aquelas imagens próximas à região da próstata onde fica o recipiente com o gel. 
Nas figuras a seguir são apresentadas as distribuições normalizadas de dose para o TPS (Figura 7.2.2a) e para o Gel (Figura 7.2.2b), no caso do gel se tem um total de 104 imagens.

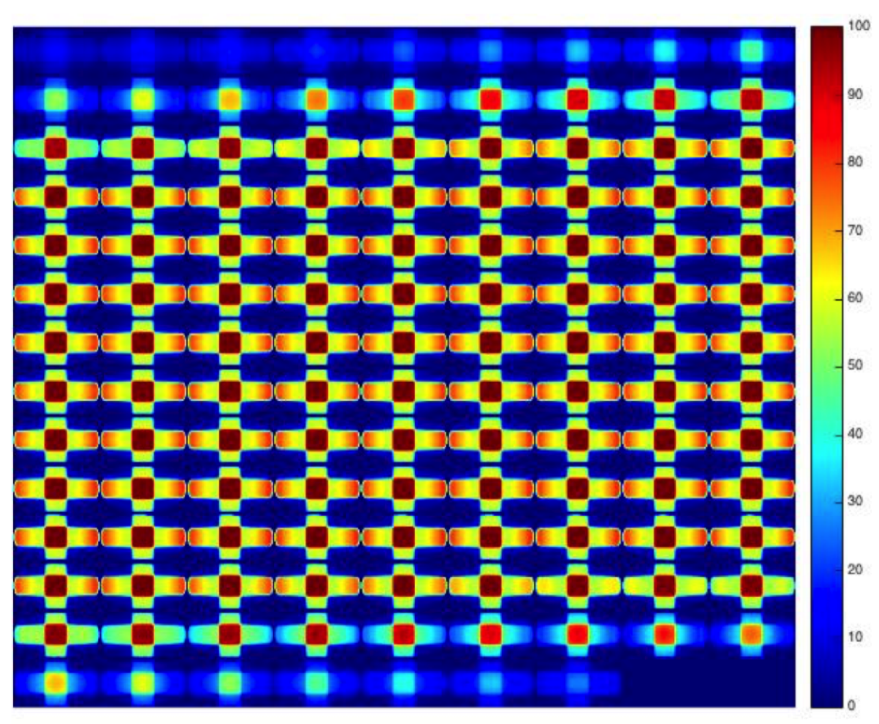

(a) TPS

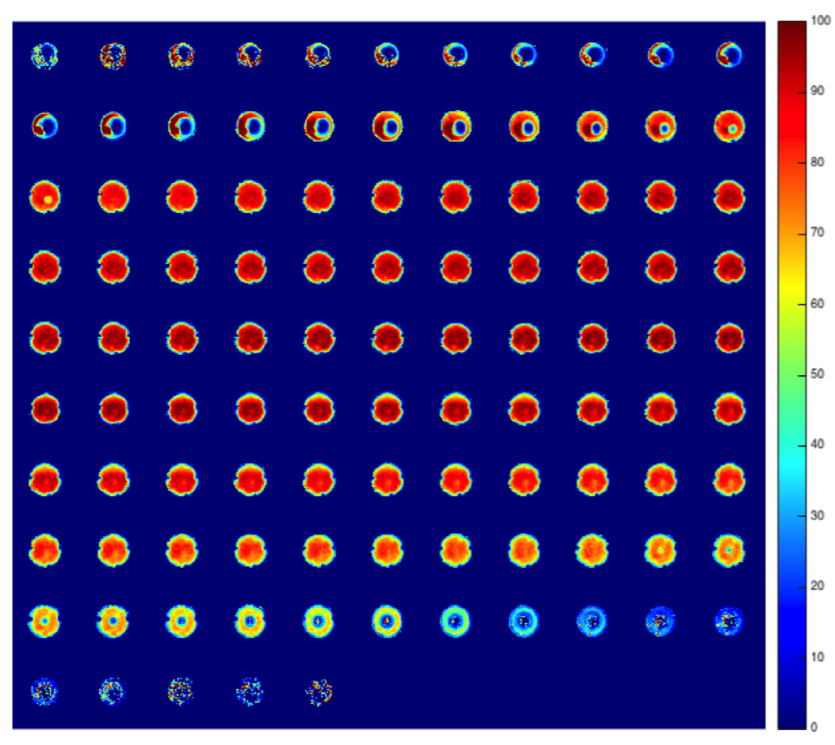

(b) GEL

Figura 7.2.2: Cortes axiais para as duas distribuições de dose. (a) Distribuição de dose do TPS, organizadas em 14 linhas e 9 colunas. (b) Distribuição de dose obtida pelo gel, e se encontra organizada em 11 colunas e 10 linhas. 
Em nosso planejamento são desenhadas diferentes estruturas no volume do fantom, tais como paciente, prótese femoral esquerda e direita e o PTV como se mostra anteriormente em uma imagem importada pelo CERR. Dessas estruturas só o PTV é importante, não obstante, a região do PTV fica dentro da região quadrada em vermelho (Figura 7.2.2a), portanto e para facilitar as leituras, foi desenhado um contorno de cor azul com as medidas do recipiente gel inicialmente mostrada na figura (6.6.3a), o que nos permite fazer o análise entre os dois volumes alvo. A seguir são apresentadas as distribuições de dose nos diferentes planos de referência Axial, Coronal e Sagital para o TPS e o Gel.
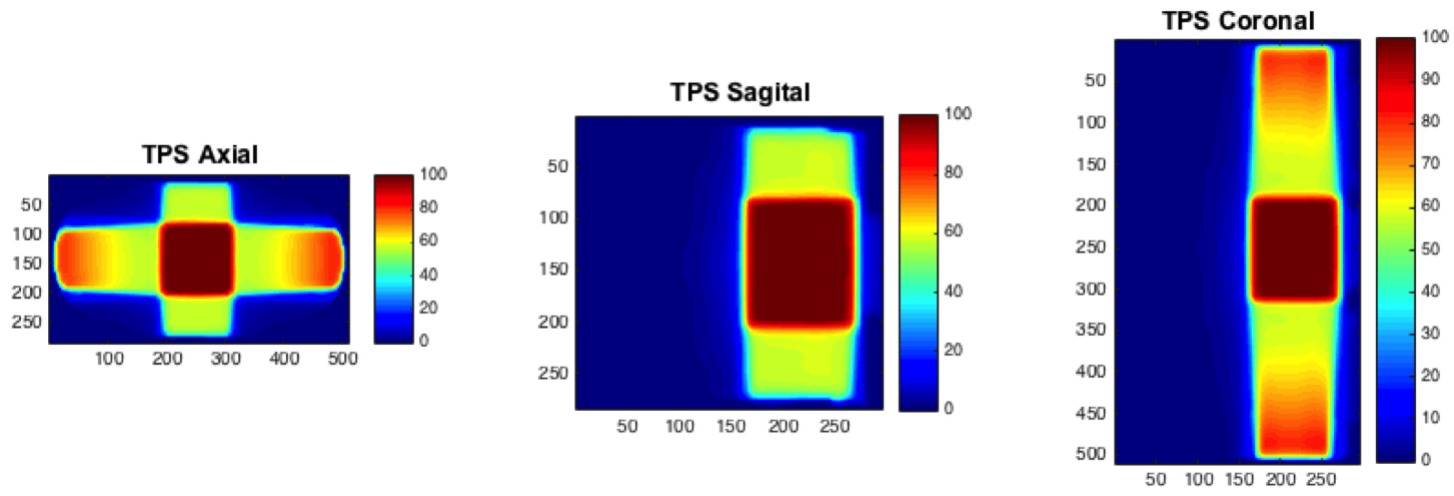

(a) TPS
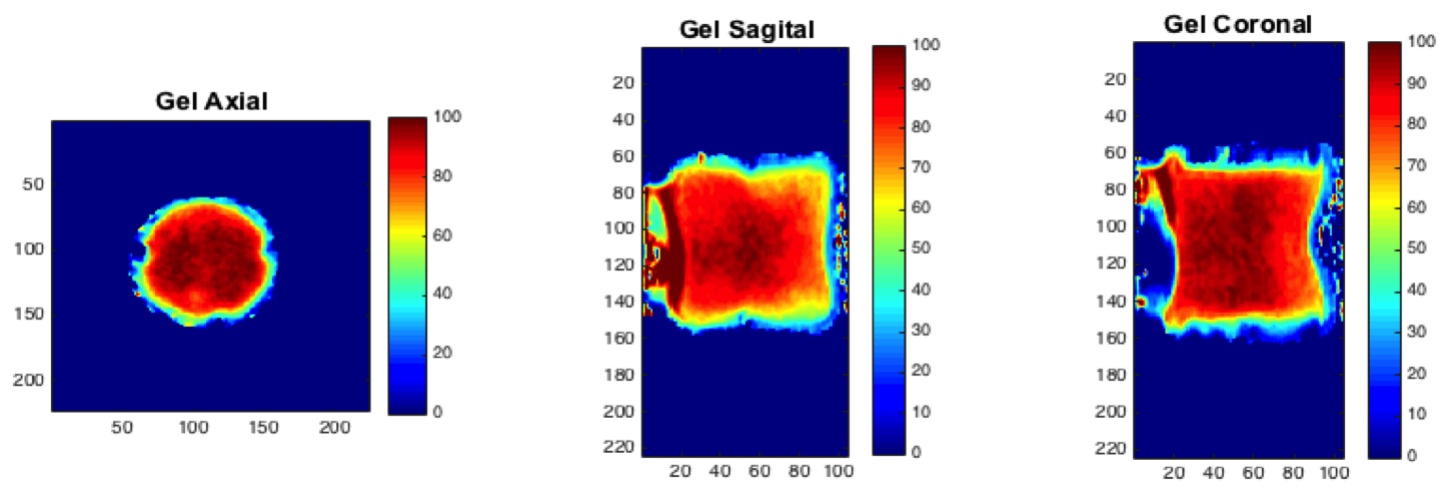

(b) GEL

Figura 7.2.3: (a) Distribuição de dose (TPS) no plano Axial, Coronal e Sagital. (b) Distribuição de dose do gel com as diferentes visualizações, Axial, Sagital e Coronal.

O número de fatias a ser analisada foi de 20, tanto para o TPS como para o gel. A figura (7.2.4), apresenta as distribuições de dose do TPS (a) e o gel (b) para o intervalo 
das 20 fatias.

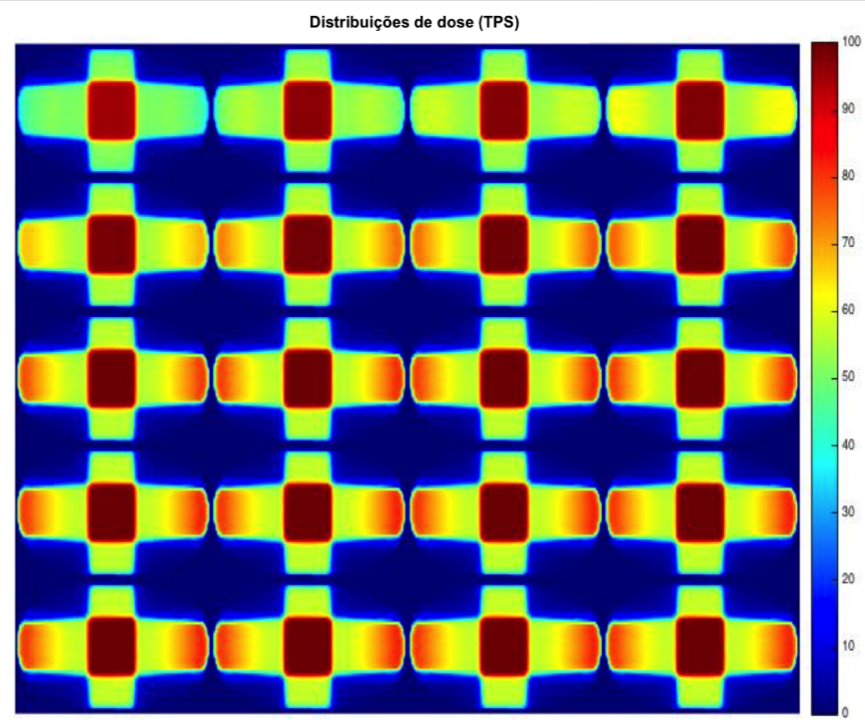

(a)

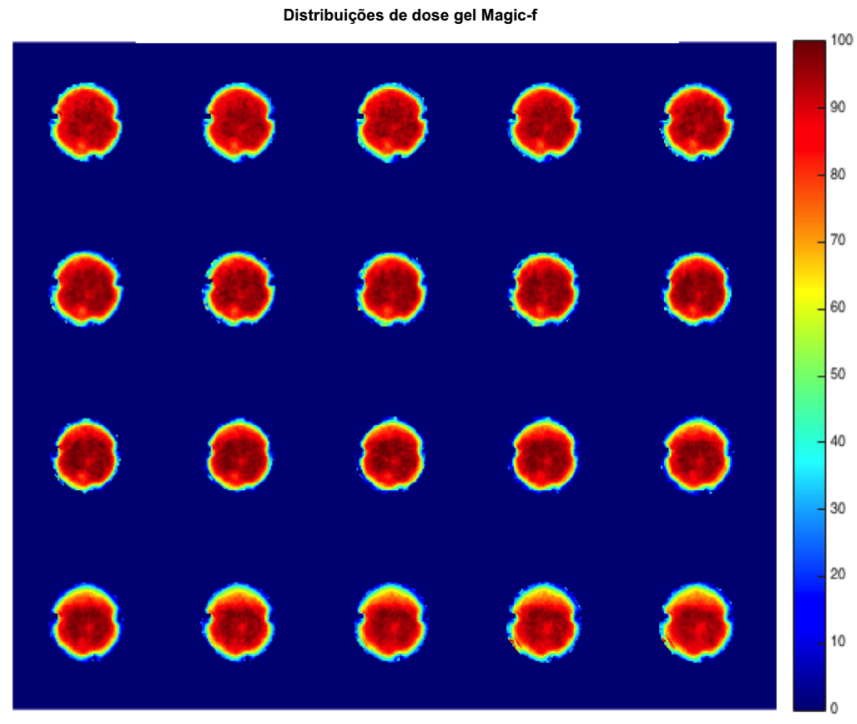

(b)

Figura 7.2.4: Cortes axiais com as 20 distribuições de doses relativa do volume analisado. (a) Distribuição de dose TPS para as fatias desde um $\mathrm{Z}=171$ até $\mathrm{Z}=221$. (b) Distribuição de dose gel para fatias desde um $\mathrm{Z}=44$ até $\mathrm{Z}=63$.

A analise é feita de duas formas, uma delas onde é analisado o volume completo do recipiente e outra com um volume menor, esse último com a finalidade de eliminar as 
bordas do recipiente evitando a presença de artefatos que possam prejudicar a análise. Na figura (7.2.5) são mostrados os resultados da análise gama para cada uma das imagens escolhidas, realizadas com os critérios mencionados previamente. Um percentagem de aprovação média do $93 \%$ na região selecionada foi encontrado. Os pontos que são aprovados no gama 3D são aqueles que tem os tons cinza, e para os pontos que não passam os critérios de aprovação são visualizados com os tons amarelo e vermelhos.

Na figura (7.2.6) é realizado um quadrado de $20 \times 20 \mathrm{~cm}$ de cor vermelho para a simulação da região da próstata. Se a análise gama tomara em conta somente essa região teríamos um percentagem de pontos aprovados por acima do 93\%, pois em pelo menos 15 das fatias analisadas anteriormente é possível observar como o tons de cinza nessa região é superior.

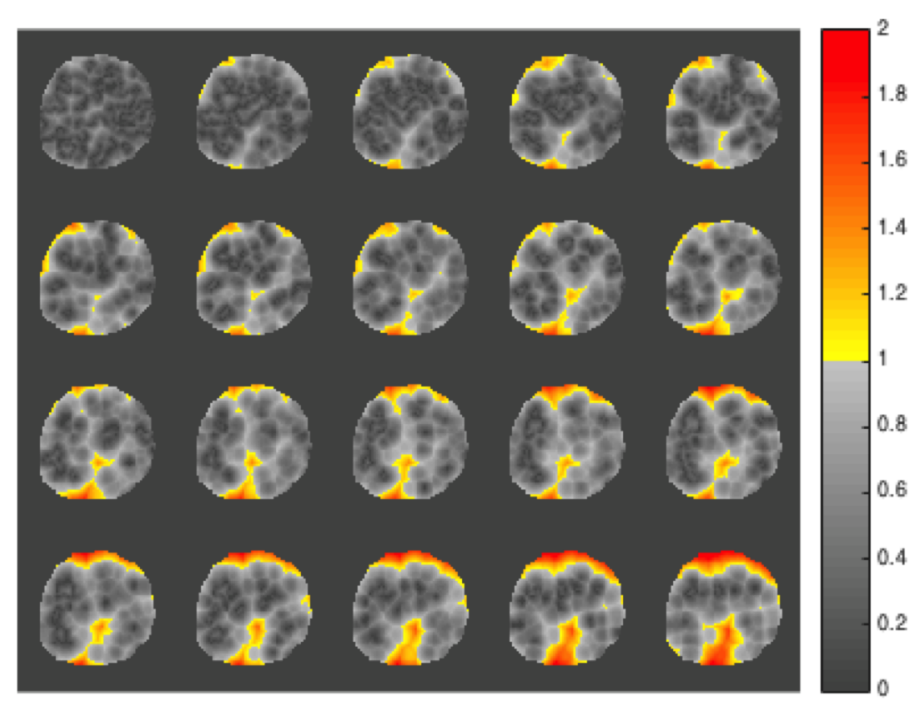

Figura 7.2.5: Cortes axiais do volume analisado mostrando o análise gama para as 20 fatias. 


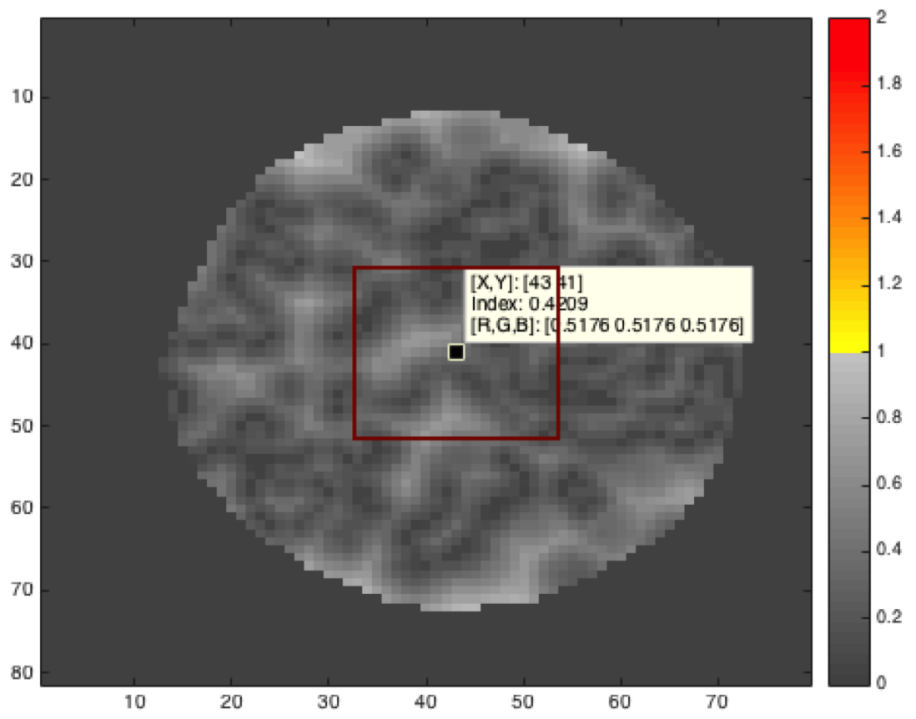

Figura 7.2.6: Corte axial analisado com a análise gama 3D, apresenta o valor do índice gama no ponto $\mathrm{X}=42$ e $\mathrm{Y}=41$ de 0,4209 , e além disso, um quadrado vermelho é feito para simular o volume aproximado da próstata.

\section{Parte II - Resultados de dosimetria termolumines- cente}

A seguir são apresentados os procedimentos de seleção e calibração dos dosímetros, e a simulação do tratamento com o objeto simulador. O primeiro que se apresenta é a seleção e calibração dos dosímetros e o segundo é a avaliação do tratamento planejado. Essa segunda parte mostra os resultados da irradiação do objeto simulador duas vezes, cada uma irradiada com 2 Gy. Como já mencionado, a dose que chega até as próteses metálicas por cada irradiação é da ordem de 1 Gy, e é de esperar uma dose total de 2 Gy em cada próteses femoral.

\subsection{Curva de calibração do dosímetro TL}

Incialmente, se escolheram 20 dosímetros de fluoreto de lítio, colocados dois por embalagem para previamente ser irradiados com diferentes doses com o fim de fazer a curva 
de calibração. Após feita a irradiação são colocados por 10 minutos em um forno a $100^{\circ} \mathrm{C}$, e finalizado o processo térmico começa a leitura deles junto com os outros 20 dosímetros utilizados no tratamento. Na tabela a seguir se apresenta 5 colunas que representam os diferentes valores de dose aplicada, os valores leitura 1 e 2 em nC e seus respectivos fatores de calibração. Os fatores de calibração são determinados a partir da equação (6.10.1).

Tabela 7.2: Apresentação dos valores de leitura 1 e 2 por meio do equipamento Harshaw, com seus devidos fatores de calibração.

\begin{tabular}{ccccc}
\hline Dose $(\mathrm{Gy})$ & Leitura 1(nC) & Leitura 2 $(\mathrm{nC})$ & $\begin{array}{c}\text { Fator de } \\
\text { calibração } \mathbf{1} \\
(\mathrm{mGy} / \mathrm{nC})\end{array}$ & $\begin{array}{c}\text { Fator de } \\
\text { calibração 2 } \\
(\mathrm{mGy} / \mathrm{nC})\end{array}$ \\
\hline 0,5 & 758,80 & 825 & 0,59 & 0,53 \\
1,0 & 1400 & 1400 & 0,53 & 0,57 \\
1,5 & 1980 & 2270 & 0,62 & 0,56 \\
2,0 & 3180 & 2770 & 0,60 & 0,65 \\
2,5 & 3670 & 3670 & 0,59 & 0,64 \\
3,0 & 4710 & 5000 & 0,58 & 0,61 \\
4,0 & 6780 & 7430 & 0,58 & 0,55 \\
6,0 & 10270 & 10970 & 0,63 & 0,60 \\
9,0 & 15240 & 14620 & 0,56 & 0,56 \\
10,0 & 19010 & 16900 & 0,56 & 0,62 \\
\hline
\end{tabular}

Na tabela (7.3) são colocados os resultados da leitura de luz emitida pelo dosímetro em valores de dose (dose leitura 1 e 2), usando para isso a equação (6.10.2). Se pode observar como os valores de dose lida vão tendo um comportamento linear com o aumento da dose aplicada. Com o fim de construir uma melhor curva de calibração é feito uma média entre os valores das leituras 1 e 2. 
Tabela 7.3: Valores de leituras 1 e 2 convertidos em dose.

\begin{tabular}{cccc}
\hline Dose (Gy) & Dose leitura 1 (Gy) & Dose leitura 2 (Gy) & Média (Gy) \\
\hline 0,5 & 0,44 & 0,44 & 0,44 \\
1,0 & 0,75 & 0,80 & 0,78 \\
1,5 & 1,24 & 1,27 & 1,25 \\
2,0 & 1,93 & 1,80 & 1,86 \\
2,5 & 2,19 & 2,35 & 2,27 \\
3,0 & 2,75 & 3,08 & 2,92 \\
4,0 & 3,94 & 4,11 & 4,02 \\
6,0 & 6,53 & 6,66 & 6,60 \\
8,0 & 8,61 & 8,20 & 8,41 \\
10,0 & 10,67 & 10,59 & 10,63 \\
\hline
\end{tabular}

A partir dos valores da tabela (7.3), é levantada o gráfico da curva de calibração dos dosímetros, desta maneira e como se pode apreciar na figura (7.3.1), se obtém um comportamento linear com o aumento da dose aplicada e além disso, a sensibilidade dos dosímetros é a esperada pois, o valor foi de 1.

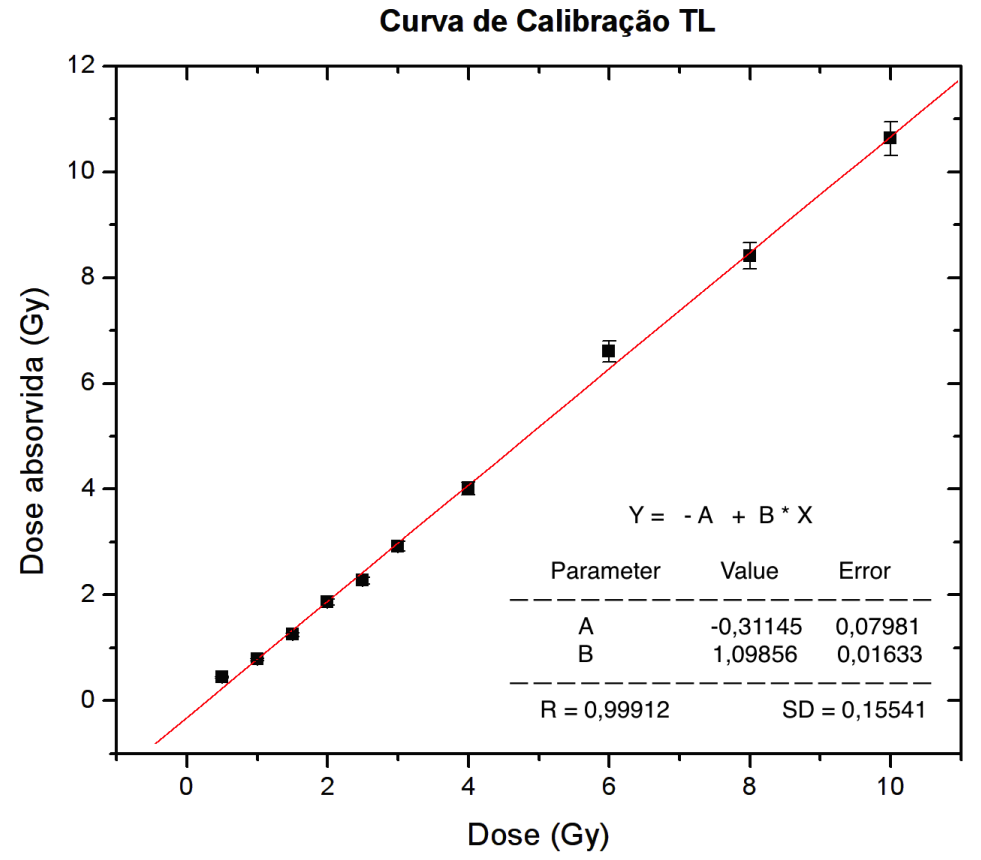

Figura 7.3.1: Curva de calibração TL. No eixo horizontal temos a dose aplicada e no eixo vertical a dose convertida após a leitura da luz emitida pelo dosímetro. 


\subsection{Avaliação do tratamento previamente planejado pelo TPS}

O planejamento do tratamento indicava que por cada 2 Gy que fosse dado ao objeto simulador $1 \mathrm{~Gy}$ estaria recebendo as próteses femorais. Agora, antes de fornecer os resultados de dose absorvida é necessário lembrar as localizações destes dosímetros. Um total de 20 pastilhas TL são distribuídas ao redor do fantom, começando com as pernas esquerda e direita, nelas são localizados os dosímetros do 1-4 para um total de 8. Na parte do quadril esquerdo e direito se localizaram 10 dosímetros do 5-9. E finalmente no osso sacro são colocados as últimas duas pastilhas com o número 10. Para uma melhor interpretação é apresentada uma tabela com os números dos dosímetros utilizados e seu correspondente localização.

Tabela 7.4: Distribuição dos dosímetros Tl no objeto simulador (Phantom)

\begin{tabular}{|c|c|c|c|}
\hline & Número de dosímetro & & Localização no fantom \\
\hline \multirow{8}{*}{ Perna Direita } & 49 & & 1 \\
\hline & 50 & Perto da cabeça do fêmur & 2 \\
\hline & 52 & & 3 \\
\hline & 53 & & 4 \\
\hline & 54 & \multirow{5}{*}{ Quadril } & 5 \\
\hline & 56 & & 6 \\
\hline & 57 & & 7 \\
\hline & 58 & & 8 \\
\hline & 59 & & 9 \\
\hline \multirow{12}{*}{$\begin{array}{c}\text { Perna } \\
\text { Esquerda }\end{array}$} & 61 & Osso sacro & 10 \\
\hline & 34 & \multirow{4}{*}{ Perto da cabeça do fêmur } & 1 \\
\hline & 36 & & 2 \\
\hline & 37 & & 3 \\
\hline & 35 & & 4 \\
\hline & 39 & \multirow{6}{*}{ Quadril } & 5 \\
\hline & & & \\
\hline & 43 & & 6 \\
\hline & 45 & & 7 \\
\hline & 46 & & 8 \\
\hline & 47 & & 9 \\
\hline & 48 & Osso sacro & 10 \\
\hline
\end{tabular}

Os valores das leituras de dose são apresentadas na tabela (7.5). Claramente podemos 
observar como os valores das doses absorvidas na interface mostram alguns pontos com doses maiores às esperadas, como por exemplo, a região do osso sacro registra uma dose média de 3,73 Gy com uma diferença de dose esperada de 1,73 Gy. É de esperar um aumento da dose medida em distâncias próximas à superfície do implante metálico, no entanto, a dose absorvida mais elevada foi encontrada no osso sacro, aumento causado possivelmente pela interação dos fótons com o metal e pela forma como foi feito o planejamento do tratamento pois, foram planejados campos de 0, 90, 180 e 270 graus. A tendência de dose medida que deveriam se obter foi avaliada pelo TPS feito inicialmente. Esses niveles de dose medida acima do valor esperado podem variar de acordo com a espessura do implante, material, distância envolvida entre os tecidos sadios e a energia de radiação.

Tabela 7.5: Leitura da dose absorvida por parte dos dosímetros TL localizados ao longo do objeto simulador.

\begin{tabular}{cccc}
\hline $\begin{array}{c}\text { Localização } \\
\text { dos dosímetros }\end{array}$ & Número & Fator de calibração & Dose medida (Gy) \\
\hline & 49 & 0,59 & 2,16 \\
& 50 & 0,58 & 0,75 \\
& 52 & 0,60 & - \\
Perna Direita & 53 & 0,57 & 2,26 \\
& 54 & 0,61 & 1,89 \\
& 56 & 0,61 & 2,26 \\
& 57 & 0,61 & 2,56 \\
& 58 & 0,59 & 1,50 \\
& 59 & 0,60 & 2,09 \\
Perna & 61 & 0,59 & 3,79 \\
\hline Esquerda & 34 & 0,53 & 1,80 \\
& 36 & 0,56 & 0,51 \\
& 37 & 0,54 & 2,27 \\
& 35 & 0,58 & 2,33 \\
& 43 & 0,71 & 1,63 \\
& 43 & & 2,33 \\
& 46 & 0,60 & 1,85 \\
& 47 & 0,61 & 1,35 \\
& 48 & 0,57 & 3,89 \\
& & 0,51 & 3,68 \\
\hline
\end{tabular}




\section{Parte III - Resultados de dosimetria por ressonância spin-eletrônico de alanina}

Nesta sessão são apresentados os resultados correspondentes aos dosímetros de alanina. Inicialmente é feita uma curva de calibração para o lote de dosímetros utilizados, e posteriormente os valores de leitura de dose obtidos na irradiação do objeto simulador são mostrados.

\subsection{Curva de calibração}

As leituras dos dosímetros foram feitas através da dosimetria ESR, obtendo-se para cada pastilha de alanina seu correspondente espectro. Dez dosímetros foram irradiados com doses conhecidas de 0,0, 5,0, 7,0, 9,0, 11,0, 13,0, 15,0, 17,0, 19,0, 21,0 Gy, inseridas em uma placa de acrílico mostrada na figura (6.9.1). Os valores das amplitudes e peso para cada dosímetro são apresentados na tabela a seguir.

Tabela 7.6: Valores de dose irradiadas com suas correspondentes amplitudes, determinadas por dosimetria de ESR.

\begin{tabular}{cccc}
\hline Dose (Gy) & Amplitude & Massa (mg) & Amplitude / Massa \\
\hline 0,0 & 453,8 & 147 & 3,087075 \\
5,0 & 2126 & 149 & 14,26846 \\
7,0 & 2738 & 148 & 18,5 \\
9,0 & 3539 & 148 & 23,91216 \\
11,0 & 4155 & 151 & 27,51656 \\
13,0 & 4540 & 146 & 31,09589 \\
15,0 & 5726 & 149 & 38,42953 \\
17,0 & 5832 & 144 & 40,5 \\
19,0 & 6962 & 148 & 47,04054 \\
21,0 & 7752 & 153 & 50,66667 \\
\hline
\end{tabular}

A partir dos valores de dose irradiada e das amplitudes registradas na tabela (7.6), é construída nossa curva de calibração e por meio de um ajuste linear é obtida a equação da reta o que nos permite obter os parâmetros necessário para o calculo de dose absorvida, posteriormente descrita. 


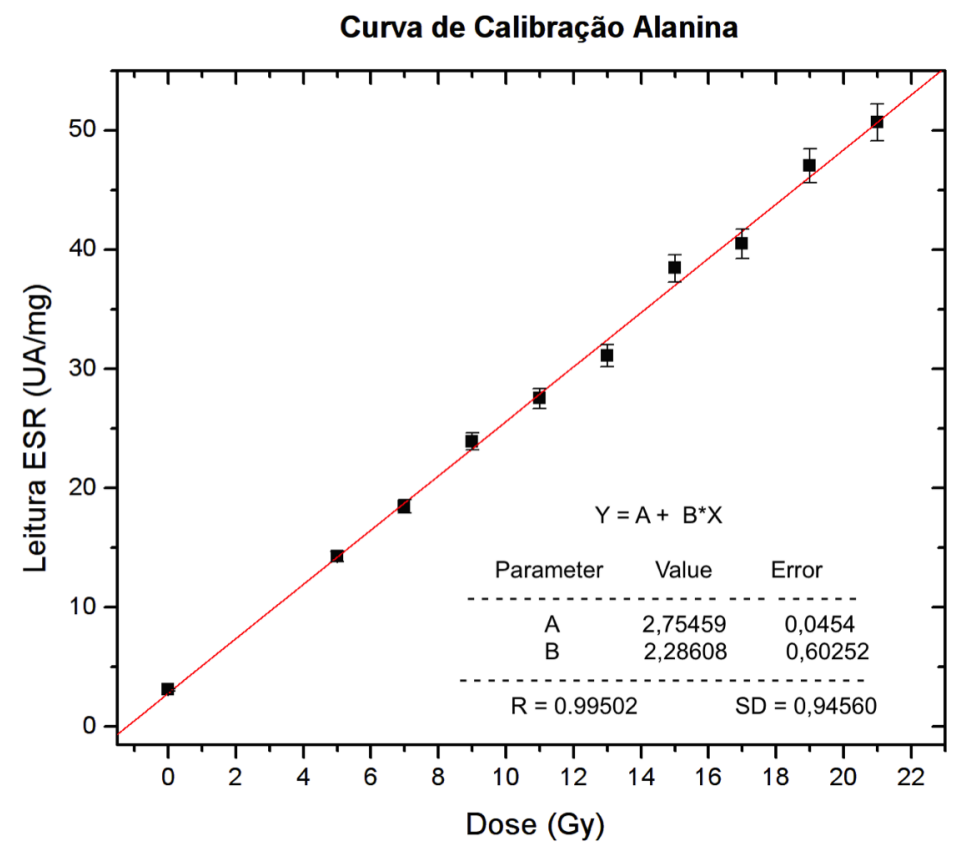

Figura 7.5.1: Curva de calibração da alanina.

Como foi mencionado, através da curva de calibração e os valores das amplitudes dos espectros de cada dosímetro é possível determinar a quantidade de dose absorvida, e como a dose apresenta um comportamento linear para um intervalo de dose alto, a dose pode ser calculada por regressão linear, por meio do método dos mínimos quadrados, determinada pela equação a seguir:

$$
\operatorname{DOSE}=\frac{1}{b}(\mathrm{I}-a)
$$

onde b é o coeficiente angular da reta, a é o coeficiente linear da reta (para a equação da reta $\mathrm{Y}=\mathrm{A}+\mathrm{B}^{*} \mathrm{X}$ ) e I é a amplitude da linha central do espectro ESR divida pela massa para cada dosímetro.

De acordo, com a equação (7.5.1) foi determinada a dose absorvida para os 20 dosímetros usados no tratamento. 


\subsection{Avaliação do tratamento previamente planejado pelo TPS para os dosímetros de alanina}

Para a verificação da dose planejada com a dose medida nos dosímetros de alanina foram utilizadas um total de 20 pastilhas de alanina as quais são distribuídas perto da cabeça do fêmur das perna direita e esquerda e no quadril. O resto de parâmetros aplicados na irradiação foram descritos em materiais e métodos (seção 6 - parte II). Os resultados das leituras dos dosímetros foram distribuídos de acordo com a localização de cada um deles, pois era importante manter uma correlação entre as posições dos dosímetros TL. Portanto, á análise será feito da mesma forma que para os TL, no entanto, não é possível fazer uma comparação ponto por ponto já que se trata de diferentes formas de planejamento. Em primeiro lugar, a tabela (7.7) apresenta os 10 dados de amplitude obtidos por dosimetria ESR para a perna direita e em segundo lugar, na tabela (7.8), estão escritos os valores das amplitudes para a perna esquerda.

Tabela 7.7: Valores das amplitudes para cada dosímetro localizados na perna direita.

\begin{tabular}{cccc}
\hline Posição & Amplitude & Massa (mg) & Amplitude / Massa \\
\hline 1 & 0 & 140 & - \\
2 & 1425 & 135 & 7,92 \\
3 & 1077 & 137 & 5,90 \\
4 & 1587 & 136 & 8,75 \\
5 & 1574 & 142 & 8,31 \\
6 & 1858 & 137 & 10,17 \\
7 & 1576 & 136 & 8,69 \\
8 & 1823 & 137 & 9,98 \\
9 & 1717 & 143 & 9,01 \\
10 & 2200 & 133 & 12,41 \\
\hline
\end{tabular}


Tabela 7.8: Amplitudes obtidas por dosimetria ESR para a perna esquerda.

\begin{tabular}{cccc}
\hline Posição & Amplitude & Massa (mg) & Amplitude / Massa \\
\hline 1 & 0 & 134 & - \\
2 & 733 & 132 & 4,16 \\
3 & 485 & 135 & 2,69 \\
4 & 555 & 138 & 3,02 \\
5 & 1007 & 140 & 5,39 \\
6 & 1587 & 134 & 8,88 \\
7 & 1711 & 138 & 9,30 \\
8 & 1587 & 137 & 8,69 \\
9 & 1472 & 121 & 9,12 \\
10 & 2613 & 135 & 14,52 \\
\hline
\end{tabular}

Os resultados de dose absorvida tanto para a prótese femoral direita como esquerda são calculados através da equação (7.5.1), utilizando os parâmetros de coeficiente angular, coeficiente linear e com a amplitude do espectro de cada dosímetro. Os valores dessas leituras são apresentadas em tabelas, para o implante metálico direito corresponde à tabela (7.9), e para o implante metálico esquerdo a tabela (7.10).

Tabela 7.9: Valores de dose absorvida para cada dosímetro de alanina localizado na prótese métalica direita.

\begin{tabular}{cccc}
\hline Número de dosímetro & Dose ESR (Gy) & Erro \pm & Desvio padrão dose \\
\hline 1 & 0,00 & - & - \\
2 & 2,26 & 0,05 & 0,16 \\
3 & 1,37 & 0,16 & 0,48 \\
4 & 2,62 & 0,01 & 0,04 \\
5 & 2,43 & 0,03 & 0,10 \\
6 & 3,24 & 0,05 & 0,17 \\
7 & 2,60 & 0,01 & 0,04 \\
8 & 3,16 & 0,04 & 0,14 \\
9 & 2,73 & - & - \\
10 & 4,22 & 0,17 & 0,52 \\
\hline
\end{tabular}


Tabela 7.10: Valores de dose absorvida para cada dosímetro de alanina localizado na prótese metálica esquerda.

\begin{tabular}{cccc}
\hline Número de dosímetro & Dose ESR (Gy) & Erro \pm & Desvio padrão dose \\
\hline 1 & 0,00 & - & - \\
2 & 0,62 & 0,16 & 0,48 \\
3 & 0,00 & 0,23 & 0,70 \\
4 & 0,11 & 0,22 & 0,66 \\
5 & 1,15 & 0,09 & 0,29 \\
6 & 2,68 & 0,08 & 0,24 \\
7 & 2,86 & 0,10 & 0,30 \\
8 & 2,60 & 0,07 & 0,21 \\
9 & 2,79 & 0,09 & 0,28 \\
10 & 5,15 & 0,37 & 1,11 \\
\hline
\end{tabular}

\subsection{Discussão}

Buscando impulsar um controle de qualidade mais rigoroso em tratamentos de câncer para pacientes com próteses metálicas é proposto o uso da dosimetria gel magic- $f$, dosimetria TL e a dosimetria com alanina. A técnica emprega o uso de quatro campos de radiação que vão incidir sobre o volume alvo previamente localizado. O fator complicador de se tratar pacientes que usem próteses metálicas é a presença de inomogeneidades de um elemento com alto número atômico, que resulta na atenuação da radiação através da inomogeneidade, bem como perturbações locais conhecidas como efeitos de interfase. Existem inumeráveis relatos sobre os efeitos de atenuação em materiais não equivalentes ao tecido [14]. No entanto, os campos de irradiação para a pélvis são geralmente mais grandes que essas inomogeneidades e portanto, aquela sub dose é quase imperceptível e termina sem valor algum. Claro esta que, dependendo das caraterísticas como a energia de radiação, densidade, número atômico e espessura da inomogeneidade, os efeitos ao longo prazo chegam a ser considerados.

Nosso objetivo de pesquisa foi determinar o impacto das perturbações geradas por essas próteses na distribuição de dose absorvida tanto no gel como na dose absorvida pontualmente por parte dos dosímetros termoluminescentes e os disímetros de alanina. Como foi dito em diferentes ocasiões, quando o feixe de fótons passa através das pró- 
teses aparecem perturbações nas distribuição de dose absorvida devido ao aumento de atenuação e as interações entre a interface osso metal. Nesse caso, se tento calcular o aumento na dose medida por meio do sistema de planejamento de tratamento (TPS), colocando a pélvis e próteses femorais dentro dos cilindros e elipsoides (ver seção 6.1), preenchido completamente com água, tratamento feito sem correções de heterogeneidades. O volume alvo que corresponde à próstata é simulado por meio de um recipiente cilíndrico, cujo planejamento consistia de 70 Gy de dose entregada ao "tumor" com um feixe de fótons de $6 \mathrm{MV}$ com a técnica de caixa de quatro campos.

Foram usados três recipientes preenchidos com gel usados para a avaliação do tratamento, dois desses são irradiados com uma dose de 2 Gy cuja curva de calibração é a mesma pois se trata do mesmo lote de gel. O recipiente número três é considerado como nossa referencia. As distribuições de dose do TPS e medidas foram comparadas pela análise gama com critérios de $3 \%$ para diferença de dose e $3 \mathrm{~mm}$ para a distancia de concordância. Para o recipiente 1 a análise foi feita em 20 cortes, com uma coordenada $\mathrm{Z}=44$ até $\mathrm{Z}=63 \mathrm{com}$ um percentagem de aprovação nesses pontos do $93 \%$, esses pontos de aprovação corresponde a um volume menor que o recipiente, para assim evitar problemas frequentes como contaminação de oxigênio e a interferência de artefatos no fantom. Segundo esses resultados o planejamento avaliado com dosimetria gel 3D passaria o teste de controle de qualidade convencional usados pelo serviço de radioterapia. Não obstante, os pontos de aprovação do volume todo foi do $70 \%$. Já para o recipiente 2, um total de 20 cortes $(Z=36$ até $Z=55$ ) são analisados e se obtém um percentagem de aprovação do $80 \%$, mas para as fatias do $Z=36$ até $Z=50$ se decide fazer um novo análise gama e o percentagem de pontos aprovados para essas 15 imagens foi do $90 \%$. 


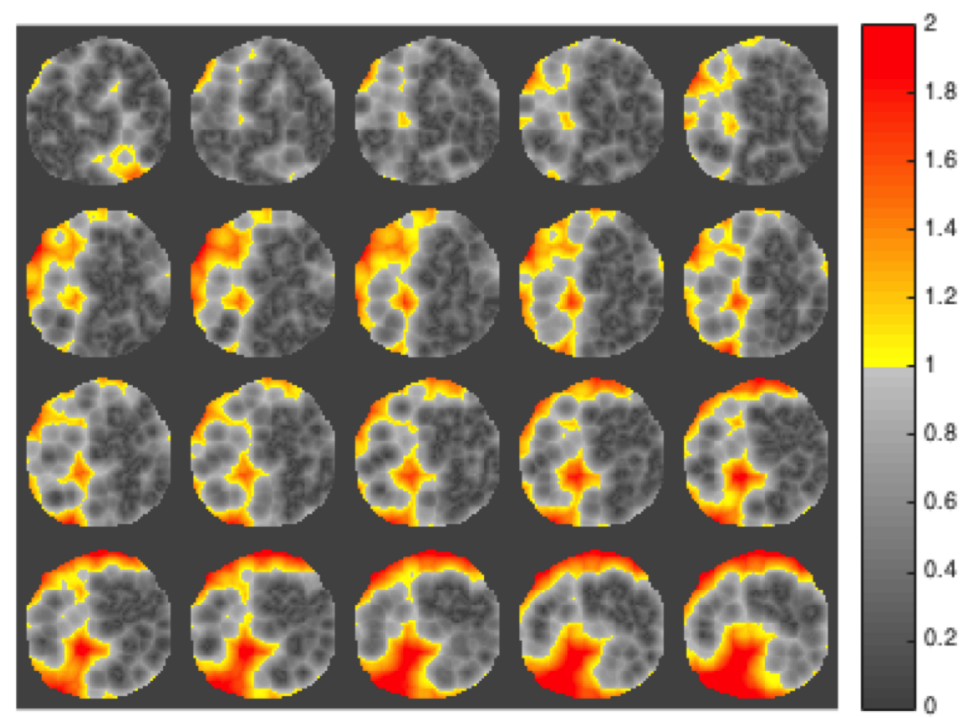

Figura 7.7.1: Cortes axiais para o volume analisado apresentando a análise gama.

Nesse contexto, o efeito desses implantes levam a uma redução da distribuição de dose no volume alvo do fantom. Hazuka et al.,[12] publicou uma série de informações acerca do fator de transmissão através de próteses de quadril de Co-Cr-Mo, Ti e aço inoxidável para feixes de fótons de 4 a $10 \mathrm{MV}$. Os valores de transmissão foram medidos em um fantom de água com uma câmera de íons de $0,1 \mathrm{~cm}^{3}$, com o feixe posicionado com o seu eixo central passando pelo centro aproximado da haste solida de cada próteses. As medidas de perfis de dose foram usadas para correlacionar o feixe de transmissão com as dimensões da seção transversal de cada próteses, essas medidas de transmissão mostraram um valor baixo de 0.657 com 4 MV para o Co-Cr-Mo. Com o aumento do tamanho de campo e da energia esse fator também aumenta como se pode ver na tabela (7.11). 
Tabela 7.11: Fatores de transmissão para feixes de 4 e 10 MV, para três materiais de próteses [12].

\begin{tabular}{|c|c|c|c|c|c|c|c|c|c|c|c|c|}
\hline $\begin{array}{l}\text { Energia dos } \\
\text { fotons }(\mathrm{MV})\end{array}$ & \multicolumn{6}{|c|}{4} & \multicolumn{6}{|c|}{10} \\
\hline $\begin{array}{l}\text { Tamanho do } \\
\text { campo }\left(\mathrm{cm}^{2}\right)\end{array}$ & 8 & $\times$ & 8 & 15 & $x$ & 15 & 8 & $x$ & 8 & 15 & $\times$ & 15 \\
\hline $\begin{array}{l}\text { Profundidade } \\
\text { da próteses } \\
(\mathrm{cm})\end{array}$ & 10 & & 15 & 10 & & 15 & 10 & & 15 & 10 & & 15 \\
\hline $\begin{array}{c}\text { Aço } \\
\text { inoxidável }\end{array}$ & 0,763 & & 0,764 & 0,786 & & 0,795 & 0,807 & & 0,799 & 0,816 & & 0,819 \\
\hline $\mathrm{Co}-\mathrm{Cr}-\mathrm{Mo}$ & 0,657 & & 0,672 & 0,708 & & 0,714 & 0,735 & & 0,736 & 0,748 & & 0,749 \\
\hline $\mathrm{Ti}$ & 0,861 & & 0,855 & 0,869 & & 0,876 & 0,887 & & 0,879 & 0,891 & & 0,894 \\
\hline
\end{tabular}

Os resultados desse estudo mostravam que para cada prótese em uma dada energia e profundidade, a transmissão aumentava com o aumento do campo devido ao aumento da dispersão do fantom que desloca parcialmente o efeito de blindagem das próteses. Os aumentos foram entre $2 \%$ e $8 \%$ para as três próteses mas, as dimensões de cada prótese era diferente o que nos leva a concluir que essas diferenças de transmissão não se devem somente ao materiais dos implantes. No entanto, dados da fabricação de próteses de diferentes materiais com dimensões geometrias similares foram publicadas por Sibata et al., [53] para $6 \mathrm{MV}$ e $18 \mathrm{MV}$. Novamente se encontrou um aumento no fator de transmissão, e além disso, os autores definem ainda um índice de perturbação IP para ter em conta a atenuação média sobre a geometria do dispositivo. O CoCr-Mo mostra o valor de atenuação mais alto, não obstante, os valores para o aço inoxidável são consideravelmente altos, o valor de atenuação do titânio é mais baixo. Para uma informação completa sobre este estudo procurar a referência [14]. Agora, antes de concluir e dar veracidade aos problemas relacionados com implantes metálicos, são apresentados os resultados para a dosimetria termoluminescente e para as alaninas. Inicia-se por determinar os valor das doses absorvidas na interface osso metal nas diferentes regiões de localização dos TL. Região 1 : Cabeça do fêmur direito, apresenta na região perpendicular ao campo de irradiação um aumento de dose de 0,16 Gy e o campo paralelo ao osso um aumento em 0,26 Gy. Região 2: Quadril direito, se encontro um aumento médio de 0,3 Gy com respeito à dose esperada, mostrando que a diferença mais alta de dose absorvida nesse caso, foi para o dosímetro localizado mais perto do implante metálico. Região 3: Fêmur esquerdo, aumento nos dois casos, um com 0,27 
Gy e outro com 0,33 Gy. Região 4: No quadril as doses ficaram mais cerca do valor esperado pois, só em dois casos a dose superou o limite estabelecido, esses casos são para o TL-43 com aumento 0,33, para o TL-47 o aumento de dose absorvida foi de 1,89 Gy. Já na parte do osso sacro se encontraram diferenças de doses quase do mesmo valor, 1,79 Gy para a parte direita e 1,68 Gy para a esquerda. Se observa uma semelhança no aumento da dose na parte direita e esquerda pois, na hora do montagem se procurou manter as mesmas localizações (Figura 6.9.2). Como exemplo disso, na região do osso sacro a diferença de dose absorvida foi de 0,11 Gy. No entanto, o aumento como tal com a dose esperada é grande pois, se consideramos um tratamento de próstata fracionado em 34 sessões com 2 Gy cada um, os tecidos sadios como o reto estariam sendo afeitados por aproximadamente 28,71 Gy.

Os valores de dose absorvida por parte dos dosímetros de alanina foram comparados com as doses planejadas por parte do sistema de planejamento de tratamento CMX XIO. Esse planejamento apresenta a distribuição da dose em torno à região dos implantes metálicos e quadril. Com a análise da figura do planejamento (Figura 6.3.2 ${ }^{1}$ ), se estabelece que o $55 \%$ da dose prescrita se encontra nessa região. A doses a entregar foi de 6 Gy o que corresponde a 3 Gy na zona de nosso interesse.

Nas tabela (7.9 e 7.10) se mostram os resultados obtidos em termos de doses absorvidas tanto na parte direita como esquerda do fantom, cujos aumentos se diferençiam um pouco aos encontrados para os TL pois, embora a região do osso sacro permaneceu como o lugar de maior dose em pontos como na cabeça do fêmur a dose absorvida foi bastante menor. Partindo disso, na região do quadril direito foi obtido um aumento de dose para os dosímetros 6 e 8 de 0,24 e 0,16 Gy respetivamente. No quadril esquerdo não se registro aumento por parte dos dosímetros. Finalmente a dose absorvida maior é no osso sacro, os valores de dose encontrados tanto da parte direita como esquerda são preocupantes pois uma diferença de dose de 1,22 e 2,42 Gy. Essa diferença de dose em um paciente submetido a um tratamento de 70 Gy fracionado em 35 sessoes cada uma com 2 Gy, estaria recebiendo 25,81 Gy nas regiões do osso sacro e ao redore.

A seguir são apresentadas duas tabelas com as diferenças percentuais entre as doses planejadas e as doses medidas por parte de cada técnica. Analisando a tabela (7.12), é possível perceber que a dose absorvida na prótese femoral direita obtida pela dosimetria

\footnotetext{
${ }^{1}$ Esse planejamento dos dosímetros de alanina apresenta as mesmas distribuições de dose que para o gel magic- $f$ e os TL, portanto, o screenshot da figura (6.3.2) pode ser considerado como ajuda ilustrativa das distribuições de dose e das estruturas que involucram o fantom.
} 
TL é maior com respeito á quantidade de dose que foi absorvida no dosímetros de alanina pois, um maior número de TL conseguiram fornecer uma informação mais ampla. Na tabela (7.13) se observa o mesmo comportamento, novamente observaramse doses maiores do que as planejadas para as regiões analisadas. Isso indica que a interface do metal com o osso provoca um aumento da dose local. Os dosimetros de TL e Alanina forneceram valores diferentes. Isso se deve a que foram resultados obtidos em duas irradiações diferentes e as respostas especificas dos dosímetros em função da energia. Mas esse é um ponto que merece uma investigação mais detalhada em outro trabalho.

Tabela 7.12: Comparação das leituras de dose absorvida para os TL e as alaninas para o implante metálico direito.

\begin{tabular}{cccc}
\hline & & Dose absorvida (Gy) & Diferença percentual de dose \% \\
\hline & 1 & 2,16 & 8 \\
\multirow{5}{*}{ TL (2 Gy) } & 4 & 2,26 & 13 \\
& 6 & 2,26 & 13 \\
& 7 & 2,56 & 28 \\
& 9 & 2,09 & 4,50 \\
& 10 & 3,79 & 89,50 \\
\hline \multirow{6}{*}{ Alanina (3 Gy) } & 6 & 3,24 & 8 \\
& 8 & 3,16 & 5,33 \\
& 10 & 4,22 & 40,66 \\
\hline
\end{tabular}

Tabela 7.13: Comparação das leituras de dose absorvida para os TL e as alaninas para o próteses femoral esquerda.

\begin{tabular}{cccc}
\hline & & Dose absorvida (Gy) & Diferença percentual de dose \% \\
\hline & 3 & 2,27 & 13,5 \\
& 4 & 2,33 & 16,5 \\
& 6 & 2,33 & 16,5 \\
\multirow{2}{*}{ TL (2 Gy) } & 9 & 3,89 & 94,5 \\
& 10 & 3,68 & 84 \\
\hline Alanina (3 Gy) & 10 & 5,42 & 80,66 \\
\hline
\end{tabular}

A figura (7.7.2) apresenta as doses absorvidas das próteses femorais direita e esquerda para o fantom, mostrando o número de dosímetro TL e da Alanina que contém essa dose. De acordo a isso, é possível comparar as doses medidas em pontos aproximadamente iguais em dois tratamentos, um planejado em 2 Gy e outro com 3 Gy. 


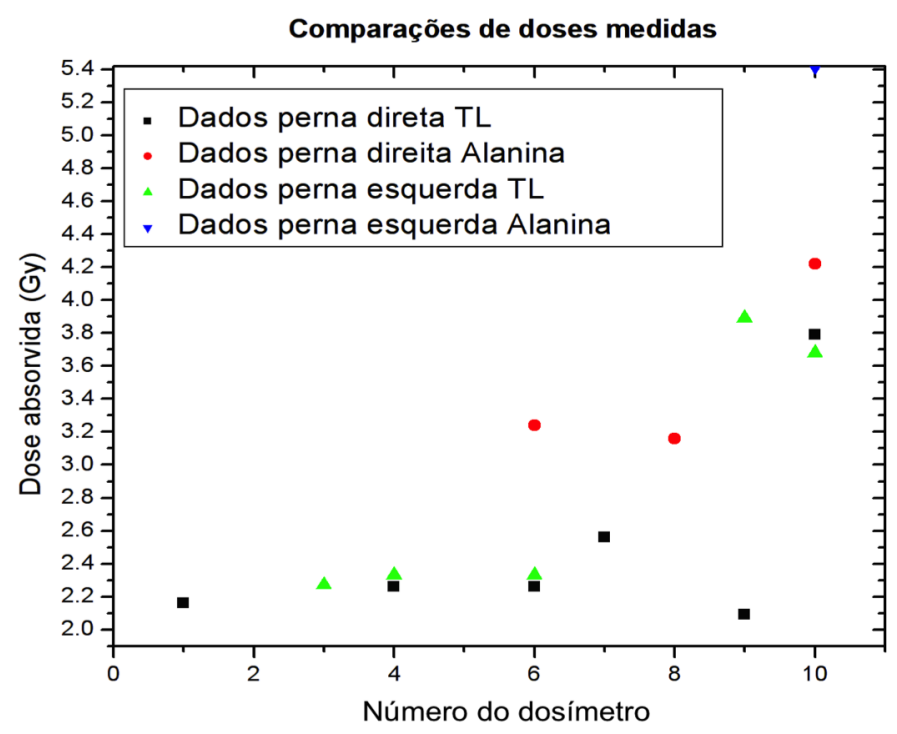

Figura 7.7.2: Comparação de doses medidas em pontos aproximadamente iguais em dois tratamentos

Finalmente podemos respaldar essa diminuição de dose na distribuição de dose obtida nos mapas de relaxometria como um problema de perturbação na radiação ionizante que incide sobre pacientes que contém próteses metálicas. Devido ao número atômico efetivo desses dispositivos que combinados com a energia de radiação, o tamanho de campo usado e a espessura provocam uma dispersão da radiação cujos efeitos ao longo prazo em tecidos sadios provocam doenças como necroses óssea ou problemas associados com deslocamentos de quadril. 


\section{Capítulo 8}

\section{Conclusões}

Neste trabalho se estudou os efeitos das próteses metálicas em pacientes com câncer de próstata, aplicando para isso, a dosimetria 3D com o gel magic- $f$, a dosimetria termoluminescente e a dosímetria ESR com dosímetros de LiF e alanina. A pesquisa pode ser classificada como uma simulação de tratamentos de um controle de qualidade pois, era importante saber como os valores de dose absorvidas nas regiões de interesses estavam sendo afeitadas tanto em diminuição como em aumento das mesmas. Um tratamento de radioterapia convencional para câncer de próstata planejado a 70 Gy foi utilizado e avaliado por meio da análise gama.

Mediante o analise gama $(3 \% / 3 \mathrm{~mm})$ para o volume alvo planejado se consegue avaliar o uso do gel magic- $f$ como dosímetro 3D para técnicas convencionais. Qualitativamente os resultados associados ao controle de qualidade tridimensional, realizado com a dosimetria gel indicam boas semelhanças entre as distribuições planejadas por parte do sistema de planejamento ( CMX XIO (Elekta)).

Por outra parte, e de acordo com as medidas de absorção de dose determinadas com os TL e alanina se detecta um aumento da dose, onde tecidos sadios são afetados. O aumento é atribuído à dispersão do feixe de fótons que interagem com os implantes.

Quando é comparado os resultados aqui com os da literatura, verifica-se uma semelhança de resultados pois existem estudos mostrando diferentes modelos de próteses usados como control de qualidade em diversas situações que concordam com o aumento da dose influencida pelos dispositivos . 


\section{Referências Bibliográficas}

[1] H Cortés, J Vásquez, and M Plazas. Implementación de un dosímetro en gel para verificación dosimétrica de tratamientos con rapidarc tm. (document), 3.2.1, 3.2.2, 3.2.3, 3.3.4, 3.4.1.2

[2] Paul Tofts. Quantitative MRI of the brain: measuring changes caused by disease. John Wiley \& Sons, 2005. (document), 3.4.1.1, 3.4.1, 3.4.2, 3.4.3

[3] Yves De Deene. Review of quantitative mri principles for gel dosimetry. In Journal of Physics: Conference Series, volume 164, page 012033. IOP Publishing, 2009. (document), 3.2, 3.4.1, 3.4.1.1, 3.4.4, 3.4.5, 3.4.1.4, 3.4.1.4, 3.4.7

[4] Juliana Fernandes Pavoni. Dosimetria tridimensional por imagens de ressonância magnética com gel MAGIC modificado. $\mathrm{PhD}$ thesis, Universidade de São Paulo. (document), 3.1, 3.2, 3.2, 3.4.1.1, 3.4.1.1, 3.4.6, 3.4.1.5, 6.6.2.1

[5] Cinthia M Papp. Construcción de un fantoma antropomórfico para mediciones de dosis en manos en procedimientos de braquiterapia. PhD thesis, Universidad Nacional de Cuyo, 2012. (document), 4.2.1, $4.2 .2,6.8 .1$

[6] Eirik Malinen, Elin A Hult, Eli O Hole, and Einar Sagstuen. Ala- 
nine radicals, part 4: Relative amounts of radical species in alanine dosimeters after exposure to 6-19 mev electrons and $10 \mathrm{kv}-15 \mathrm{mv}$ photons. Radiation research, 159(2):149-153, 2003. (document), 5.2 .2

[7] Guilherme Gonçalves Alves. Influência das próteses metálicas na radioterapia de próstata através de dosimetria por EPR. PhD thesis, Universidade de São Paulo. (document), 5.2.3, 6.1, 6.1.1, 6.1, 6.1.2, 6.1

[8] John Wertz. Electron spin resonance: elementary theory and practical applications. Springer Science \& Business Media, 2012. (document), 5.3.1

[9] Henry Lavalle Sullasi, Renata Libonati Azevedo, and Anne Marie Pessis. Datação de dentes por espectroscopia rpe fundamentos, metodologia e aplicações. (document), 5.3.2, 5.3.1

[10] C Baldock, RP Burford, N Billingham, GS Wagner, S Patval, RD Badawi, and SF Keevil. Experimental procedure for the manufacture and calibration of polyacrylamide gel (pag) for magnetic resonance imaging (mri) radiation dosimetry. Physics in medicine and biology, 43(3):695, 1998. (document), 3.1, 3.3.3

[11] Clive Baldock. Historical overview of the development of gel dosimetry: a personal perspective. In Journal of Physics: Conference Series, volume 56, page 14. IOP Publishing, 2006. (document), 3.1, 3.1

[12] Chester Reft, Rodica Alecu, Indra J Das, Bruce J Gerbi, Paul Keall, Eugene Lief, Ben J Mijnheer, Nikos Papanikolaou, Claudio Sibata, and Jake Van Dyk. Dosimetric considerations for patients with hip 
prostheses undergoing pelvic irradiation. report of the aapm radiation therapy committee task group 63. Medical physics, 30(6):11621182, 2003. (document), 7.7, 7.11

[13] N Howlader, AM Noone, M Krapcho, N Neyman, R Aminou, W Waldron, SF Altekruse, CL Kosary, J Ruhl, Z Tatalovich, et al. Seer cancer statistics review, 1975-2008. bethesda, md: National cancer institute; 2011. Also available online Last accessed December, 1, 2011. 1

[14] Chester Reft, Rodica Alecu, Indra J Das, Bruce J Gerbi, Paul Keall, Eugene Lief, Ben J Mijnheer, Nikos Papanikolaou, Claudio Sibata, and Jake Van Dyk. Dosimetric considerations for patients with hip prostheses undergoing pelvic irradiation. report of the aapm radiation therapy committee task group 63. Medical physics, 30(6):11621182, 2003. 1, 7.7, 7.7

[15] Sung-Yen Lin, Tieh-Chi Chu, Jao-Perng Lin, and Mu-Tai Liu. The effect of a metal hip prosthesis on the radiation dose in therapeutic photon beam irradiations. Applied radiation and isotopes, 57(1):1723, 2002. 1

[16] JF PAVONI and O BAFFA. An evaluation of dosimetric characteristics of magic gel modified by adding formaldehyde (magic-f). Radiation measurements, 47(11-12):1074-1082, 2012. 1, 3.1

[17] Yves De Deene, Carlos De Wagter, B Van Duyse, S Derycke, Wilfried De Neve, and Eric Achten. Three-dimensional dosimetry using polymer gel and magnetic resonance imaging applied to the verification of conformal radiation therapy in head-and-neck cancer. Radiotherapy and Oncology, 48(3):283-291, 1998. 1, 3.3.3, 3.4.1.2 
[18] Peter M Fong, Derek C Keil, Mark D Does, and John C Gore. Polymer gels for magnetic resonance imaging of radiation dose distributions at normal room atmosphere. Physics in medicine and biology, 46(12):3105, 2001. 1, ??

[19] KM Harrison, MA Ebert, T Kron, SJ Howlett, D Cornes, CS Hamilton, and JW Denham. Design, manufacture, and evaluation of an anthropomorphic pelvic phantom purpose-built for radiotherapy dosimetric intercomparison. Medical physics, 38(10):5330-5337, 2011. 1

[20] GG Alves, A Kinoshita, HF de Oliveira, FS Guimarães, LL Amaral, and O Baffa. Accuracy of dose planning for prostate radiotherapy in the presence of metallic implants evaluated by electron spin resonance dosimetry. Brazilian Journal of Medical and Biological Research, 48(7):644-649, 2015. 1

[21] A Venning, B Healy, K Nitschke, and C Baldock. Investigation of the magas normoxic polymer gel dosimeter with pyrex glass walls for clinical radiotherapy dosimetry. Nuclear Instruments and Methods in Physics Research Section A: Accelerators, Spectrometers, Detectors and Associated Equipment, 555(1):396-402, 2005. 1, ??

[22] P Alexander, A Charlesby, and M Ross. The degradation of solid polymethylmethacrylate by ionizing radiation. In Proceedings of the Royal Society of London A: Mathematical, Physical and Engineering Sciences, volume 223, pages 392-404. The Royal Society, 1954. 3.1

[23] Howard L Andrews, Raymond E Murphy, and Edward J LeBrun. Gel dosimeter for depth-dose measurements. Review of Scientific Instruments, 28(5):329-332, 1957. 3.1 
[24] Marek Maryanski, John Gore, and Robert Schulz. Threedimensional detection, dosimetry and imaging of an energy field by formation of a polymer in a gel, June 14 1994. US Patent 5,321,357. $3.1,3.3 .1$

[25] Nivia Aparecida Silva, Patricia Nicolucci, and Oswaldo Baffa. Spatial resolution of magnetic resonance imaging fricke-gel dosimetry is improved with a honeycomb phantom. Medical physics, 30(1):17-20, 2003. 3.1

[26] Yves De Deene, Peter Hanselaer, Carlos De Wagter, Eric Achten, and Wilfried De Neve. An investigation of the chemical stability of a monomer/polymer gel dosimeter. Physics in medicine and biology, 45(4):859, 2000. ??, 6.2.1

[27] Yves De Deene, C Hurley, A Venning, K Vergote, Melissa Mather, BJ Healy, and C Baldock. A basic study of some normoxic polymer gel dosimeters. Physics in Medicine and Biology, 47(19):3441, 2002. ??, ??, ??, ??

[28] AJ Venning, KN Nitschke, PJ Keall, and C Baldock. Radiological properties of normoxic polymer gel dosimeters. Medical physics, 32(4):1047-1053, 2005. ??

[29] S Brindha, AJ Venning, B Hill, and C Baldock. Experimental study of attenuation properties of normoxic polymer gel dosimeters. Physics in medicine and biology, 49(20):N353, 2004. ??, ??

[30] C Hurley, A Venning, and C Baldock. A study of a normoxic polymer gel dosimeter comprising methacrylic acid, gelatin and tetrakis (hydroxymethyl) phosphonium chloride (magat). Applied radiation and isotopes, 63(4):443-456, 2005. ??, 3.3.3, 3.3.5, 3.4.2 
[31] Yves De Deene, K Vergote, Carolien Claeys, and Carlos De Wagter. The fundamental radiation properties of normoxic polymer gel dosimeters: a comparison between a methacrylic acid based gel and acrylamide based gels. Physics in medicine and biology, 51(3):653, 2006. ??, ??

[32] A Jirasek, M Hilts, C Shaw, and P Baxter. Investigation of tetrakis hydroxymethyl phosphonium chloride as an antioxidant for use in x-ray computed tomography polyacrylamide gel dosimetry. Physics in medicine and biology, 51(7):1891, 2006. ??

[33] M McJury, M Oldham, VP Cosgrove, PS Murphy, S Doran, MO Leach, and S Webb. Radiation dosimetry using polymer gels: methods and applications. The British Journal of Radiology, 73(873):919-929, 2000. 3.3 .1

[34] Marek J Maryanski, John C Gore, Richard P Kennan, and Robert J Schulz. Nmr relaxation enhancement in gels polymerized and crosslinked by ionizing radiation: a new approach to $3 \mathrm{~d}$ dosimetry by mri. Magnetic resonance imaging, 11(2):253-258, 1993. 3.3.1

[35] SJ Hepworth, MO Leach, and SJ Doran. Dynamics of polymerization in polyacrylamide gel (pag) dosimeters:(ii) modelling oxygen diffusion. Physics in medicine and biology, 44(8):1875, 1999. 3.3.1

[36] MJ Maryanski, C Audet, and JC Gore. Effects of crosslinking and temperature on the dose response of a bang polymer gel dosimeter. Physics in Medicine and Biology, 42(2):303, 1997. 3.3.3

[37] Yves De Deene, Carlos De Wagter, Wilfried De Neve, and Eric Achten. Artefacts in multi-echo t2 imaging for high-precision gel dosi- 
metry: Ii. analysis of b1-field inhomogeneity. Physics in medicine and biology, 45(7):1825, 2000. 3.4.1.3

[38] Peter Magnusson, Sven ÅJ Bäck, and Lars E Olsson. Mri image plane nonuniformity in evaluation of ferrous sulphate dosimeter gel (fegel) by means of $\mathrm{t}$ 1-relaxation time. Magnetic resonance imaging, 17(9):1357-1370, 1999. 3.4.1.4

[39] MJ Maryanski, YZ Zastavker, and John C Gore. Radiation dose distributions in three dimensions from tomographic optical density scanning of polymer gels: Ii. optical properties of the bang polymer gel. Physics in Medicine and Biology, 41(12):2705, 1996. 3.4 .2

[40] JC Gore, M Ranade, MJ Maryanski, and RJ Schulz. Radiation dose distributions in three dimensions from tomographic optical density scanning of polymer gels: I. development of an optical scanner. Physics in medicine and biology, 41(12):2695, 1996. 3.4 .2

[41] Mark Oldham, Jeffrey H Siewerdsen, Anil Shetty, and David A Jaffray. High resolution gel-dosimetry by optical-ct and mr scanning. Medical physics, 28(7):1436-1445, 2001. 3.4 .2

[42] Marek J Maryanski and Manisha K Ranade. Laser microbeam ct scanning of dosimetry gels. In Medical Imaging 2001, pages 764-774. International Society for Optics and Photonics, 2001. 3.4.2

[43] C Audet, M Hilts, A Jirasek, and C Duzenli. Ct gel dosimetry technique: comparison of a planned and measured 3d stereotactic dose volume. Journal of Applied Clinical Medical Physics, 3(2):110118, 2002. 3.4.3 
[44] V Krstelj. Ultrasonic testing of polymer materials. Insight, 38(9):640-644, 1996. 3.4.4

[45] A Maffezzoli, VA Luprano, G Montagna, F Esposito, and L Nicolais. Ultrasonic wave attenuation during water sorption in poly (2-hydroxyethyl methacrylate) hydrogels. Polymer Engineering \&3 Science, 36(13):1832-1838, 1996. 3.4.4

[46] Melissa L Mather, Andrew K Whittaker, and Clive Baldock. Ultrasound evaluation of polymer gel dosimeters. Physics in medicine and biology, 47(9):1449, 2002. 3.4.4

[47] MASSAHIRO MIYAMOTO. Estudo e aplicação da dosimetria termoluminescente na datação. PhD thesis, Universidade de São Paulo, 1973. 4.2

[48] Claudio Castelo Branco Viegas, Ricardo Tadeu Lopes, Luiz Antonio Ribeiro da Rosa, and Delano Valdivino Santos Batista. Dosimetria in vivo com uso de detectores semicondutores e termoluminescentes aplicada ao tratamento de câncer de cabeça e pescoço. $M$. Sc., Dissertação, COPPE/UFRJ, Rio de Janeiro, RJ, Brasil, 2003. 4.4.1

[49] DF Regulla and U Deffner. Dosimetry by esr spectroscopy of alanine. The International Journal of Applied Radiation and Isotopes, 33(11):1101-1114, 1982. 5.2

[50] Marc Desrosiers and David A Schauer. Electron paramagnetic resonance (epr) biodosimetry. Nuclear Instruments and Methods in Physics Research Section B: beam interactions with materials and atoms, 184(1):219-228, 2001. 5.3, 5.3 
[51] Stephen WS McKeever, Marko Moscovitch, and Peter David Townsend. Thermoluminescence dosimetry materials: properties and uses. 1995. 6.8

[52] JR Cameron, D Zimmerman, G Kenney, R Buch, R Bland, and $\mathrm{R}$ Grant. Thermoluminescent radiation dosimetry utilizing lif. Health Physics, 10(1):25-29, 1964. 6.8

[53] CH Sibata, HC Mota, PD Higgins, D Gaisser, JP Saxton, and $\mathrm{KH}$ Shin. Influence of hip prostheses on high energy photon dose distributions. International Journal of Radiation Oncology* Biology* Physics, 18(2):455-461, 1990. 7.7 